O problema de corte de estoque com demanda estocástica

Douglas José Alem Junior 
SERVIÇO DE PÓS-GRADUAÇÃO DO ICMC-USP

Data de Depósito: 14/02/2007

Assinatura:

\title{
O problema de corte de estoque com demanda estocástica
}

\author{
Douglas José Alem Junior
}

Orientador: Prof Dr Marcos Nereu Arenales

Dissertação apresentada ao Instituto de Ciências Matemáticas e de Computação - ICMC-USP, como parte dos requisitos para obtenção do título de Mestre em Ciências de Computação e Matemática Computacional.

USP - São Carlos

Fevereiro/2006 
Aos meus pais. 



\section{Agradecimentos}

Aos meus pais, Douglas e Maria Aparecida, por terem sempre vibrado com as minhas conquistas e pertmitido que mais esse sonho tenha se realizado - não existem palavras que sejam suficientes para eu demonstrar o quão especial eles são na minha vida;

A todos os professores que sempre acreditaram em mim;

À professora mais amada, minha mãe;

Aos professores e amigos que me estimularam a escolher o belo caminho da academia e me ajudaram a superar vários empecilhos, o Professor Paulo Caetano, a Professora Selma Arenales e o Professor Benê;

Ao professor Marcos Nereu Arenales pela orientação, amizade, e confiança depositada no desenvolvimento deste trabalho e de outros que ainda deverão ser desenvolvidos.

A todos os amigos que estão ao meu lado e sempre estiveram, aqueles que não estão mais geograficamente próximos, mas estão vibrando por mim;

A todos do LOT, meninas, meninos e professores, Todos sempre dispostos a ajudar o amigo mal-humorado e agüentar muitas reclamações...

Aqueles que eu não mencionei, sintam-se agradecidos também...

À FAPESP pela credibilidade e apoio financeiro;

À Deus, por tudo o que ELE representa. 



\section{Resumo}

O presente trabalho desenvolve uma extensão do problema de corte de estoque unidimensional no caso em que a demanda pelos vários tipos de itens não é exatamente conhecida. Para considerar a aleatoriedade, foi proposto um modelo de programação estocástica de dois estágios com recurso. As variáveis de primeiro estágio são os números de barras cortadas por padrão de corte, e as variáveis de segundo estágio, os números de itens produzidos em escassez e em escassez. O objetivo do modelo é minimizar o custo total esperado. Para resolver a relaxação linear do modelo, foram propostos um método exato baseado no método Simplex com geração de colunas e uma estratégia heurística, que considera o valor esperado da demanda na resolução do problema de corte de estoque. As duas estratégias foram comparadas, assim como a possibilidade de resolver o problema de corte ignorando as incertezas. Finalmente, observou-se que é mais interessante determinar o valor ótimo do modelo recurso quando o problema sofre mais influência da aleatoriedade. 



\section{Abstract}

This paper presents an integer linear optimization model of large scale for the one-dimensional cutting stock problem in the case which a demand is considered a random variable. To take this randomness into account, the problem was formulated as a two-stage stochastic linear program with recourse. The first stage decision variables are given by the number of bars that has to be cut according to each pattern, and the second stage decision variables by the number of holding items or backordering items production. The model objective is minimizes the total expected cost. We propose two methods to solve the model linear relaxation, one of them it is a Simplex-based method with column generation. The second method is a heuristic strategy that adopted the expected value of demand. We compare both strategies and the possibly of ignoring uncertainties on model. Finally, we observe that is much more interesting to determine the optimal recourse model solution when we have problems that are more afected by randomness. 



\section{Conteúdo}

\begin{tabular}{lll}
\hline 1 & Introdução & 1
\end{tabular}

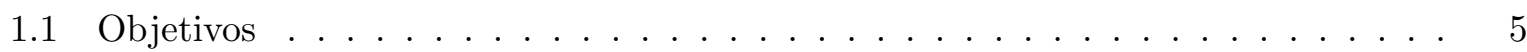

$1.2 \quad$ Organização da Monografia $\ldots \ldots \ldots \ldots \ldots \ldots \ldots$

\begin{tabular}{|lll}
\hline 2 & O Problema de Corte de Estoque & 7
\end{tabular}

$2.1 \quad$ Formulação Matemática do Problema de Corte de Estoque Unidimensional $\quad$. . $\quad 7$

$2.2 \quad$ O Método Simplex Aplicado ao PCE $\ldots \ldots \ldots \ldots \ldots \ldots$

$2.2 .1 \quad$ O Método Simplex . . . . . . . . . . . . . . . . . . . . . 10

$2.2 .2 \quad$ Geração de Colunas . . . . . . . . . . . . . . . . . . . . . . . 12

$2.2 .3 \quad$ Algoritmo do Método Simplex com Geração de Colunas . . . . . . . . . . . 14

3 Introdução à Programação Estocástica 15

$3.1 \quad$ Espaço de Probabilidade e Variáveis Aleatórias . . . . . . . . . . . . . . . . . . 15

3.2 Abordagem por Cenários $\ldots \ldots \ldots \ldots \ldots \ldots \ldots$

3.3 Tipos de Solução em PE: "Espere e Veja" e "Aqui e Agora" . . . . . . . . . . . . 17

3.4 Modelo de 2-Estágios com Recurso $\ldots \ldots \ldots \ldots$. . . . . . . . . . . 18

$3.4 .1 \quad$ Formulação Geral do Modelo de 2-Estágios com Recurso . . . . . . . . . . . 19

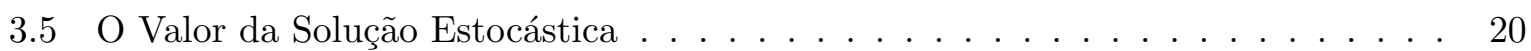

4 O Problema de Corte de Estoque com Demanda Estocástica 23

4.1 Definição e Formulação do Problema . . . . . . . . . . . . . . . . . . . . . . . 23 
\begin{tabular}{lll}
\hline 5 & Estratégias de Solução & 27
\end{tabular}

5.1 Estratégia GCE: Geração de Colunas Especializada . . . . . . . . . . . . . . . 27

$5.1 .1 \quad$ Identificação dos Tipos de Colunas . . . . . . . . . . . . . . . . . 27

$5.1 .2 \quad$ Construção da Matriz Básica Inicial ． . . . . . . . . . . . . . . . . . . . . 28

$5.1 .3 \quad$ Determinação das Soluções Básicas . . . . . . . . . . . . . . . . . . . . . . 32

5.1 .4 Determinação do Custo básico Inicial $\ldots \ldots$. . . . . . . . . . . . 32

5.1 .5 Cálculo dos Custos Relativos . . . . . . . . . . . . . . . . . . . 33

5.1 .6 Outro Detalhe da Implementaçã: Resolução dos Sistemas Lineares . . . . 35

$5.1 .7 \quad$ Algoritmo da Estratégia $G C E \ldots \ldots \ldots$

$5.2 \quad$ Estratégia $H D E:$ Heurística de Demanda Esperada $\ldots \ldots \ldots \ldots$. . . . . . 36

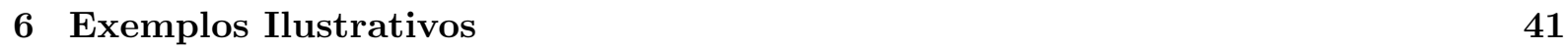

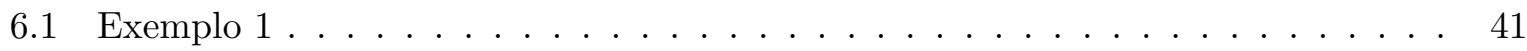

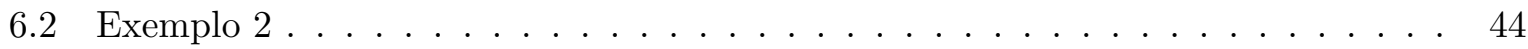

\begin{tabular}{lll}
\hline 7 & Experimentos Computacionais & 47
\end{tabular}

7.1 Testes A . . . . . . . . . . . . . . . . . . . . . . . . . . . . . . . 48

$7.1 .1 \quad$ Primeiro Conjunto de Testes $\ldots \ldots \ldots \ldots$. . . . . . . . . . 48

$7.1 .2 \quad$ Segundo Conjunto de Testes $\ldots \ldots \ldots \ldots$. . . . . . . . . 57

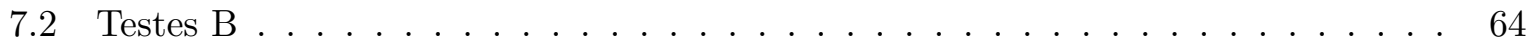

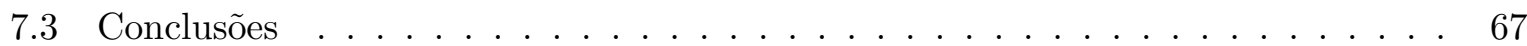

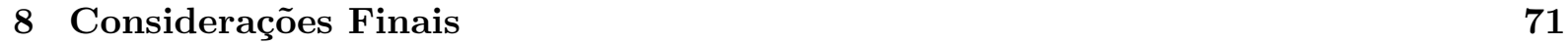

$\begin{array}{lll}9 & \text { Pesquisas Futuras } & 73\end{array}$

$9.1 \quad$ O Problema de Corte de Estoque com Restrições de Chance . . . . . . . . . . . . 73

\begin{tabular}{ll}
\hline Referências Bibliográficas & 76
\end{tabular}

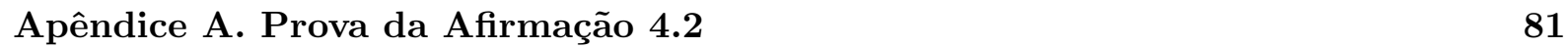




\section{Lista de Tabelas}

$4.1 \quad$ Estrutura dual bloco-angular do programa linear estocástico . . . . . . . . . . . 26

$5.1 \quad$ Dados do exemplo $1 . \ldots \ldots \ldots \ldots \ldots$

5.2 Exemplo de uma matriz básica inicial. . . . . . . . . . . . . . 30

$6.1 \quad$ Dados do exemplo $1 . \ldots \ldots \ldots \ldots \ldots$. . . . . . . . . . . . . . . . . . 42

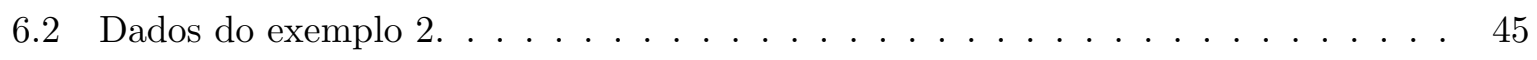

6.3 Padrões de corte: $G C E \ldots \ldots \ldots \ldots \ldots \ldots \ldots$

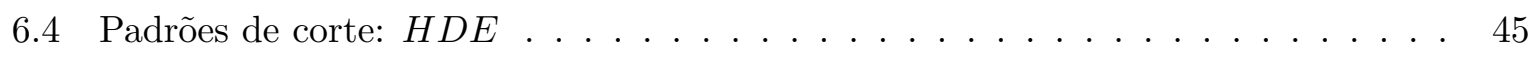

7.1 Classes do Primeiro Conjunto de Testes . . . . . . . . . . . . . . . . . 49

$7.2 \quad$ Valores médios das soluções $P R$ e $E P V E, V S E$ e ganho. . . . . . . . . . . . . 50

7.3 Escassez e Excesso de Produção. . . . . . . . . . . . . . . . . . . . . 53

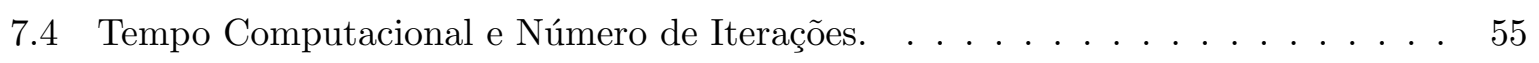

7.5 Classes do segundo conjunto de testes $\ldots \ldots \ldots \ldots \ldots \ldots$

$7.6 \quad$ Escassez e excesso de produção. . . . . . . . . . . . . . . . . . . . . 59

7.7 Variação da Escassez e Excesso de Produção na Classe $28 . \ldots \ldots$. . . . . . . . . . . 61

7.8 Variação da Escassez e Excesso de Produção na Classe 28.7 . . . . . . . . . . . . . 61

7.9 Valores Médios das Soluções $P R$ e $E P V E, V S E$ e ganho. . . . . . . . . . . . 63

7.10 Valores médios (\%) de itens em escassez e em excesso nos grupos. . . . . . . . . 65

7.11 Valores Médios das Soluções $P R$ e $E P V E, V S E$ e ganho. . . . . . . . . . . 66 



\section{Lista de Figuras}

1.1 (a) Barra; (b) barra cortado em 4 itens. . . . . . . . . . . . . . . . 2

1.2 (a) Placa; (b) placa cortada em 8 itens. . . . . . . . . . . . . . 2

$1.3 \quad$ (a) Contêiner; (b) 4 caixas empacotadas no contêiner. . . . . . . . . . . . . 3

$1.4 \quad$ (a) Rolo; (b) rolo cortado em itens. . . . . . . . . . . . . . . . . . . . . . 3

7.1 Comparação entre as funções objetivos. . . . . . . . . . . . . . . . . . . . . 51

$7.2 \quad V S E$ e Ganho . . . . . . . . . . . . . . . . . . . . . . . . . . . 52

7.3 Número de Itens em Excesso e em Escassez. . . . . . . . . . . . . . . . . . . . . . 54

$7.4 \quad$ \# de Elementos da Matriz. . . . . . . . . . . . . . . . . . . . . . 56

7.5 Número de Iterações. . . . . . . . . . . . . . . . . . . . . . . . . . 56

7.6 Tempo Computacional. . . . . . . . . . . . . . . . . 56

7.7 Número de itens em excesso e em escassez. . . . . . . . . . . . . . . . . . . 60

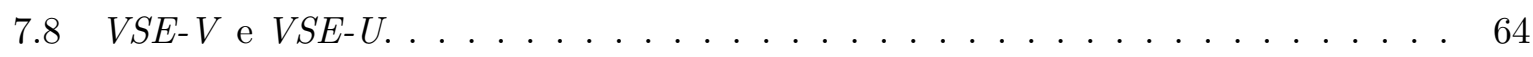

7.9 Ganho-V e Ganho-U. . . . . . . . . . . . . . . . . . . . . . . 64 



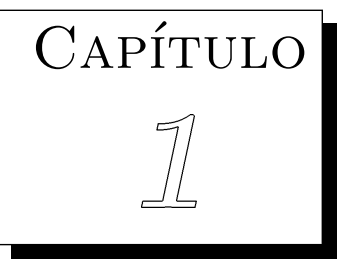

\section{Introdução}

Kantorovich e Zalgaller (1951) foram os pioneiros na aplicação da programação linear aos problemas de corte de estoque. Eles assumiram que o estoque tinha que ser cortado em grandes quantidades, o que lhes permitia ignorar as dificuldades de arredondar as soluções ótimas em soluções inteiras. Outros pesquisadores, como Paull e Walter (1954) estudaram problemas similares, mas apresentaram métodos capazes de resolver apenas problemas pequenos (Dowsland e Dowsland (1992)). Após a publicação dos trabalhos de Gilmore e Gomory (1961, 1963), entretanto, intensificaram-se os estudos acerca dos PCE, uma vez que os métodos propostos por eles eram capazes de resolver problemas com milhares de variáveis.

Basicamente, Gilmore e Gomory (1961) propuseram o método Simplex com geração de colunas para resolver o problema de corte de estoque unidimensional sem as restrições de integralidade. O método supera a dificuldade computacional básica dos problemas de corte com inúmeros padrões de corte, pois a cada iteração apenas alguns padrões de corte são armazenados e um número relativamente pequeno é gerado durante a resolução. Já em Gilmore e Gomory (1963), foi proposta uma adaptação do método apresentado no trabalho de 1961 e foi realizado um estudo de caso numa empresa de corte de papel. O algoritmo adaptado também pode ser aplicado no corte de tubos de metal e aço.

Nas últimas décadas, os PCE ganharam atenção especial de muitos pesquisadores, interessados tanto nas diversas aplicações do problema quanto nas dificuldades básicas relacionadas 
a sua resolução, uma vez que a maioria dos PCE pertence à classe NP-completo. Em relação à aplicação dos PCE, pode-se afirmar que esses problemas são vistos em indústrias de madeira, papel, vidro, móveis, plástico, chapas de madeira ou aço, metalúrgicas, entre outras.

Na literatura, existe uma grande diversidade de problemas de corte e empacotamento. Assim, Dyckhoff (1990) apresentou uma tipologia para classificá-los conforme algumas características, tais como: dimensionalidade, tipo de seleção dos objetos/itens, variedade de objetos/itens, entre outros. Wäscher et al. (2006) propôs uma extensão da tipologia de Dyckhoff, em que foi criado um novo critério de categorização e organização dos problemas de corte e empacotamento. Com relação à dimensionalidade, os problemas de corte podem ser classificados como:

1. Unidimensional: apenas uma dimensão é relevante no processo de corte. Aplicações: corte de barras de aço com a mesma seção transversal, bobinas de papel, placas de alumínio, tubos para produção de treliças, etc. A Figura 1.1 ilustra este tipo de problema:

(a)

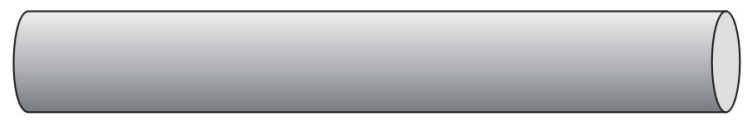

(b)

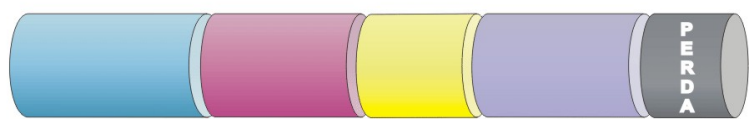

Figura 1.1: (a) Barra; (b) barra cortado em 4 itens.

2. Bidimensional: duas dimensões (comprimento e largura) são relevantes no processo de corte, uma vez que todas as peças cortadas têm a mesma espessura. Resolver este tipo de problema consiste em combinar geometricamente os itens ao longo do comprimento e da largura dos objetos em estoque. Exemplos de aplicação: corte de placas de vidro, madeiras, etc. A Figura 1.2 ilustra este tipo de problema.
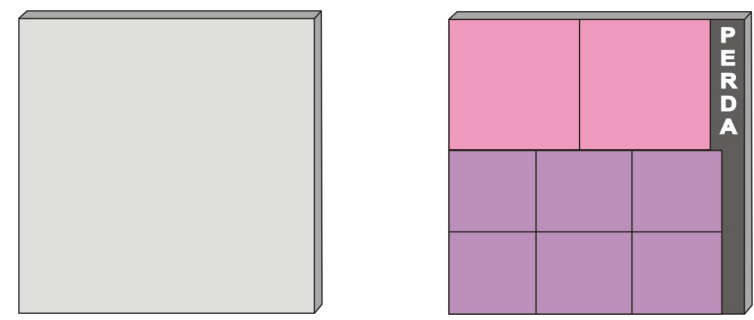

Figura 1.2: (a) Placa; (b) placa cortada em 8 itens.

3. Tridimensional: três dimensões são relevantes no processo de corte. Exemplo de aplicação: corte de espuma para a produção de colchões, travesseiros, etc. Outras aplicações são relacionadas aos problemas de empacotamento, isto é, carregar caixas dentro de contêineres ou caminhões (Morabito (1992)). Na Figura 1.3 ilustra-se um problema de empacotamento. 

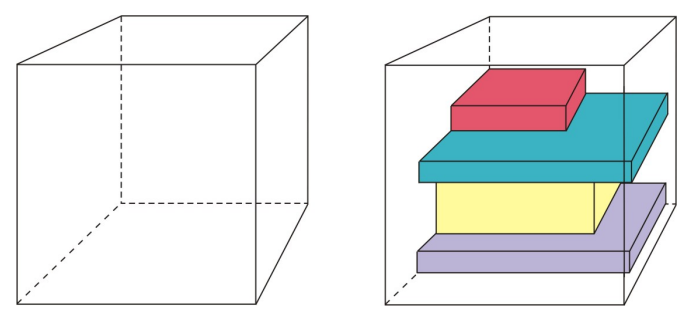

Figura 1.3: (a) Contêiner; (b) 4 caixas empacotadas no contêiner.

4. 1.5 - dimensional: duas dimensões são relevantes para a solução do problema. Porém, apenas uma delas tem tamanho fixado. Um exemplo desse tipo de problema é o de um rolo de tecido que tem largura fixa e comprimento suficientemente grande para a produção de roupas. A Figura 1.4 ilustra o problema de corte 1.5 - dimensional, em que o comprimento total cortado $L$ deve ser minimizado.

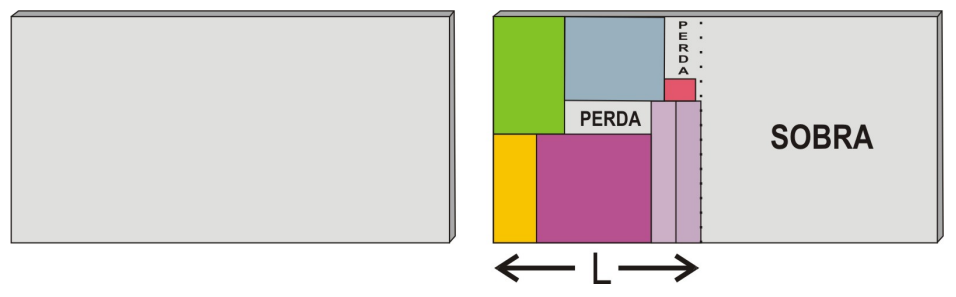

Figura 1.4: (a) Rolo; (b) rolo cortado em itens.

5. 2.5 - dimensional: três dimensões são relevantes na resolução do problema. Porém, uma delas é variável. Um exemplo é o carregamento de um contêiner com largura e altura fixa e suficientemente comprido para acomodar um volume de carga. A Figura 1.4 pode ser interpretada como uma visão lateral deste caso.

6. N-dimensional: mais de três dimensões são relevantes para a solução. Um exemplo para esse tipo de problema é a alocação de tarefas num dia de trabalho que utilizam diferentes recursos renováveis, porém limitados (Morabito (1992)).

Por mais que os estudos até então realizados em relação ao problema de corte de estoque pareçam ter sido exaustivos, ainda há vários aspectos deste problema que merecem ser investigados. A motivação crescente que contribui para o estudo de tal tema é a importância econômica das aplicações aliada à complexidade de resolução (Poldi (2003)).

Embora a literatura a respeito dos problemas de corte de estoque seja muito rica, com trabalhos nas mais variadas direções da pesquisa científica, a introdução de incertezas (variáveis aleatórias, parâmetros estocásticos, etc.) nos PCE ainda se constituem numa abordagem pouco explorada. 
Nas situações em que falta informação a respeito da demanda do PCE, e algumas decisões devem ser tomadas mesmo com essa incerteza, tipicamente se acaba tomando a demanda como a média (ou o valor esperado) de algumas possíveis ocorrências que se considere plausível, ou obtem-na por alguma técnica de previsão, a partir dos dados históricos, por exemplo.

Se a demanda prevista configurar-se na prática (situação muito rara, mas bastante desejada!), tudo corre bem e o decisor não precisa perder tempo com ações contingenciais de nenhuma espécie. Entretanto, nas situações mais comuns, a demanda prevista não é observada na prática, o que pode tornar o planejamento do corte obsoleto para a dada situação e ocasionar problemas com estoques excessivos ou muitos clientes insatisfeitos com o não atendimento dos pedidos.

O que se propõe, nesse trabalho, é uma metodologia adicional para a análise ou tomada de decisão sob incertezas relacionadas à demanda no PCE. Não é possível dizer com certeza se a consideração das incertezas num problema de corte sempre resulta numa solução ótima melhor. Mas é possível chegar bem perto de uma resposta satisfatória se for analisada a influência da aleatoriedade nos dados.

No melhor do nosso conhecimento, existem pouquíssimos trabalhos na literatura que abordam esse tema. Gemmils e Sanders (1990) consideram o problema de corte de estoque com incertezas como um problema de portfólio. Neste caso, o objetivo de minimizar a perda de material é substituído pelo propósito de determinar uma composição ótima de objetos de variados tamanhos, com a finalidade de manter no estoque e atender a variadas listas de materiais (bill of materials). No modelo geral do problema de portfólio, as incertezas estão associadas às listas de materiais, que podem possuir uma distribuição de probabilidade conhecida. No artigo, o autor propõe um guia de seleção de portfólio para várias situações envolvendo, por exemplo, problema de corte unidimensional e bidimensional, demandas aleatórias uniformemente distribuídas num intervalo e vários tipos de itens requisitados.

Já em Krichagina et al. (1998), é utilizada análise estocástica para o problema de corte de estoque sob incertezas. Neste trabalho é modelado o problema de produzir itens de diversos tamanhos para compor o estoque de produtos acabados. O objetivo é determinar uma política dinâmica de agendamento (scheduling) de tarefas de modo a minimizar as interrupções esperadas das máquinas de corte de papel, o desperdício, os estoques e a demanda não atendida, e os custos de preparação. Para resolver o problema, é proposto um procedimento de 2 passos: programação linear e controle Browniano. Como o número de padrões de corte tende a ser muito grande, o objetivo do primeiro passo é selecionar apenas alguns padrões que serão efetivamente 
empregadas no segundo passo. O procedimento fornece uma solução efetiva, mas subótima.

Vale ressaltar também que a palavra incerteza está relacionada a situações em que as distribuições de probabilidade de algum parâmetro não estão disponíveis. Para os casos em que tais distribuições são conhecidas ou dadas, o termo mais apropriado é risco. Então, em programação estocástica, por exemplo, é comum que os problemas apresentem riscos associados. Contudo, como a maioria dos trabalhos encontrados na literatura tratam dos termos como se fossem equivalentes, será cometido um abuso de linguagem e será utilizada a expressão incerteza em algumas partes do trabalho.

\subsection{Objetivos}

Os dois objetivos primários desse trabalho de mestrado são: propor uma variação do modelo matemático clássico do problema de corte de estoque (unidimensional, não-capacitado e sem restrições de estoque de barras) em que seja possível possível incorporar as incertezas relacionadas à demanda; especializar o método Simplex com geração de colunas para resolver o problema proposto. O objetivo secundário pode ser sumarizado em introduzir uma nova postura de observação e análise dos problemas de corte de estoque, sob a ótica da programação estocástica.

Para analisar a adequação do modelo matemático proposto e o método de solução, foram geradas muitas classes de problemas pequenos e médios, que foram testados e analisados convenientemente, de maneira que fosse possível concluir algumas propriedades características do problema, que também se constitue num objetivo a ser alcançado no presente trabalho.

\subsection{Organização da Monografia}

No Capítulo 2, é apresentado o problema de corte de estoque unidimensional clássico e o método de solução baseado na técnica de geração de colunas. Antes de apresentar o algoritmo proposto por Gilmore e Gomory (1961) para resolver o problema, são feitas algumas considerações a respeito do método Simplex e o processo de geração de colunas. O Capítulo 3 apresenta uma introdução à programação estocástica, alguns conceitos e técnicas importantes, o modelo de dois estágios com recurso e uma idéia de restrições probabilísticas. O Capítulo 4 apresenta o modelo matemático proposto para o problema de corte de estoque com demanda estocástica e suas principais características. No Capítulo 5, são apresentadas duas estratégias para resolver o modelo de corte de dois estágios: a primeira é uma especialização do método Simplex com 
Geração de Colunas, e a segunda é uma estratégia heurística adaptada de uma metodologia conhecida em programação estocástica que avalia a qualidade de certas soluções. O Capítulo 6 apresenta dois exemplos numéricos para ilustrar as estratégias de solução. O Capítulo 7 segue com os experimentos computacionais e, finalmente, as considerações finais são apresentadas no Capítulo 8, assim como sugestões de pesquisas futuras. 


\section{CAPÍTUlo}

\section{O Problema de Corte de Estoque}

\subsection{Formulação Matemática do Problema de Corte de Estoque Unidimensional}

O PCE unidimensional consiste em cortar barra: $\bigsqcup^{1}$ de tamanho $L$ para produzir itens de tamanho $l_{i} \leq L$ em quantidades $d_{i}$ conhecidas. Supõe-se que a quantidade de barras seja suficiente para atender toda a demanda. Para cortar uma barra de tamanho $L$, utiliza-se um padrão de corte, conforme a definição a seguir.

Definição 2.1 Padrão de corte é a maneira como um objeto disponível em estoque é cortado para a produção dos itens demandados. A um padrão de corte é associado um vetor $m$-dimensional que contabiliza os itens produzidos:

$$
\mathbf{a}=\left(\alpha_{1}, \alpha_{2}, \ldots, \alpha_{m}\right)^{T}
$$

em que $\alpha_{i}$ é a quantidade de itens do tipo $i$ no padrão de corte $\mathbf{a}$.

No caso unidimensional, um padrão de corte a deve satisfazer a restrição física:

${ }^{1}$ Sem perda de generalidade, os objetos em estoque são denominados de barras, ao se tratar do PCE unidimensional. 


$$
\begin{aligned}
& l_{1} \alpha_{1}+l_{2} \alpha_{2}+\ldots+l_{m} \alpha_{m} \leq L \\
& \alpha_{i} \geq 0, i=1, \ldots, m \text { e inteiro. }
\end{aligned}
$$

Existe um número finito de padrões de corte. Porém, na prática, este número é muito grande.

Definição 2.2 Um padrão de corte que produza apenas um tipo de item é chamado de padrão de corte homogêneo.

Isto é, um padrão de corte é homogêneo se o vetor associado possuir apenas uma coordenada não nula: $\left(0, \ldots, \alpha_{i}, \ldots, 0\right), \alpha_{i} \neq 0$. Em problemas de corte de estoque com $m$ tipos de itens demandados sempre existem $m$ padrões de corte homegêneos, cujos vetores asssociados definem uma matriz diagonal.

De maneira geral, a modelagem matemática de um problema de corte de estoque pode ser construída em duas etapas: na primeira, definem-se todos os possíveis padrões de corte, e na segunda, a freqüência com que cada padrão de corte será utilizado para atender a demanda.

Supondo que o número de possíveis soluções do sistema (2.1) seja n, é possível representálas pelos vetores $\mathbf{a}_{j}$, em que $\alpha_{i j} \in \mathbf{a}_{j}$ é o número de itens do tipo $i$ no padrão de corte $j, \forall i, j$.

$$
\mathbf{a}_{1}=\left[\begin{array}{c}
\alpha_{11} \\
\alpha_{21} \\
\vdots \\
\alpha_{m 1}
\end{array}\right], \mathbf{a}_{2}=\left[\begin{array}{c}
\alpha_{12} \\
\alpha_{22} \\
\vdots \\
\alpha_{m 2}
\end{array}\right], \cdots, \mathbf{a}_{n}=\left[\begin{array}{c}
\alpha_{1 n} \\
\alpha_{2 n} \\
\vdots \\
\alpha_{m n}
\end{array}\right],
$$

Seja $x_{j}$ a freqüência com que os padrões de corte são utilizados e $c_{j}$ o custo de cortar a barra segundo o padrão de corte $j$. Então, um possível modelo matemático para o problema de corte de estoque unidimensional irrestrito quanto ao estoque de barras é dado por:

$$
\begin{array}{ll}
\text { PCE }=\min & f(\mathbf{x})=\sum_{j=1}^{n} c_{j} x_{j} \\
\text { s.a. } & \sum_{j=1}^{n} a_{i j} x_{j}=d_{i}, i=1, \ldots, m \\
& x_{j} \in\left(Z^{+}\right)^{n}, j=1, \ldots, n .
\end{array}
$$

A função objetivo visa minimizar o custo de cortar as barras. As primeiras restrições garantem que a demanda seja satisfeita, e as últimas restrições garantem que a freqüência com que o padrão de corte $j$ é repetido seja um número inteiro não-negativo. É comum os 
problemas de corte possuírem uma quantidade elevada de padrões de corte, fato que torna inviável a determinação de todos eles a priori, como o suposto no modelo (2.2). Além disso, esse modelo exige que as variáveis $x_{j}$ sejam inteiras, fato que o torna difícil de ser resolvido computacionalmente.

Em notação matricial, o o modelo 2.2 pode ser definido da seguinte maneira:

$$
\begin{array}{ll}
\min & f(\mathbf{x})=\mathbf{c}^{T} \mathbf{x} \\
\text { s.a. } & \mathbf{A x}=\mathbf{d} \\
& \mathbf{x} \in \mathbf{Z}^{+},
\end{array}
$$

em que $\mathbf{A} \in \Re^{m \times n}$ a matriz cujas colunas representam os padrões de corte.

Um outro objetivo interessante a ser otimizado refere-se à minimização da perdå total incorrida durante o processo de corte. A função objetivo do modelo 2.2 é tal que:

$$
c_{j}=L-\left(\alpha_{1 j} l_{1}+\alpha_{2 j} l_{2}+\ldots+\alpha_{m j} l_{m}\right),
$$

em que $c_{j}$ define a perda no padrão de corte $j, j=1, \ldots, n$.

Mostra-se que minimizar o total de objetos cortados (isto é, $c_{j}=1, j=1, \ldots, n$ ) e minimizar a perda total são objetivos equivalentes, no caso em que só há um tipo de objeto em estoque e restrições de igualdade (Poldi (2003)).

\subsection{O Método Simplex Aplicado ao PCE}

Na prática, as dificuldades computacionais mencionadas na resolução do modelo PCEUI são contornadas com a relaxação linear da condição de integralidade sobre as variáveis $x_{j}$ e a posterior utilização do método Simplex com geração de colunas, que fornece uma solução ótima contínua para o problema. Este métodd ${ }^{3}$ de solução para o problema de corte de estoque foi objeto de estudo de Gilmore e Gomory (1961, 1963), e consiste, basicamente, em substituir um dos padrões de corte básicos (uma determinada coluna $a_{j}$ ) por um novo padrão de corte (determinado pela resolução de um problema da mochila) que melhore a solução básica atual.

\footnotetext{
${ }^{2} \mathrm{Na}$ prática, considera-se "perda" todo tipo de retalho advindo do processo de corte que não tem dimensão adequada para ser utilizado para produzir itens no futuro. Ao contrário das perdas, as sobras de material podem ser estocadas para futura utilização. Veja Cherri e Arenales (2005).

${ }^{3}$ A abordagem proposta por Gilmore e Gomory (1961) salienta que a solução contínua do problema relaxado constitui-se numa boa solução aproximada para o problema original, quando a demanda é suficientemente alta e exige uma alta freqüência dos padrões de corte.
} 
Soluções heurísticas para o problema original (inteiro) podem ser obtidas por procedimentos de arredondamento da solução contínua. Mais detalhes podem ser encontrados em Poldi e Arenales (2003) e Wäescher e Gau (1996).

\subsubsection{O Método Simplex}

Por simplicidade, considere o seguinte problema de otimização linear escrito em notação matricial:

$$
\begin{array}{ll}
\min & f(\mathbf{x})=\mathbf{c}^{T} \mathbf{x} \\
\text { s.a: } & \mathbf{A x}=\mathbf{d}, \quad \mathbf{x} \geq \mathbf{0},
\end{array}
$$

em que $A \in \Re^{m \times n}$. Suponha que o posto $(\mathbf{A}, \mathbf{d})=\operatorname{posto}(\mathbf{A})=m$. Esta hipótese elimina possíveis restrições redundantes e casos triviais de inconsistência do sistema $\mathbf{A x}=\mathbf{d}$.

Definição 2.3 O conjunto de vetores do $\Re^{n}$ que satisfazem as restrições de (2.1) é chamado de região factivel e é denotado por $S: S=\left\{\mathbf{x} \in \Re^{n} \mid \mathbf{A x}=\mathbf{d}, \mathbf{x} \geq \mathbf{0}\right\}$. Se $\hat{\mathbf{x}} \in S$, diz-se que $\hat{\mathbf{x}} e ́$ uma solução factível.

Considere uma partição nas colunas da matriz $\mathbf{A}$, chamada de partição básica, dada por $\mathbf{A}=[\mathbf{B}, \mathbf{N}]$, sendo $\mathbf{B} \in \Re^{m \times m}$ não-singular e $\mathbf{N} \in \Re^{m \times(n-m)}$. A matriz $\mathbf{B}$ é chamada de matriz básica e a matriz $\mathbf{N}$, não-básica.

Esta partição nas colunas da matriz $\mathbf{A}$ também define uma partição nos vetores $\mathbf{x}$ e c: $\mathbf{x}=\left[\mathbf{x}_{\mathbf{B}}, \mathbf{x}_{\mathbf{N}}\right]^{T}$ e $\mathbf{c}=\left[\mathbf{c}_{\mathbf{B}}, \mathbf{c}_{\mathbf{N}}\right]^{T}$. As variáveis $\mathbf{x}_{\mathbf{B}}$ são chamadas de variáveis básicas e os custos das variáveis básicas são representados por $\mathbf{c}_{\mathbf{B}}$. As variáveis $\mathbf{x}_{\mathbf{N}}$ são as variáveis não-básicas e $\mathbf{c}_{\mathbf{N}}$ representa os custos associados a estas variáveis. O sistema 2.4 pode ser rescrito por:

$$
\begin{array}{ll}
\min & f(\mathbf{x})=\mathbf{c}_{\mathbf{B}}^{T} \mathbf{x}_{\mathbf{B}}+\mathbf{c}_{\mathbf{N}}^{T} \mathbf{x}_{\mathbf{N}} \\
\text { s.a: } & \mathbf{B x}_{\mathbf{B}}+\mathbf{N x}_{\mathbf{N}}=\mathbf{d} \\
& \mathbf{x}_{\mathbf{B}} \geq \mathbf{0}, \quad \mathbf{x}_{\mathbf{N}} \geq \mathbf{0} .
\end{array}
$$

A solução geral do sistema de equações lineares que definem as restrições pode ser escrita da seguinte forma:

$$
\mathbf{B} \mathbf{x}_{\mathbf{B}}+\mathbf{N} \mathbf{x}_{\mathbf{N}}=\mathbf{d} \Leftrightarrow \mathbf{x}_{\mathbf{B}}=\mathbf{B}^{-1} \mathbf{d}-\mathbf{B}^{-1} \mathbf{N x}_{\mathbf{N}}
$$

Definição 2.4 A solução particular associada à partição básica obtida por: $\mathbf{x}_{\mathbf{B}}^{0}=\mathbf{B}^{-1} \mathbf{d} e$ $\mathbf{x}_{\mathbf{N}}^{0}=\mathbf{0}$ é chamada de solução básica. Se $\mathbf{x}_{\mathbf{B}}^{0}=\mathbf{B}^{-1} \mathbf{d} \geq \mathbf{0}$, então a solução básica é dita primal-factível e dizemos que a partição básica é primal-factível. 
Demonstra-se que se um problema de otimização linear tem uma solução ótima então existe uma solução básica primal-factível ótima.

É possível escrever as variáveis básicas da função objetivo de 2.5 em termos das variáveis não-básicas:

$$
\begin{aligned}
f(\mathbf{x}) & =\mathbf{c}_{\mathbf{B}}^{T}\left(\mathbf{B}^{-1} \mathbf{d}-\mathbf{B}^{-1} \mathbf{N x}_{\mathbf{N}}\right)+\mathbf{c}_{\mathbf{N}}^{T} \mathbf{x}_{\mathbf{N}} \\
& =\mathbf{c}_{\mathbf{B}}^{T} \mathbf{B}^{-1} \mathbf{d}+\left(\mathbf{c}_{\mathbf{N}}^{T}-\mathbf{c}_{\mathbf{B}}^{T} \mathbf{B}^{-1} \mathbf{N}\right) \mathbf{x}_{\mathbf{N}} .
\end{aligned}
$$

Note que, segundo a definição 2.4 , a função objetivo para a solução básica vale $f\left(\mathbf{x}^{0}\right)=$ $\mathbf{c}_{\mathbf{B}}^{T} \mathbf{B}^{-1} \mathbf{d}=\mathbf{c}_{\mathbf{B}}^{T} \mathbf{x}_{\mathbf{B}}^{0}$

Definição 2.5 O vetor $\pi \in \Re^{m}$ definido por $\pi^{T}=\mathbf{c}_{\mathbf{B}}^{T} \mathbf{B}^{-1}$ é chamado de vetor multiplicador Simplex.

A função objetivo $f(\mathbf{x})$ em termos das componentes das variáveis não-básicas pode ser escrita da seguinte maneira:

$$
f(\mathbf{x})=f\left(\mathbf{x}^{0}\right)+\sum_{j \in \mathcal{N}}\left(c_{j}-\pi^{T} \mathbf{a}_{j}\right) x_{j},
$$

sendo que $\mathbf{a}_{j} \in \mathbf{N}$ corresponde à coluna $j$ de $\mathbf{N}$ e $\mathcal{N}$ é o conjunto dos índices das colunas da matriz N. Os coeficientes das variáveis não-básicas $x_{j}: c_{j}-\pi^{T} \mathbf{a}_{j}$ são chamados custos reduzidos ou custos relativos.

Definição 2.6 Estratégia Simplex é o nome dado à seguinte perturbação da solução básica inicial, faz-se:

1. $x_{k}=\varepsilon \geq 0$ para algum $k \in \mathcal{N}$, tal que $c_{k}-\pi^{T} \mathbf{a}_{k}<0$;

2. $x_{j}=0$ para todo $j \neq k, j \in \mathcal{N}$.

Observe que diminuir $f(\mathbf{x})$, com $\mathbf{x} \geq \mathbf{0}$, implica em escolher, necessariamente, uma componente $x_{k}$ de forma que o custo relativo desta seja estritamente menor que zero.

Fazendo $x_{k}=\varepsilon \geq 0$ e $x_{j}=0, \forall j \in \mathcal{N}-\{k\}$, as variáveis básicas são alteradas resultando em uma nova solução dada por:

$$
\begin{aligned}
& \mathbf{x}_{\mathbf{B}}=\mathbf{x}_{\mathbf{B}}^{\mathbf{0}}+\varepsilon \mathbf{y}, \\
& \mathbf{x}_{\mathbf{N}}=\varepsilon \mathbf{e}_{k},
\end{aligned}
$$

e o valor da função objetivo é dado por:

$$
f(\mathbf{x})=f\left(\mathbf{x}^{0}\right)+\left(c_{k}-\pi^{T} \mathbf{a}_{k}\right) \varepsilon,
$$

em que $\mathbf{y}=-\mathbf{B}^{-1} \mathbf{a}_{k}$ e $\mathbf{e}_{k}=(0, \ldots, 1, \ldots, 0)^{T} \in \Re^{n-m}$, com 1 na $k$-ésima componente. 
A direção $\mathbf{s} \in \Re^{n}$, dada por: $\mathbf{s}=\left(\mathbf{s}_{\mathbf{B}}, \mathbf{s}_{\mathbf{N}}\right)^{T}=\left(\mathbf{y}, \mathbf{e}_{k}\right)^{T}$, define uma perturbação da solução básica e é chamada direção Simplex.

Se a solução básica for não-degenerada, isto é, $\mathbf{x}_{\mathbf{B}}^{0}>\mathbf{0}$, de 2.6 e 2.7 segue que $\mathbf{s}$ é uma direção factível e de descida.

De 2.6 podemos determinar o maior valor de $\varepsilon$, impondo $\mathbf{x}_{\mathbf{B}} \geq \mathbf{0}$, já que as demais restrições são satisfeitas $\forall \varepsilon \geq 0$ :

$$
\varepsilon^{0}=-\frac{x_{B_{l}}^{0}}{y_{l}}=\min \left\{-\frac{x_{B_{i}}^{0}}{y_{i}} \mid y_{i}<0, \quad i=1, \ldots, m\right\}
$$

em que $x_{B_{i}}^{0}$ é a $i$-ésima componente de $\mathbf{x}_{\mathbf{B}}^{0}$. Naturalmente, se $y_{i} \geq 0, i=1, \ldots, m$, então não há limitante para $\varepsilon, f(\mathbf{x}) \rightarrow-\infty$ (a direção s é um raio de descida) e o problema (2.4) não tem solução ótima.

Para esta escolha de $\varepsilon$, a $l$-ésima componente de $\mathbf{x}_{\mathbf{B}}$ anula-se, enquanto que apenas uma variável de $\mathbf{x}_{\mathbf{N}}$ torna-se positiva: $x_{k}=\varepsilon^{0}>0$ (a menos de degeneração: $\left.\varepsilon^{0}=0\right)$. Isto sugere uma nova partição básica $\mathbf{A}=\left[\mathbf{B}^{\prime}, \mathbf{N}^{\prime}\right]$, nque a $l$-ésima coluna de $\mathbf{B}^{\prime}$ é substituída por $\mathbf{a}_{k} \in \mathbf{N}$. Esta nova partição é básica primal-factível, e a solução básica associada é dada por: $\mathbf{x}^{\mathbf{1}}=\mathbf{x}^{\mathbf{0}}+\varepsilon^{0} \mathbf{s}$.

Pode-se escolher qualquer $k$ tal que $\left(c_{k}-\pi^{T} \mathbf{a}_{k}\right)<0$ para que uma nova solução básica factível seja gerada com um valor menor para a função objetivo. Um critério (conhecido como a regra de Dantzig ou regra de máxima descida) para a escolha do índice $k$ da coluna que deverá tornar-se básica é dado por:

$$
\left(c_{k}-\pi^{T} \mathbf{a}_{k}\right)=\min \left\{\left(c_{j}-\pi^{T} \mathbf{a}_{j}\right), j=1, \ldots, n\right\} .
$$

isto é, deve-se escolher a direção Simplex com o menor custo relativo.

Para determinar o menor custo relativo é preciso examinar todas as $n$ colunas da matriz A. A solução ótima é obtida quando todos os custos reduzidos forem não-negativos, fato afirmado pelo teorema seguinte.

Teorema 2.1 Se a partição básica $\mathbf{A}=[\mathbf{B}, \mathbf{N}]$ for primal-factível e $c_{j}-\pi^{T} \mathbf{a}_{j} \geq 0, j=1, \ldots, n$, então a solução básica associada atual é ótima.

\subsubsection{Geração de Colunas}

Enquanto que a relaxação linear do modelo 2.2 supera a dificuldade inerente de achar uma solução para o programa inteiro, o procedimento de geração de colunas contorna a dificuldade 
de armazenar todas as colunas (padrões de corte) da matriz $\mathbf{A}$ a priori e testar, a cada iteração, todas elas para determinar aquela que apresenta o menor custo relativo.

O procedimento de geração de colunas consiste em gerar uma coluna $k$, isto é, um novo padrão de corte, com a utilização do critério de Dantizg, que procura a variável $x_{k}$ com o menor custo relativo. O problema resulta em:

$$
c_{k}-\pi^{T} \mathbf{a}_{k}=\min \left\{c_{j}-\pi^{T} \mathbf{a}_{j}, j=1, \ldots, n\right\}
$$

sendo que $\pi$ é o vetor multiplicador Simplex de uma determinada iteração.

Observe que se $c_{j}=c_{b}, j=1, \ldots, n$, (isto é, o custo é fixado para todo padrão de corte e denominado custo de cortar a barra) então 2.9 se torna:

$$
\min \left\{c_{j}-\pi^{T} \mathbf{a}_{j}\right\}=c_{b}-\max \left\{\pi^{T} \mathbf{a}_{j}\right\}
$$

Logo, encontrar uma coluna não-básica que substituirá uma coluna básica corresponde a resolver o problema:

$$
\begin{array}{ll}
\operatorname{maximizar} & \pi_{1} \alpha_{1}+\pi_{2} \alpha_{2}+\ldots+\pi_{m} \alpha_{m} \\
\text { sujeito a que } & \left(\alpha_{1}, \alpha_{2}, \ldots, \alpha_{m}\right)^{T} \text { corresponda a um padrão de corte. }
\end{array}
$$

em que $\left(\alpha_{1}, \alpha_{2}, \ldots, \alpha_{m}\right)^{T}$ representa, genericamente, uma coluna não-básica.

Para que a coluna $\mathbf{a}_{j}=\left(\alpha_{1}, \alpha_{2}, \ldots, \alpha_{m}\right)^{T}$ corresponda a um padrão de corte, é necessário e suficiente satisfazer as seguintes restrições

$$
\begin{aligned}
& l_{1} \alpha_{1}+l_{2} \alpha_{2}+\ldots+l_{m} \alpha_{m} \leq L \\
& \alpha_{i} \geq 0, \quad \text { e inteiro, } i=1, \ldots, m .
\end{aligned}
$$

Assim, o problema 2.9 poderá ser reescrito como:

$$
\begin{array}{ll}
g(\mathbf{a})=\max & \sum_{i=1}^{m} \pi_{i} \alpha_{i} \\
\text { s.a. } & \sum_{i=1}^{m} l_{i} \alpha_{i} \leq L \\
& \alpha_{i} \in Z^{+}, i=1, \ldots, m,
\end{array}
$$

que é um problema da mochila irrestrito, isto é, não há um limitante superior para a quantidade máxima de $\alpha_{i}$. A primeira restrição assegura que todos os itens cortados não ultrapassem o

\footnotetext{
${ }^{4}$ Outras restrições podem surgir dependendo do processo de corte, como por exemplo, limitação do número de facas, compartimentação, etc. (veja Hoto et al. (2006)).
} 
tamanho $L$ da barra (restrição física), e a segunda restrição garante que os padrões de corte sejam constituídos por números inteiros e positivos.

Se o menor dos custos relativos for maior ou igual a zero, ou seja, $c_{b}-g(\mathbf{a}) \geq 0$, a solução do problema relaxado é ótima. Caso contrário, a coluna de menor custo relativo entra na base e as iterações continuam com os passos usuais do método Simplex.

\subsubsection{Algoritmo do Método Simplex com Geração de Colunas}

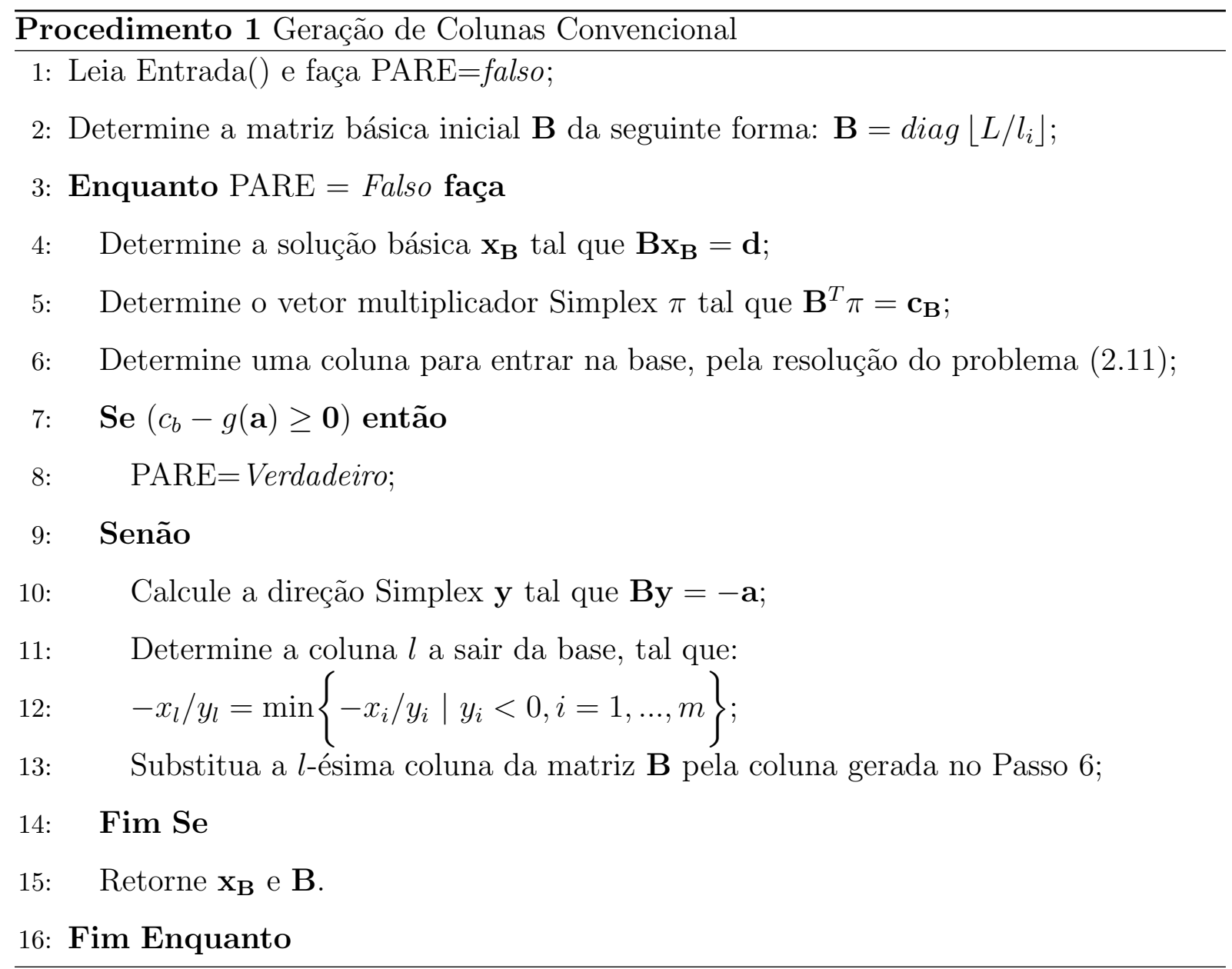




\section{Introdução à Programação Estocástica}

A Programação estocástica (PE) pode ser definida, simplificadamente, como uma técnica de programação matemática que lida com dados incertos, que podem ser representados por variáveis aleatórias. Tal técnica é especialmente utilizada quando eventos futuros não podem ser perfeitamente previstos. As próximas seções descrevem algumas notações e conceitos importantes comuns à PE.

\subsection{Espaço de Probabilidade e Variáveis Aleatórias}

Muitos parâmetros de um problema podem ser considerados incertos e, por isso, são representados por variáveis aleatórias. Custos de produção e de distribuição dependem dos custos de aquisição de matérias-primas e de combustíveis, que são valores aleatórios por natureza. Demandas futuras dependem das condições de mercado que são incertas. Para modelar as incertezas mencionadas, é utilizada a letra grega $\xi$ que designa uma variável aleatória (ou um vetor aleatório). A letra $w$ denota uma possível realização (ou saída) da variável aleatória, e o conjunto de todas as possíveis realizações é chamado de espaço amostral, que é freqüentemente denotado por $\Omega$.

Um evento ${ }^{1} \mathcal{A}$ é um subconjunto de $\Omega$. Suponha, por exemplo, que $\xi$ seja uma variável

\footnotetext{
${ }^{1}$ Um evento $\mathcal{A}$ também pode ser definido como uma combinação de saídas $w \in \Omega$.
} 
aleatória discreta representando o rendimento dos títulos do governo para o próximo mês. O espaço amostral é constituído de quatro possíveis realizações para tal rendimento: $0,5 \%, 2,0 \%$, $2,7 \%$ e $5 \%$. Então, um evento $\mathcal{A}$ pode ser o rendimento dos títulos de até $2 \%$ ou o rendimento abaixo de $2,7 \%$. Uma probabilidade pode ser associada a cada evento $\mathcal{A}$. Para $P$ ser uma probabilidade, é necessário que $0 \leq P(\mathcal{A}) \leq 1$ para todo $\mathcal{A} \subseteq \Omega, P(\Omega)=1$ e $P\left(\mathcal{A}_{1} \cup \mathcal{A}_{2}\right)=P\left(\mathcal{A}_{1}\right)+P\left(\mathcal{A}_{2}\right)$, se $\mathcal{A}_{1} \cap \mathcal{A}_{2}=\{\}$. Ao terno $(\Omega, \mathcal{A}, P)$ designa-se o nome de espaço de probabilidade.

Para uma particular v.a. $\boldsymbol{\xi}$, define-se a sua distribuição de probabilidade acumulada como $F_{\boldsymbol{\xi}}(x)=P(\{w \mid \boldsymbol{\xi} \leq x\})$. Uma v.a. discreta assume um número finito ou contável de diferentes valores, que são melhor representados por sua distribuição de probabilidade, que é uma lista de possíveis valores $\xi^{s}, s \in \mathbb{S}^{2}$, com probabilidades associadas,

$$
f\left(\xi^{s}\right)=P\left(\boldsymbol{\xi}=\xi^{s}\right) \text { tal que } \sum_{s \in S} f\left(\xi^{s}\right)=1 .
$$

A esperança de uma v.a. discreta é definida da seguinte maneira:

$$
E(\boldsymbol{\xi})=\sum_{s \in S} \xi^{s} f\left(\xi^{s}\right)
$$

\subsection{Abordagem por Cenários}

Em termos de programação estocástica, é comum que as realizações $w \in \Omega$ sejam utilizadas para descrever possíveis estados dos mundo ou cenários. Isso é especialmente observado quando a distribuição de probabilidade da v.a. não é conhecida ou quando é muito custoso computacionalmente considerar uma distribuição discreta com muitas possíveis realizações. Nesse caso, é selecionado um conjunto relativamente pequeno de realizações da v.a., que é denominado de cenário e atribui-se uma probabilidade para refletir a sua ocorrência. Os cenários podem ser os quartis de uma determinada distribuição de probabilidade, dados históricos, previsões de algum "expert" ou gerados por simulação. Para ilustrar, considere os exemplos a seguir.

1. Uma v.a. pode assumir qualquer valor do seguinte conjunto: $\Omega=\{1,2,3,4,5,6,7\}$. Supondo que se queira formar um cenário a partir dos quartis dessa distribuição, então tal cenário pode ser representado por $s=\{2,4,6\}$.

\footnotetext{
${ }^{2} \mathrm{~S}$ representa o número total de realizações da uma v.a. discreta.
} 
2. A demanda por carros no próximo mês pode ser alta, média ou baixa, sendo que as respectivas probabilidades de cada possível cenário são 0,6, 0,1 e 0,3.

3. Precisa-se determinar hoje a variação que as ações da Petrobrás vão sofrer amanhã. Não se sabe ao certo qual será a variação, mas um "expert" estima um cenário otimista em que as ações sofrem uma alta de 3,5\% com probabilidade 0,7 e um cenário pessimista em que as ações sobem apenas $0,6 \%$ com probabilidade 0,3 .

4. A demanda por um determinado produto no próximo trimestre não é exatamente conhecida, mas se sabe que ela está em torno de 1000 unidades. Para fazer o planejamento da produção, o gerente vislumbra 4 possíveis ocorrências equiprováveis para a demanda: 300 unidades do produto, se o país passar por uma crise financeira séria; 800 unidades, se a economia sofrer uma pequena queda; 1200 unidades, se a economia não sofrer grandes impactos e 2000 unidades, caso haja um aquecimento econômico.

Os cenários são uma ferramenta muito importante na tomada de decisão, quando não se tem certeza sobre o valor que um determinado parâmetro pode assumir no futuro. Considerando a análise de cenário ${ }^{3}$ é possível analisar os riscos de uma decisão em várias situações, e optar pela decisão que minimize o risco, por exemplo. Muitos trabalhos da literatura propõem resolver vários problemas determinísticos, um para cada cenário independente, e depois combinar as soluções obtidas de forma que o resultado final seja uma solução razoável para o problema estocástico original (Rockafellar e Wets, 1991). Outros trabalhos consideram os cenários num único problema de grande porte e determinam as soluções baseadas na dependência dos cenários (Alonso-Ayuso et al., 2003).

Não é a intenção desse trabalho mostrar como os cenários devem ser escolhidos ou construídos. Para uma leitura mais detalhada sobre a construção de cenários e questões adjacentes, veja Kowenberg (2001).

\subsection{Tipos de Solução em PE: "Espere e Veja" e "Aqui e Agora"}

Em PE, é importante distinguir entre dois tipos de solução que podem ser consideradas no tratamento dos problemas: a solução espere e veja (traduzida do inglês, wait and see) e a solução aqui e agora (traduzida do inglês, here and now). Essas duas soluções refletem o tipo de ambiente dentro dque são tomadas as decisões do problema de programação estocástica. Na solução espere

\footnotetext{
${ }^{3}$ Da literatura, scenario analysis.
} 
e veja, é permitido esperar a efetiva ocorrência do parâmetro aleatório para então determinar os valores das variáveis de decisão do problema. Por outro lado, na situação aqui e agora, deve-se determinar os valores das variáveis de decisão antes da ocorrência da variável aleatória, mas é possível que sejam tomadas medidas corretivas caso as decisões tomadas precisem ser melhoradas. A notação usada para designar a situação espere e veja é fiel à notação comumente utilizada na literatura e representada pelas iniciais $W S$. A situação aqui e agora é representada pelas iniciais de problema recurso, que é um tipo de modelo de programação estocástica que permite recurso, isto é, ações de melhoria. Por simplicidade de notação, a função objetivo dos problemas com recurso são também designadas por $P R$, enquanto as soluções dos problemas referentes à situação $W S$ são representadas pelas próprias iniciais. Os detalhes são apresentados nas próximas seções. Uma discussão mais aprofundada sobre as situações $W S$ e $P R$ pode ser encontrada em Mandansky (1960).

\subsection{Modelo de 2-Estágios com Recurso}

A seguir, é relatado um exemplo simples para ilustrar a forma geral de um modelo de PE de dois-estágios. O exemplo foi adaptado de Dantzig (1955).

Uma empresa possui 100 itens em estoque na sua planta de produção e precisa transportar alguns deles para a planta de acabamento a um custo unitário de $\$ 1$. A demanda em relação aos itens não é conhecida no momento em que eles são transportados. Se a quantidade de itens na planta de acabamento for menor do que a quantidade necessária para atender a demanda, então a planta de acabamento deve adquirir os itens faltantes no varejo ao preço de $\$ 2$ por item ou, caso tenham sido transportados itens em excesso, eles devem ser estocados na própria planta de acabamento a um custo de $\$ 0,50$. O problema consiste em determinar quantos itens devem ser transportados da planta de produção à planta de acabamento, de forma que os custos incorridos no processo sejam mínimos.

Observe que a primeira decisão a ser tomada é decidir quantos itens serão transportados da planta de produção à planta de acabamento, sem que se tenha informação a respeito da demanda. Tal decisão, em PE, é denominada de decisão de primeiro estágio, assim como todas as decisões tomadas antes da realização das variáveis aleatórias. O período em que estas decisões são tomadas é chamado de primeiro estágio. Depois que os itens foram transportados, a demanda torna-se conhecida. Então, as decisões de segundo estágio podem ser tomadas, isto é, os itens faltantes são comprados no varejo e os itens em excesso são estocados na planta de acabamento. 
O período em que as decisões de segundo estágio são tomadas é denominado de segundo estágio.

\subsubsection{Formulação Geral do Modelo de 2-Estágios com Recurso}

O exemplo mostrado ilustra um caso de modelo de PE com recurso. Neste tipo de problema, tem-se um conjunto de decisões que devem ser tomadas sem informação completa a respeito de algum parâmetro aleatório e outro conjunto de decisões que deve ser tomado depois de informação completa:

- $\mathbf{x} \in \Re^{n_{1}}$ é o vetor das variáveis de decisão de primeiro estágio que deve ser fixado antes dos valores aleatórios tornarem-se conhecidos. O valor ótimo dessas variáveis é baseado nos dados disponíveis e não é, necessariamenre, condicional à realização das variáveis aleatórias;

- $\mathbf{y} \in \Re^{n_{2}}$ é o vetor das variáveis de segundo estágio, que também podem ser chamadas de ações-recurso, ações corretivas ou decisões de controle. Essas variáveis são determinadas após a realização das variáveis aleatórias. O valor ótimo para y depende das decisões de primeiro estágio e da realização das variáveis aleatórias.

De forma geral, o problema de programação estocástica de dois estágios com recurso (também conhecido por modelo de dois estágios ou problema recurso) introduzido por Dantzig e Beale (1955) pode ser formulado da seguinte maneira:

$$
\begin{array}{ll}
\min & z=\mathbf{c}^{T} \mathbf{x}+E_{\xi}\left[\min \mathbf{q}(w)^{\mathbf{T}} \mathbf{y}(w)\right] \\
\text { s.a. } & \mathbf{A} \mathbf{x}=\mathbf{b} \\
& \mathbf{T}(w) \mathbf{x}+\mathbf{W} \mathbf{y}(w)=\mathbf{h}(w) \\
& \mathbf{x} \in\left(\Re^{+}\right)^{n_{1}}, \mathbf{y}(w) \in\left(\Re^{+}\right)^{n_{2}}
\end{array}
$$

em que $\mathbf{c} \in \Re^{n_{1}}$ é o vetor de custo do primeiro estágio, $\mathbf{A} \in \Re^{m_{1} \times n_{1}}$ é a matriz dos coeficientes do primeiro estágio e $\mathbf{b} \in \Re^{m_{1}}$. Esses parâmetros são referentes ao primeiro estágio e, portanto, são determinísticos. Por outro lado, $\mathbf{q}(w) \in \Re^{n_{2}}$ é o vetor de custo do segundo estágio para uma dada realização $w, \mathbf{W} \in \Re^{m_{2} \times n_{2}}$ é a matriz dos coeficientes de segundo estágio (chamada de matriz recurso) e $\mathbf{h}(w) \in \Re^{m_{2}}$. Finalmente, $\mathbf{T}(w) \in \Re^{m_{2} \times n_{1}}$ é a matriz que relaciona os dois estágios do problema estocástico, para cada possível realização $w$.

A expressão $E_{\xi}$ denota a esperança matemática com respeito ao vetor aleatório $\xi$, cujas componentes, para cada possível realização $w$, são dadas por: 


$$
\xi^{T}=\left(\mathbf{q}(w), \mathbf{h}(w), T_{1}(w), \ldots, T_{m_{2}}(w)\right)
$$

com $T_{i}(w)$ sendo a $i$-ésima linha da matriz tecnológica $\mathbf{T}(w)$.

Os problemas com recurso podem ser classificados em algumas categorias, dependendo do tipo de matriz recurso que possuem. Então, um problema de programação estocástica com recurso é dito possuir

- recurso fixo, se a matriz $\mathbf{W}$ do problema recurso for determinística;

- recurso completo, se o problema de segundo estágio for factível parquequer valor das variáveis de primeiro estágio;

- recurso completo relativo, se o problema de segundo estágio for factível parquequer valor das variáves de primeiro estágio que satisfazem as restrições de primeiro estágio.

- recurso simples, se a matriz recurso $\mathbf{W}$ puder ser expressa como [I, -I], em que I é a matriz identidade.

Recurso simples é um caso especial de recurso completo, que é um caso especial de recurso completo relativo.

Para mais detalhes em programação estocástica linear de dois estágios, veja Dantzig e Beale (1955). Como referências gerais de programação estocástica, veja Kall e Wallace (1994) e Birge e Louveaux (1997).

\subsection{O Valor da Solução Estocástica}

Muitos modelos matemáticos são afetados pela aleatoriedade das variáveis, mas isso não implica que se deve, necessariamente, introduzi-la nos modelos. A presente seção descreve uma abordagem (ou medida de desempenho) para determinar a importância da aleatoriedade. A medida considerada o valor da solução estocástica (VSE).

O VSE pode ser considerado como o custo de ignorar a aleatoriedade dos parâmetos na escolha de uma decisão. Seu cálculo supõe que, em vez de de resolver o problema recurso (3.1), o decisor prefira resolver o problema do valor esperado $(P V E)$, que consiste em substituir todas as variáveis aleatórias do problema pelos seus respectivos valores esperados. Matematicamente, o $P V E$ pode ser escrito da seguinte forma: 


$$
P V E=\min _{\mathbf{x}} z(\mathbf{x}, \bar{\xi})
$$

em que $\bar{\xi}=E(\boldsymbol{\xi})$ denota a esperança de $\boldsymbol{\xi}$. Uma solução ótima de 3.2 é chamada de solução do valor esperado e é representada por $\overline{\mathbf{x}}(\bar{\xi})$.

Uma pergunta que advém da possibilidade de usar a solução $\overline{\mathbf{x}}(\bar{\xi})$ é quão boa ou ruim é ela em comparação à solução do problema-recurso. Para responder a esta pergunta, define-se o resultado esperado de usar a solução do valor esperado (EPVE):

$$
\left.E P V E=E_{\boldsymbol{\xi}} z(\overline{\mathbf{x}}(\bar{\xi}), \boldsymbol{\xi})\right)
$$

A quantidade $E P V E$ mede o desempenho de $\overline{\mathbf{x}}(\bar{\xi})$, isto é, como as variáveis de decisões de segundo estágio são escolhidas otimamente em função de $\overline{\mathbf{x}}(\bar{\xi})$ e $\xi$. O VSE é então definido como:

$$
V S E=E P V E-P R
$$

Também é possível definir o $V S E$ em termos de porcentagem, isto é:

$$
\text { Ganho }=\frac{E P V E-P R}{P R} \times 100 \%=\frac{V S E}{P R} \times 100 \% .
$$

Na prática, o ganho, que é apenas uma variação do $V S E$, vai ajudar a analisar o quão grande é o $V S E$ em termos da função objetivo $P R$, e pode representar quanto o decisor pode lucrar por resolver o modelo estocástico.

Suponha que, para um determinado problema, foram obtidos os seguintes valores: $P R=$ 100 e $E P V E=120$. Claramente, $V S E=20$. Tal valor pode ser visto como a penalidade incorrida por não considerar a aleatoriedade dos parâmetros na escolha da decisão ótima. Ao mesmo tempo, é fácil inferir que a solução do problema recurso é $20 \%$ menor do que o EPVE. No capítulo 6 é resolvido um exemplo ilustrativo que exemplifica as definições e explicações relativas às duas medidas de desempenho tratadas. 



\section{O Problema de Corte de Estoque com Demanda Estocástica}

\subsection{Definição e Formulação do Problema}

Considere um PCE em que barras idênticas e em quantidades ilimitadas devem ser cortadas para a produção de um conjunto de itens cujas demandas não são exatamente conhecidas no momento em que se deve decidir sobre como cortar as barras. Entretanto, considera-se que é possível estabelecer cenários para a ocorrência da demanda, de forma que a demanda estocástica é representada por um conjunto finito e discreto de cenários $\Omega=\{1,2, \ldots, S\}$, com probabilidades associadas $\left\{p_{1}, p_{2}, \ldots, p_{S}\right\}$, em que $p_{s}>0$ para todo $s \in \Omega$ e $\sum_{s=1}^{S} p_{s}=1$. Cada cenário $s \in \Omega$ corresponde a uma particular realização do vetor demanda $\mathbf{D}^{s}=\left(d_{1 s}, d_{2 s}, \ldots, d_{m s}\right)$, em que $d_{i s}$ é a demanda do item do tipo $i$ no cenário $s$.

Suponha que o número de barras cortadas segundo o padrão de corte $j$ tenha que ser determinada antes da realização da demanda aleatório (situação aqui e agora), isto é, nenhuma política de esperar o conhecimento exato da demanda para produzir (situação espere e veja) pode ser concebida. Depois que a demanda ocorrer, é possível que o total de itens produzidos pelo processo de corte seja diferente da quantidade necessária para atendê-la. Porém, são permitidas ações corretivas para cada possível cenário $s \in \Omega$, de maneira que as violações das restrições de 
atendimento da demanda possam ser compensadas.

Assim, se a quantidade de itens produzidos pelo processo de corte for maior do que a demanda ocorrida, a ação corretiva adequada é estocar o excesso de produção. Por outro lado, caso a demanda ocorrida seja maior do que a quantidade de itens produzidos, a ação corretiva apropriada é deixar de atender parte da demanda. As ações corretivas resultam em penalidades na função objetivo do problema, que podem ser interpretadas como custos extras. Ressalta-se que outras ações corretivas poderiam ter sido vislumbradas; no caso de excesso de produção, é possível vendê-lo a outros clientes ao invés de estocar ou repassar o excesso para outras plantas. No caso de escassez de produção, há a possibilidade de comprar os itens faltantes no varejo e atender a demanda completamente, ao invés de perder parte da venda.

O problema acima descrito pode ser formulado como um problema estocástico de dois estágios com recurso simples, como será mostrado no decorrer da seção. As decisões de primeiro estágio $x_{j}$ referem-se à determinação do número de barras cortadas segundo o padrão de corte $j$, com informação da demanda dos cenários e de suas probabilidades de ocorrência. Depois que os itens foram produzidos pelo processo de corte, a demanda torna-se conhecida. Então, as decisões de segundo estágio y podem ser tomadas, isto é, os itens em excesso são estocados ou a demanda pelos itens faltantes não é atendida.

Os índices que são utilizados para modelar o problema são: $j$, que representa os padrões de corte, $j=1, \ldots, n$; $i$, que representa os tipos de itens demandados, $i=1, \ldots, m$; e $s$, que representa os cenários, $s=1, \ldots, S$. A seguir, são indicadas as variáveis e parâmetros usados para modelar o problema.

Variáveis de decisão de primeiro estágio

$a_{i j}$ : Número de itens do tipo $i$ no padrão de corte $j$;

$c_{j}$ : custo de cortar a barra segundo o padrão de corte $j$;

\section{Parâmetros de segundo estágio}

$p_{s}$ : probabilidade de ocorrência do cenário $s$;

$d_{i s}$ : demanda do item do tipo $i$ no cenário $s$;

$c_{i}^{u}$ : penalidade por item do tipo $i$ em escassez;

$c_{i}^{e}$ : penalidade por item do tipo $i$ em excesso;

Variáveis de decisão de primeiro estágio

$x_{j}$ : número de barras cortadas segundo o padrão de corte $j$; 


\section{Variáveis de decisão de segundo estágio}

$u_{i s}$ : número de itens do tipo $i$ em escassez no cenário s;

$e_{i s}$ : número de itens do tipo $i$ em excesso no cenário $\mathrm{s}$.

Então, é possível escrever o programa determinístico equivalente criado pela associação de um conjunto de decisões de segundo estágio $\mathbf{y}^{s}$ a cada possível realização $\mathbf{D}^{s}$. Como as variáveis de decisão de segundo estágio representam as duas possíveis ações corretivas descritas anteriormente, por simplicidade de notação, será considerado que $\mathbf{y}^{s}=\left(\mathbf{u}^{s}, \mathbf{e}^{s}\right)$. O problema resultante PCER é considerado a forma extensiva do programa estocástico, pois explicita as variáveis de decisão de segundo estágio para todos os cenários. No decorrer do texto, o problema $P C E R$ será designado por $P C E R R$, que denota a sua relaxação.

$$
\begin{array}{ll}
P R=\min & f\left(\mathbf{x}, \mathbf{y}^{s}\right)=\sum_{j=1}^{n} c_{j} x_{j}+\sum_{s=1}^{S} p_{s}\left(\sum_{i=1}^{m} c_{i}^{e} e_{i s}+\sum_{i=1}^{m} c_{i}^{u} u_{i s}\right) \\
\text { s.a: } \quad & \sum_{j=1}^{n} a_{i j} x_{j}+\left(u_{i s}-e_{i s}\right)=d_{i s}, \forall i, s \\
& x_{j}, e_{i s} \text { e } u_{i s} \in Z^{+}, \forall i, j, s . .
\end{array}
$$

A função objetivo consiste na minimização do custo total esperado, que é constituído pelo custo de cortar o objeto em estoque segundo o $j$-ésimo padrão de corte (primeira parcela da soma) e pelos custos esperados de segundo estágio referentes às penalidades por escassez ou excesso de produção (segunda e terceira parcela da soma, respectivamente).

As primeiras equações representam as $m$ restrições de segundo estágio para cada possível cenário $s$. Ressalta-se que, na otimalidade, apenas uma das variáveis $\left(u_{i s}\right.$ ou $\left.e_{i s}\right)$ é diferente de zero para cada umas dessas equações, isto é, $u_{i s} \times e_{i s}=\mathrm{d}^{1}$. As últimas restrições garantem que todas as variáveis sejam números inteiros não-negativos.

O programa $P C E R$ é dito possuir recurso completo, pois o segundo estágio serve apenas como medida de custo das decisões de segundo estágio. Qualquer falta de produção pode deixar de ser atendida e qualquer excesso de produção pode ser estocado. Matematicamente, considerase que a decisão sobre $\mathbf{x}$ sempre permite uma escolha factível para $\mathbf{y}$; caso contrário, a solução seria trivialmente infactível. Em outras palavras, o conjunto

$$
F=\left\{\mathbf{x} \mid \exists \mathbf{y}^{s} \geq 0 \text { para todo } s \in \Omega \text { e } \mathbf{W}^{s} \mathbf{y}^{s}=\mathbf{D}^{s}-\mathbf{A x}\right\},
$$

\footnotetext{
${ }^{1}$ No Apêndice é mostrada uma prova informal dessa afirmação.
} 
deve ser não-vazio e a escolha de $\mathbf{x}$ deve vir do conjunto $F$. A matriz $\mathbf{A}$ refere-se ao conjunto dos $n$ padrões de corte dos $m$ tipos de itens, isto é, $\mathbf{A} \in \Re^{m \times n}$. Para facilitar a notação, suponha que $\mathbf{y}=\left(\mathbf{y}^{1}, \mathbf{y}^{2}, \ldots, \mathbf{y}^{S}\right)$, e $\mathbf{y}^{s}=\left(y_{1 s}, y_{2 s}, \ldots, y_{m s}\right)$ com $y_{i s}=\left(u_{i s}, e_{i s}\right)$ para todo $i$ e $s . A$ matriz $\mathbf{W}^{s}$ é uma matriz diagonal constituída apenas por 1 e -1 , (dependendo da coluna básica). Recurso completo é freqüentemente adicionado a um modelo de programação estocástica para garantir que nenhuma saída produza resultados infactíveis. O programa estocástico é ainda um caso especial de recurso completo denominado recurso simples, pois $\mathbf{W}=[\mathrm{I},-\mathrm{I}]$. Note que há uma correspondência com as variáveis de segundo estágio, isto é, $\mathbf{y}^{s}=\left(\mathbf{u}^{s}, \mathbf{e}^{s}\right)$.

A matriz de restrições de $P C E R$ apresenta uma estrutura dual bloco-angular, como pode ser visto na tabela 4.1. Nesse tipo de estrutura matricial, tem-se um conjunto de recursos (padrões de corte) que são compartilhados pelos $S$ conjuntos de restrições (cenários). Mais detalhes sobre estruturas matriciais do tipo dual-angular podem ser obtidos em Lasdon (1973).

\begin{tabular}{cccccc|c}
$\mathbf{x}$ & $\mathbf{y}^{1}$ & $\mathbf{y}^{2}$ & $\mathbf{y}^{3}$ & $\ldots$ & $\mathbf{y}^{S}$ & \\
\hline $\mathbf{A}$ & $\mathbf{W}^{1}$ & & & & & $\mathbf{D}^{1}$ \\
$\mathbf{A}$ & & $\mathbf{W}^{2}$ & & & & $\mathbf{D}^{2}$ \\
$\mathbf{A}$ & & & $\mathbf{W}^{3}$ & & & $\mathbf{D}^{3}$ \\
$\vdots$ & & & & $\ddots$ & & $\vdots$ \\
$\mathbf{A}$ & & & & & $\mathbf{W}^{S}$ & $\mathbf{D}^{S}$
\end{tabular}

Tabela 4.1: Estrutura dual bloco-angular do programa linear estocástico

O PCER possui um total de $n+m \times(S-1)$ variáveis e $m \times S$ restrições, fazendo com que o mesmo cresça linearmente com o número de cenários. Em aplicações práticas, mesmo considerando poucos cenários para representar adequadamente os efeitos das incertezas nos parâmetros do modelo, são obtidos programas estocástico de grande porte. 


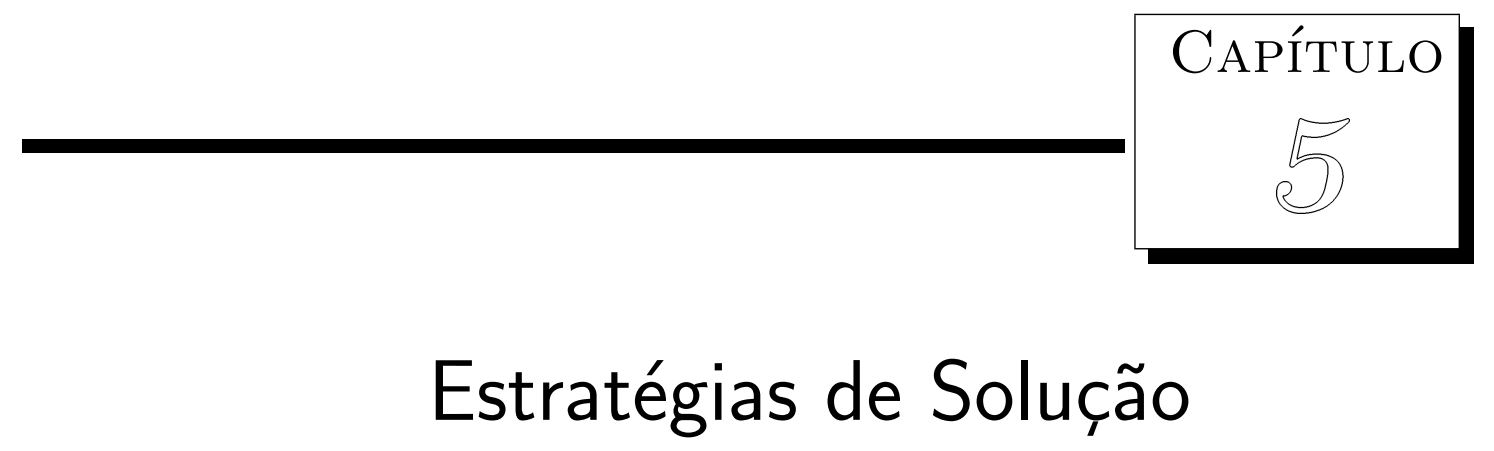

O PCER apresenta as dificuldades básicas relacionadas aos problemas gerais de corte de estoque: a condição de integralidade sobre as variáveis de decisão e o grande número de padrões de corte que podem ser gerados. Então, a restrição de integralidade do $P C E R$ é relaxada e duas estratégias são propostas para resolvê-lo: uma estratégia exata, baseada na especialização do método Simplex com geração de colunas, e uma estratégia heurística, que será muito útil para fins de comparação.

\subsection{Estratégia GCE: Geração de Colunas Especializada}

Essa estratégia possui algumas diferenças em relação ao método Simplex com geração de colunas tradicional, apresentado na Seção 2.2.3. As principais diferenças são detalhadas nas próximas subseções e os passos do algoritmo são exibidos ao final delas. Antes de apresentar as modificações dos procedimentos, é apresentado um detalhe da implementação computacional usado durante a execução do código para facilitar a identificação das variáveis.

\subsubsection{Identificação dos Tipos de Colunas}

No [PCE], todas as colunas da matriz básica $(\mathbf{B})$ referem-se a padrões de corte gerados pela resolução do problema da mochila. Entretanto, no PCERR, tem-se três tipos de colunas: as 
colunas referentes a padrões de corte, as colunas referentes aos itens em estoque e aquelas que representam os itens em falta.

Para ser possível identificar durante as iterações e ao final do algoritmo cada coluna adequadamente, foi criado um vetor de identicação (id_col). Cada coluna foi identificada por um número. As colunas de padrões de corte foram identificadas pelo número 0, enquanto as colunas de estoque e de falta, pelos números -1 e 1, respectivamente.

Observe o seguinte vetor de identificação fictício retirado de uma iteraçãquequer: id_col = $\left[\begin{array}{lllllllll}0 & 0 & 0 & 1 & -1 & -1 & 1 & -1 & 1\end{array}\right]^{T}$. Isto significa que as três primeiras colunas da matriz básica da iteração atual são colunas de padrões de corte, pois estão indicadas pelo número 0. A próxima coluna da matriz é uma coluna que representa algum item em falta, pois está identificada no vetor pelo número 1. Segue-se uma coluna representativa de algum item em estoque e assim sucessivamente.

Outros dois vetores id_cen e id_item foram criados para identificar os cenários nque ocorrem os estoques e as faltas de itens e quais são estes itens. Por exemplo, observe os seguintes vetores:

$$
\text { id_cen }=\left[\begin{array}{lllllllll}
0 & 0 & 0 & 2 & 1 & 1 & 1 & 2 & 2
\end{array}\right]^{T} \text { e id_item }=\left[\begin{array}{lllllllll}
0 & 0 & 0 & 1 & 2 & 3 & 1 & 2 & 3
\end{array}\right]^{T} .
$$

Tendo o conhecimento do vetor id_col já apresentado e com estes dois vetores, é possível afirmar que a quarta coluna da matriz básica indica que o item 1 está em falta no cenário 2. Da mesma forma, a quinta coluna de $\mathbf{B}$ indica que o item 2 foi produzido em execesso no cenário 1 e assim sucessivamente. As primeiras posições de id_cen e id_item com 0 indicam que tais colunas são referentes a padrões de corte e, portanto, devem ser desconsideradas nesta análise.

\subsubsection{Construção da Matriz Básica Inicial}

A matriz básica inicial B de PCERR possui $n \times S$ linhas e $m \times S$ colunas e é constituída por $S$ blocos de matrizes idênticas de dimensão $m$ associadas aos padrões de corte homogênos e $(S-1)$ blocos referentes aos coeficientes das variáveis $u_{i s}$ ou $e_{i s}$, sendo um bloco por cenário, exceto para o cenário $\bar{S}$ que possui a maior probabilidade de ocorrência. Por simplicidade, supôs-se que $\bar{S}=1$, o que implica $\mathbf{e}^{1}=\mathbf{u}^{1}=0$, de modo que a demanda do cenário 1 é satisfeita com igualdade. A seguir, é apresentada uma matriz básica inicial genérica. 


$$
\mathbf{B}=\left[\begin{array}{cccccc}
\mathbf{B}_{H} & & & & & \\
\mathbf{B}_{H} & \mathbf{W}_{2} & & & & \\
\vdots & & \ddots & & & \\
\mathbf{B}_{H} & & & \mathbf{W}_{s} & \\
\vdots & & & & \ddots & \\
\mathbf{B}_{H} & & & & & \mathbf{W}_{S}
\end{array}\right]
$$

em que $\mathbf{B}_{H}$ é a matriz dos padrões de corte homogêneos (determinada conforme o algoritmo da seção 2.2.3 e $\mathbf{W}_{s}$ são as matrizes diagonais associadas aos coeficientes das variáveis $u_{i s}$ ou $e_{i s}$ para cada cenário $s \neq \bar{S}=1$ :

$$
\mathbf{W}_{s}=\left[\begin{array}{cccc}
w_{1 s} & & & \\
& w_{2 s} & & \\
& & \ddots & \\
& & & w_{m s}
\end{array}\right] .
$$

A seguir, define-se os elementos $w_{i s}$ para cada matriz $\mathbf{W}_{s}, \operatorname{com} i=1, \ldots, m$ e $s=1, \ldots, S$. Para isso, tome o cenário de maior probabilidade de ocorrência $\bar{S}$. Suponha que sejam produzidos os itens conforme a demanda $D_{\bar{S}}$ desse cenário. Em seguida, para todo $i, s \neq \bar{S}$, faça $w_{i s}=-1$, se $\left(d_{i s}-d_{i \bar{S}}\right)<0$ ou $w_{i s}=1$, se $\left(d_{i s}-d_{i \bar{S}}\right) \geq 0$. Note que $w_{i s}=-1$ expressa uma situação em que os níveis de produção do item $i$ no cenário $\bar{S}$ seriam mais do que suficientes para atender a demanda do cenário $s$, se ela ocorresse efetivamente. Por outro lado, $w_{i s}=1$ reflete uma situação nque não é possível atender a demanda do item $i$ se, dada a ocorrência efetiva do cenário $s$, fossem mantidos os níveis de produção do cenário $\bar{S}$.

Como exemplo, considere os dados na Tabela 5.1. A dimensão de qualquer matriz básica é $9 \times 9$. Observe que se tem 3 padrões de corte homogêneos, um para cada item demandado e que o cenário 1 deve ser fixado como o cenário de maior probabilidade de ocorrência, $\bar{S}=1$ e $D_{1}=(1000,1500,2000)$. 


\begin{tabular}{ccccc}
\hline Item & Comprimento & \multicolumn{3}{c}{ Demanda } \\
\hline $\begin{array}{c}\text { (identificação } \\
\text { do item) }\end{array}$ & $\begin{array}{c}\text { (em unidades } \\
\text { de comprimento) }\end{array}$ & $\begin{array}{c}\text { Cenário 1 } \\
\text { Prob. }=0,6\end{array}$ & $\begin{array}{c}\text { Cenário 2 } \\
\text { Prob. }=0,3\end{array}$ & $\begin{array}{c}\text { Cenário 3 } \\
\text { Prob. }=0,1\end{array}$ \\
\hline 1 & $l_{1}=3$ & 1000 & 1200 & 1050 \\
2 & $l_{2}=4$ & 1500 & 1100 & 1350 \\
3 & $l_{3}=5$ & 2000 & 2300 & 1900 \\
\hline$L=9:$ & comprimento da barra disponível para ser cortada \\
\hline
\end{tabular}

Tabela 5.1: Dados do exemplo 1.

Para $s=2, D_{2}-D_{1}=(1200,1100,2300)-(1000,1500,2000)=(200,-400,300)$. Logo, $w_{12}=1, w_{22}=-1$ e $w_{32}=1$. Finalmente, para $s=3, D_{3}-D_{1}=(1050,1350,1900)-$ $(1000,1500,2000)=(50,-150,-100) . \operatorname{Logo}, w_{13}=1, w_{23}=-1$ e $w_{33}=1$. A matriz básica inicial do exemplo tem a forma mostrada na Tabela 5.2:

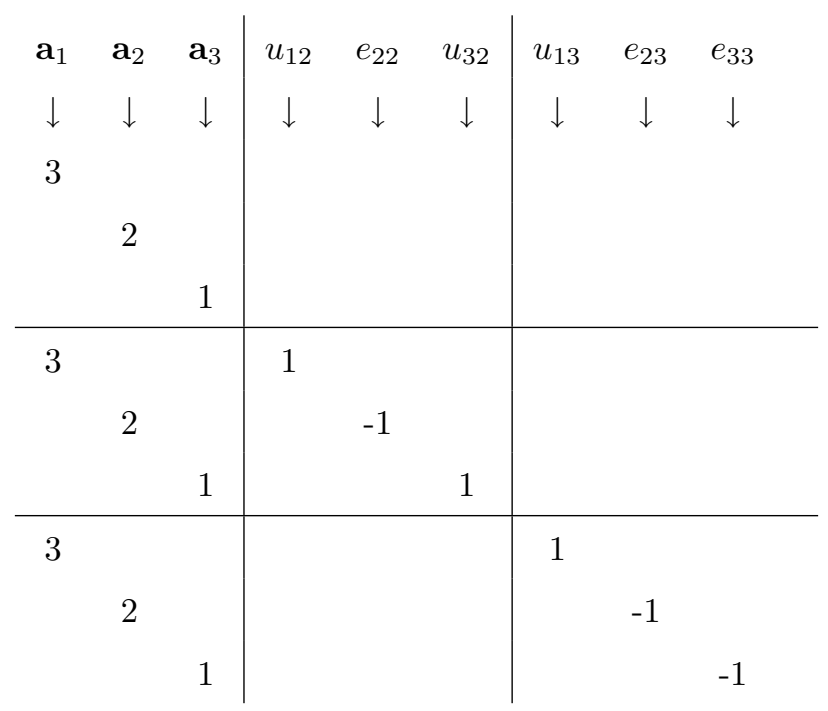

Tabela 5.2: Exemplo de uma matriz básica inicial.

A menos dos elementos da diagonal principal e as diagonais dos blocos referentes aos padrões de corte, as demais posições são constituídas por zero. Embora não seja proposta desse trabalho tratar a esparsidade da matriz de restrições, é importante salientar que técnicas específicas para esse fim podem aumentar a eficiência computacional na resolução dos sistemas lineares do método Simplex, veja Taviane e Arenales (2003).

A seguir são descritos os passos para construir a matriz básica inicial B. Os elementos da matriz $\mathbf{B}$ serão representadas por $B[i, j]$ e os elementos da matriz $\mathbf{B}_{H}, B_{H}[i, j]$. 


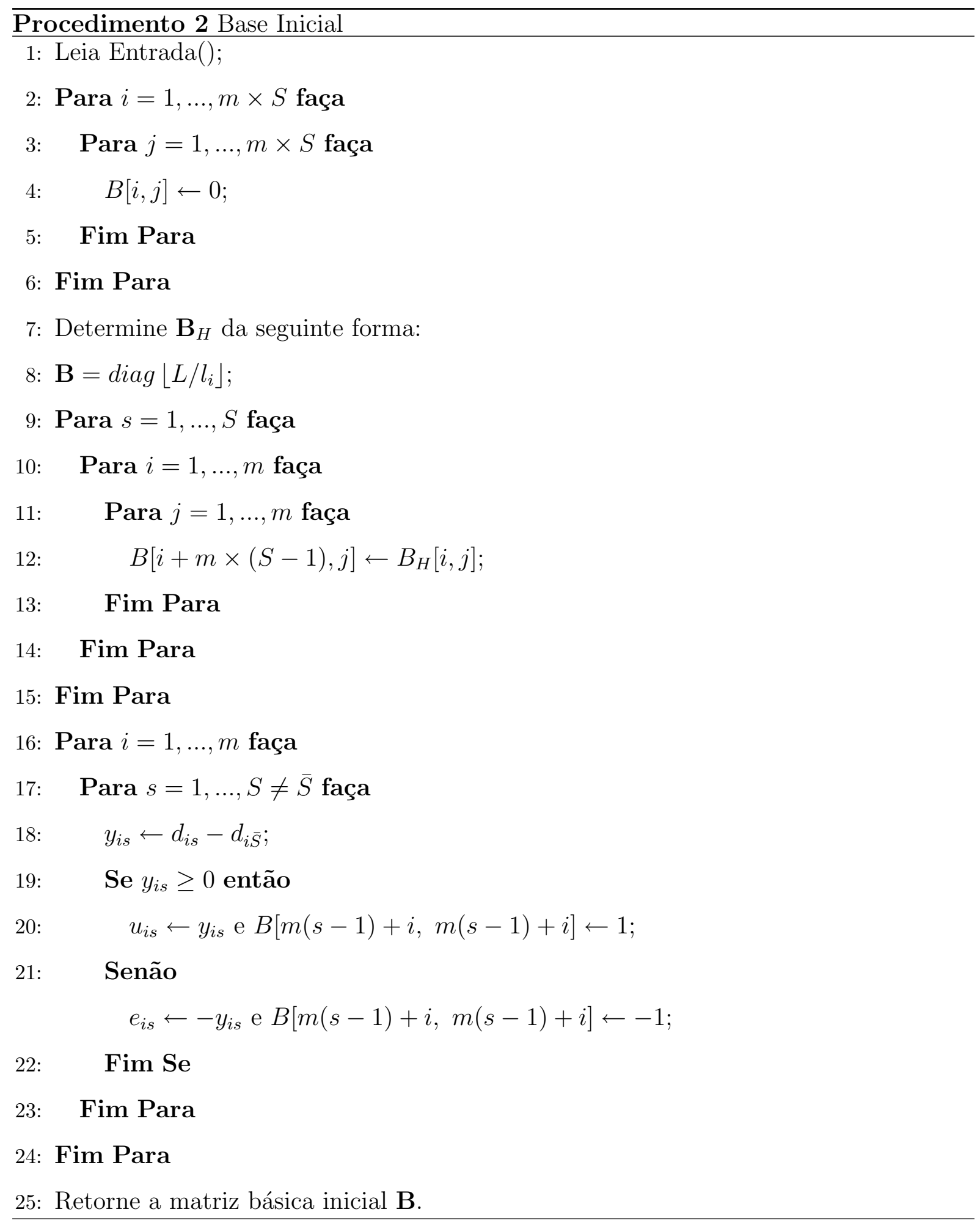




\subsubsection{Determinação das Soluções Básicas}

$\mathrm{O}$ vetor $\mathbf{x}_{\mathbf{B}}$ armazena os valores das variáveis básicas $x_{j}$ e também os valores das variáveis $u_{i s}$ e $e_{i s}$. Considere um vetor $\mathbf{x}_{\mathbf{B}}$ inicial, de maneira que as suas $m$ primeiras componentes sejam referentes às variáveis de decisão $x_{j}$ e as $(m \times S)-m$ componentes restantes designem as variáveis $u_{i s}$ e $e_{i s}$. Assim, o vetor $\mathbf{x}_{\mathbf{B}}$ inicial do exemplo anterior pode ser representado da seguinte forma:

$$
\mathbf{x}_{\mathbf{B}}=\left(x_{1}, x_{2}, x_{3}, u_{12}, e_{22}, u_{32}, u_{13}, e_{23}, e_{33}\right)^{T} .
$$

De forma genérica, o vetor $\mathbf{x}_{\mathbf{B}}$ inicial pode ser assim representado:

$\mathbf{x}_{\mathbf{B}}=(x_{1}, \ldots, x_{m}, \underbrace{y_{11}, \ldots, y_{m 1}}_{\text {cenário } 1}, \ldots, \underbrace{y_{1, \bar{S}-1}, \ldots, y_{m, \bar{S}-1}}_{\text {cenário } \bar{S}-1}, \underbrace{y_{1, \bar{S}+1}, \ldots, y_{m, \bar{S}+1}}_{\text {cenário } \bar{S}+1}, \ldots, \underbrace{y_{1 S}, \ldots, y_{m, S}}_{\text {cenário } S})^{T}$,

nque $y_{i s}$ pode representar $e_{i s}$ ou $u_{i s}$. Note que o primeiro conjunto de variáveis $y_{i s}$ corresponde às variáveis do cenário 1 e assim por diante. Além disso, o vetor $\mathbf{x}_{\mathbf{B}}$ não contém as variáveis $y_{\text {is }}$ para o cenário $\bar{S}$. Lembre-se de que a matriz básica inicial é construída baseada na idéia de que os itens são produzidos conforme a demanda $D_{\bar{S}}$. Então, não há a necessidade de armazenar as variáveis $y_{i \bar{S}}$, que são sempre nulas por construção.

Definido o vetor das variáveis básicas iniciais, é importante definir quem é o vetor demanda para esse caso. No algoritmo da Seção 2.2.3. d armazena um vetor $m$-dimensional nque cada componente $d_{i}$ representa a demanda do item do tipo $i$. Para resolver o PCERR, entretanto, o vetor $\mathbf{d}$ é definido da seguinte forma:

$$
\mathbf{d}=\left(d_{11}, \ldots, d_{m 1}, \ldots, d_{1 s}, \ldots, d_{m s}, \ldots, d_{1 S}, \ldots, d_{m S}\right)^{T}
$$

em que $d_{i s}$ é a demanda do item $i$ no cenário $s$.

Finalmente, calcula-se o vetor $\mathbf{x}_{\mathbf{B}}$ das variáveis básicas iniciais de forma que $\mathbf{B} \mathbf{x}_{\mathbf{B}}=\mathbf{d}$. Esse vetor armazena a solução básica do algoritmo SimplexMod.

\subsubsection{Determinação do Custo básico Inicial}

O vetor custo básico inicial é constituído por três valores diferentes, de acordo com as colunas que se encontram na matriz básica inicial. Nas colunas que representam os padrões de corte, o custo básico associado é o custo de cortar objeto segundo o $j$-ésimo padrão de corte, $c_{j}$. Nas colunas referentes às variáveis que contabilizam os itens em excesso e em escassez, o custo básico é a penalidade por item em excesso ou a penalidade por item em escassez multiplicada 
pela probabilidade de ocorrência do cenário correspondente. Para ilustrar, considere o exemplo mostrado na Tabela 5.1 , com $c_{j}=1$ para todo $j, c_{i}^{e}=1, i=1,2,3$ e $c_{i}^{u}=2, i=1,2,3$. Como as três primeiras colunas da matriz básica inicial são refentes aos padrões de corte, então o custo básico dessas colunas vale $c_{j}=1$. A quarta coluna corresponde à variável básica $u_{12}$. Logo, o custo básico dessa coluna vale $c_{1}^{u} \times p_{2}=2 \times 0,3=0,6$. Procedendo dessa maneira, o vetor custo básico inicial é representado por: $\mathbf{c}_{\mathbf{B}}=\left[\begin{array}{lllllllll}1 & 1 & 1 & 0,6 & 0,3 & 0,6 & 0,2 & 0,1 & 0,1\end{array}\right]^{T}$.

Determinado o vetor custo básico inicial, calcula-se o vetor multiplicador Simplex $\pi$, por $\mathbf{B}^{T} \pi=\mathbf{c}_{\mathbf{B}}$.

\subsubsection{Cálculo dos Custos Relativos}

A cada iteração do método Simplex, a coluna não básica com o menor custo relativo entra na base no lugar da coluna cuja variável primeiro anula-se. No [PCE], tem-se apenas as colunas de padrão de corte, que são geradas pela resolução de um problema da mochila. No entanto, no PCERR, tem-se 3 tipos de colunas: as colunas de padrão de corte e as colunas de escassez e de excesso de produção. Na implementação computacional, calculam-se, primeiramente, os custos relativos das últimas colunas, pois tais cálculos requerem menos esforço computacional. Caso todos os custos relativos das variáveis não básicas $u_{i s}$ e $e_{i s}$ sejam não-negativos, determina-se um novo padrão de corte para entrar na base pela resolução do problema da mochila.

Os custos relativos das variáveis não-básicas $x_{j}, u_{i s} e_{i s}$ são representados por $r_{j}, r_{i s}^{u} \mathrm{e}$ $r_{i s}^{e}$, respectivamente, que são calculados pela expressão genérica $c-\pi^{T} \mathbf{a}$, em que $c$ e a são o custo e a coluna da variável não-básica. Dependendo da variável não-básica, o custo e a coluna são apropriadamente substituídos na expressão custo relativo.

A seguir, são descritos os passos do procedimento usado para calcular os custos relativos. 


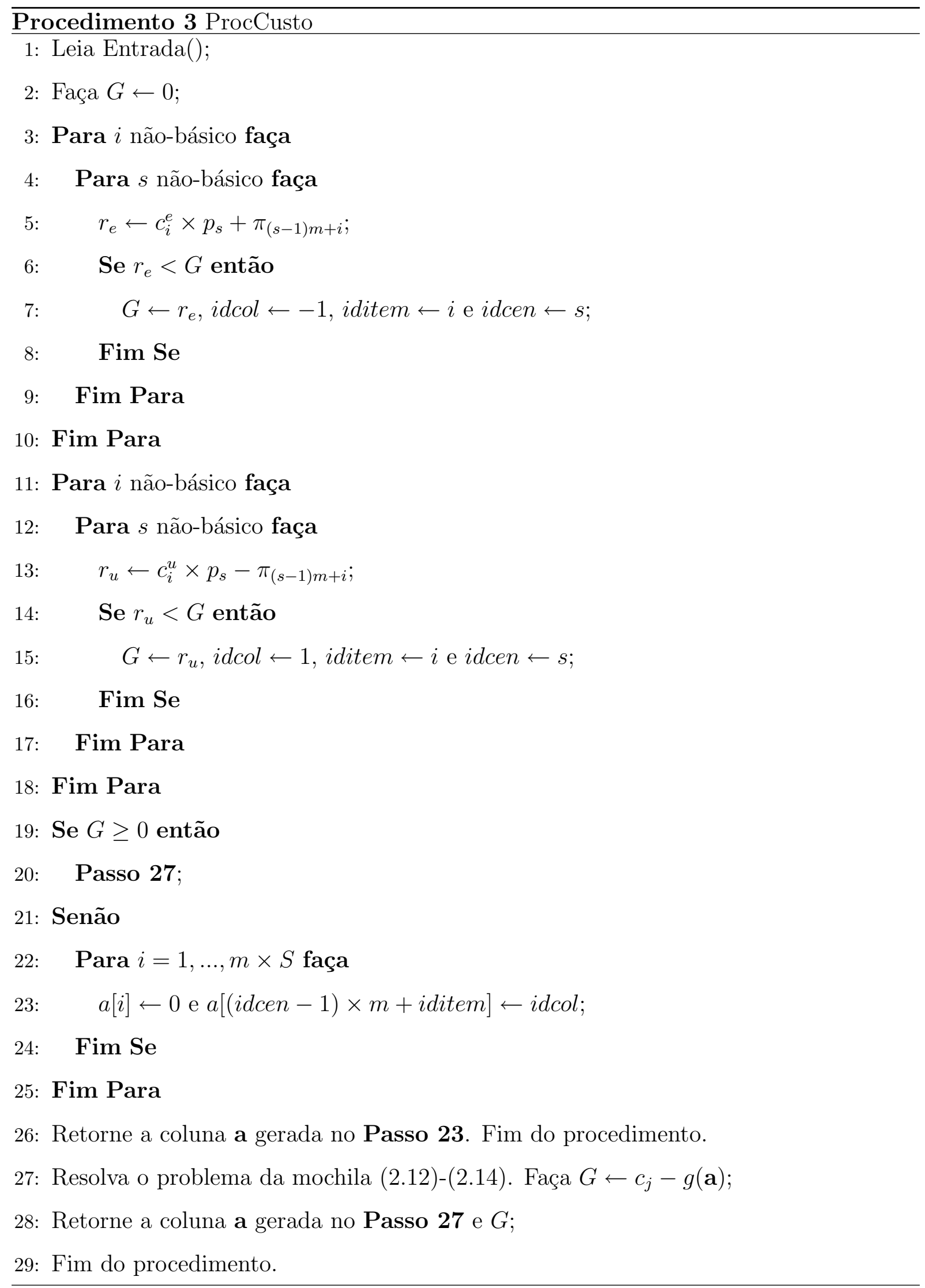


eterminados os custos relativos, é calculado o vetor y que armazena as coordenadas básicas da direção Simplex. Esse vetor é calculado pela expressão $\mathbf{B y}=-\mathbf{a}$, sendo que o vetor a é a coluna gerada pelo algoritmo ProcCusto.

Calculada a direção Simplex, calcula-se a variável que se anula primeiro quando se tenta caminhar na direção Simplex. Essa variável deixa para garantir a factibilidade da próxima solução básica.

A seguir, são descritos os passos do procedimento usado para calcular a coluna que sai da base.

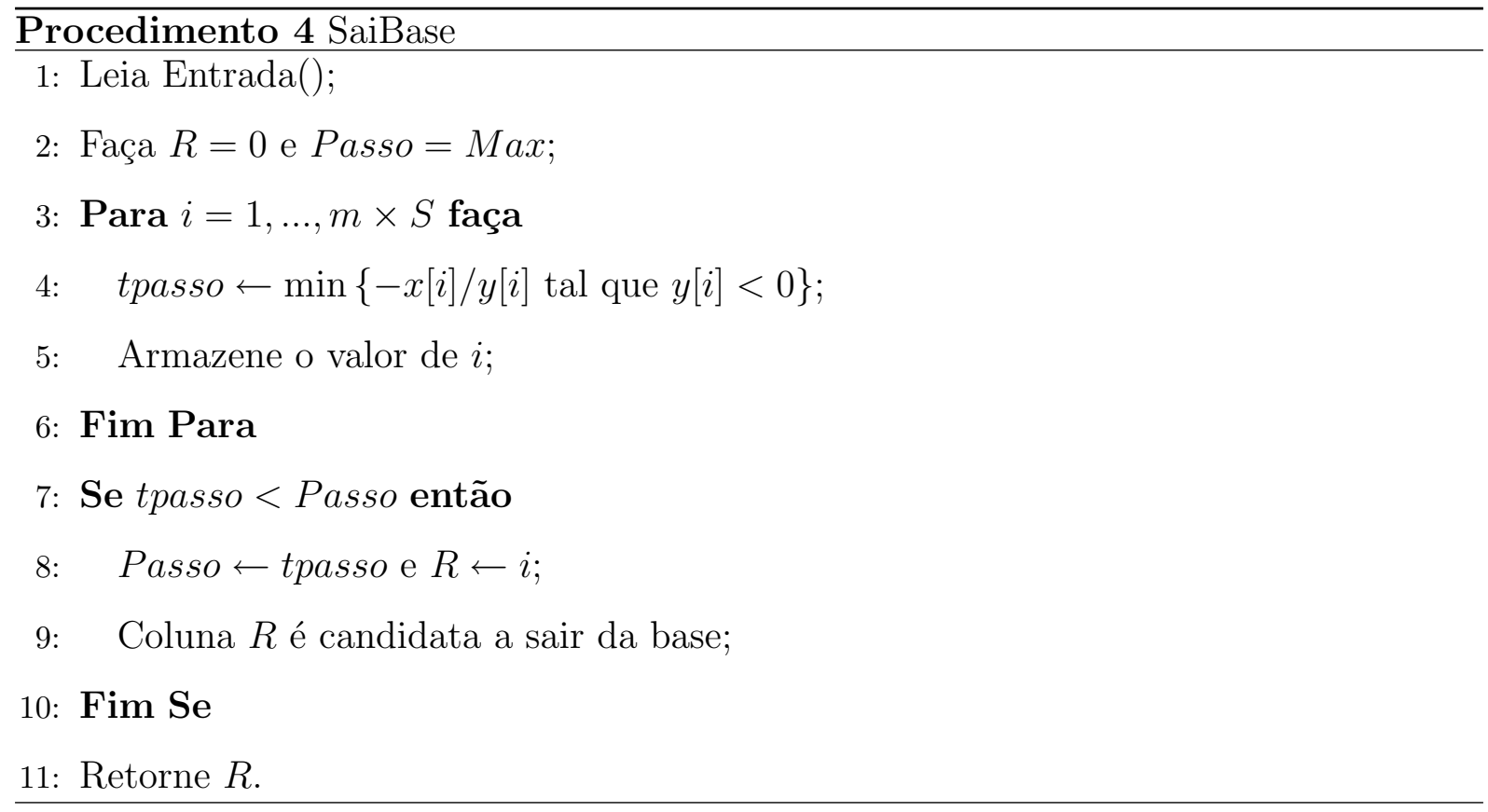

\subsubsection{Outro Detalhe da Implementaçã: Resolução dos Sistemas Lineares}

No algoritmo do método Simplex, os cálculos principais, por iteração, consistem na resolução de três sistemas básicos:

$$
\begin{array}{r}
\mathbf{B} \mathbf{x}_{\mathbf{B}}=\mathbf{d} ; \\
\mathbf{B}^{T} \pi=\mathbf{c}_{\mathbf{B}} ; \\
\mathbf{B y}=\mathbf{a} .
\end{array}
$$

Embora os métodos diretos para resolver sistemas lineares esparsos (note que a matriz básica do método Simplex com geração de colunas aplicado ao PCE com demanda estocástica 
é esparsa) e de grande porte possa perder eficiência à medida que cresce o número de equações, a decomposição LU consegue bons resultados para resolver os sistemas (5.1).

$\mathrm{Na}$ implementação, criou-se um procedimento para calcular a decomposição LU com a técnica de pivotamento parcial e calcular a solução dos sistemas triangulares resultantes, de modo que, a cada iteração, uma fatoração (todos os três sistemas possuem a mesma matriz dos coeficientes ou a sua transposta) e três resoluções de sistemas lineares por substituição reversa são realizadas.

\subsubsection{Algoritmo da Estratégia $G C E$}

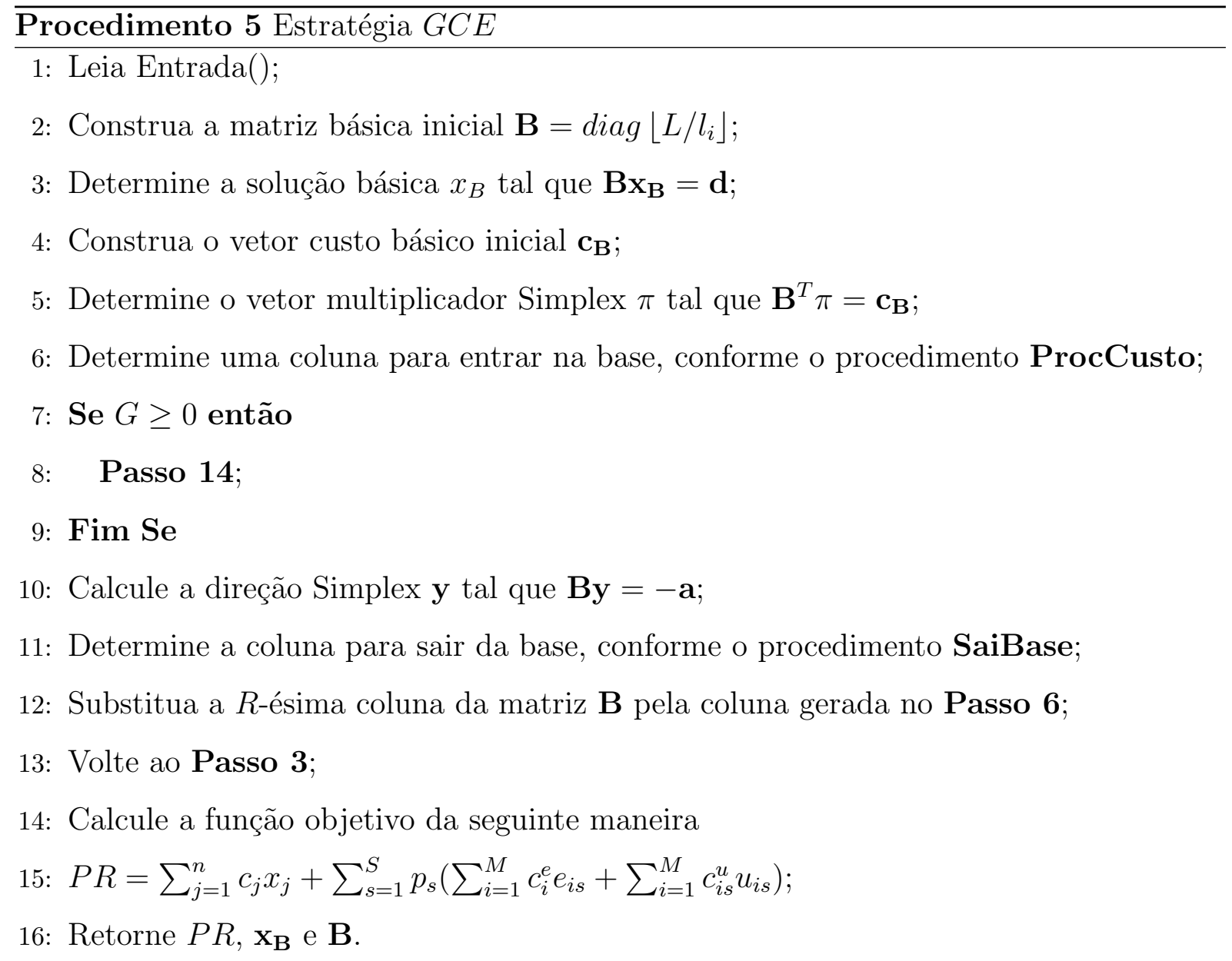

\subsection{Estratégia HDE: Heurística de Demanda Esperada}

A partir do momento em que se propõe um modelo estocástico para representar um determinado problema, é natural que se compare o valor da sua solução ótima com a correspondente solução 
ótima de um modelo determinístico. Ao comparar as soluções nos casos estocástico e determinístico, deve-se estar atento para o fato de que a solução determinística possui apenas uma decisão por período de tempo e a solução estocástica tem uma decisão por cenário por período de tempo. Portanto, comparar as decisões não é, muitas vezes, uma tarefa fácil. O que se faz é analisar algumas medidas de desempenho, ganhos, perdas, etc. para concluir se é preferível resolver o modelo estocástico ou o determinístico.

Uma idéia bem simples para aproximar um modelo estocástico de um determinístico e compará-los é substituir todas as variáveis aleatórias do modelo pelos seus valores esperados. Observe que resolver esse modelo equivale a determinar $P V E=\min _{x} z(\mathbf{x}, \bar{\xi})$, devidamente definido na seção 3.5. Porém, não é possível comparar as funções objetivos de $P R$ e $P V E$, pois elas são diferentes. O que se faz, então, é calcular as variáveis de segundo estágio para cada cenário condicionadas ao valor ótimo de PVE. Para o problema de corte particular, tem-se:

$$
\begin{aligned}
P V E=\min & \sum_{j=1}^{n} c_{j} x_{j} \\
\text { s.a. } & \sum_{i=1}^{m} a_{i j} x_{j}=\bar{d}_{i} \\
& x_{j} \in R^{+}, j=1, \ldots, n,
\end{aligned}
$$

em que $\bar{d}_{i}=\sum_{s=1}^{S} p_{s} \times d_{i s}, i=1, \ldots, m$.

Determinar as variáveis de segundo estágio para cada cenário dado o $P V E$ é simples, uma vez que elas são a diferença entre a demanda média e a demanda de cada cenário. Se essa diferença for positiva, tem-se uma variável de excesso de produção; caso contrário, tem-se uma variável de escassez. O valor esperado das variáveis de segundo estágio somado ao $P V E$ fornece o $E P V E$, que pode ser comparado à função objetivo do problema recurso. A esse procedimento heurístico de solução foi designado o nome de Heurística de Demanda Esperada (HDE).

Nesse ponto é muito importante fazer algumas considerações. A HDE é uma metodologia que também resolve o problema recurso denominado de $P C E R R$; porém, trata-se de uma heurística que resolve um problema de corte mais simples e depois calcula os valores das variáveis de segundo estágio. Entretanto, na literatura de programação estocástica, o que aqui foi apresentado sob o nome de $H D E$, é, na verdade, uma metotodologia criada para avaliar se vale a pena resolver o modelo de dois estágios com recurso ou se resolver o $P V E$ é suficiente para a tomada de decisões. Faz-se necessário uma metodologia para ajudar o decisor a optar por resolver um problema estocástico ou determinístico pela dificuldade de se comparar a função 
objetivo e as soluções entre eles, como já foi mencionado no início da seção, uma vez que o modelo estocástico de dois estágios possui variáveis de segundo estágio que podem não estar presentes numa formulação puramente determinística.

Nesse trabalho, adaptou-se a metodologia de avaliação do $P V E$ para o caso particular do problema de corte de estoque. Assim, pôde-se, ao mesmo tempo, sugerir uma método alternativo (potencialmente mais rápido) para resolver o PCERR, e analisar em que situações pode-se ignorar as incertezas e resolver apenas $P V E$, que são os casos nos quais a função objetivo $E P V E$ da $H D E$ está muito próxima da função objetivo $P R$ da $G C E$.

A seguir, são mostrados os passos da estratégia $H D E$.

\section{Procedimento 6 HDE}

1: Leia Entrada();

2: Calcule o valor esperado da demanda para cada tipo de item $\bar{d}_{i}$ da seguinte forma:

3: $\bar{d}_{i}=\left\lfloor\sum_{s=1}^{S} p_{s} d_{i s}\right\rfloor$;

4: Calcule o PVE:

5: $P V E=\min \sum_{j=1}^{n} c_{j} x_{j}$

6:

s.a. $\sum_{j=1}^{n} a_{i j} x_{j}=\bar{d}_{i}$

7:

$$
x_{j} \in \Re^{+}, j=1, \ldots, n ;
$$

8: Para $s=1, \ldots, S$ faça

9: $\quad$ Para $i=1, \ldots, m$ faça

10: $\quad y_{i s} \leftarrow \bar{d}_{i}-d_{i s}$;

11: $\quad$ Se $y_{i s} \geq 0$ então

12: $\quad e_{i s} \leftarrow y_{i s}$;

13: $\quad$ Senão

14: $\quad u_{i s} \leftarrow y_{i s}$;

15: $\quad$ Fim Se

16: $\quad$ Fim Para

17: Fim Para

18: Calcule a função objetivo EPVE:

19: $E P V E \leftarrow P V E+\sum_{s=1}^{S} p_{s}\left(\sum_{i=1}^{m} c_{i}^{e} e_{i s}+\sum_{i=1}^{m} c_{i}^{u} u_{i s}\right)$;

20: Retorne $E P V E, \mathbf{x}_{\mathbf{B}}$ e $\mathbf{B}$;

Observe que as linhas 5-7 do procedimento 6 correspondem ao $P V E$, que equivale ao 
custo total de cortar as barras. A linha 19 mostra como calcular o EPVE, que é o valor objetivo dessa estratégia, e o valor que efetivamente será comparado ao valor $P R$. 



\section{CAPÍTUlo}

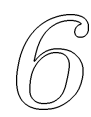

\section{Exemplos llustrativos}

\subsection{Exemplo 1}

Considere um exemplo do programa PCERR com os dados mostrados a seguir e na Tabela 6.1:

- $S=3$ cenários;

- $p_{s}=1 / 3$, para $s=1, \ldots, 3$;

- $m=3$ tipos de itens demandados;

- $L=90$ (unidades de comprimento) é o tamanho da barra disponível para cortar;

- $c_{j}=1$ é o custo de cortar o objeto, para $j=1,2,3$;

- $c_{i}^{e}=1$ é a penalidade por exceder uma unidade da demanda do item do tipo $i$, para $i=1,2,3$;

- $c_{i}^{u}=1$ é a penalidade por escassez de uma unidade da demanda do item $i$, para $i=1,2,3$; 


\begin{tabular}{cccccc}
\hline \hline Item & Comprimento & \multicolumn{3}{c}{ Demanda por } & Demanda \\
& & 1 & 2 & 3 & Espearad \\
\hline \hline 1 & $l_{1}=30$ & 30 & 45 & 12 & 43 \\
2 & $l_{2}=45$ & 41 & 30 & 18 & 32 \\
3 & $l_{3}=60$ & 60 & 22 & 35 & 23 \\
\hline \hline
\end{tabular}

Tabela 6.1: Dados do exemplo 1.

Suponha que os padrões de corte dados a priori sejam:

$$
\mathbf{a}_{1}=\left[\begin{array}{l}
3 \\
0 \\
0
\end{array}\right], \mathbf{a}_{2}=\left[\begin{array}{l}
0 \\
2 \\
0
\end{array}\right], \mathbf{a}_{3}=\left[\begin{array}{l}
1 \\
0 \\
1
\end{array}\right]
$$

O modelo de dois estágios do exemplo pode ser representado pelo seguinte programa:

$$
\begin{aligned}
& P R=\min \quad x_{1}+x_{2}+x_{3}+\sum_{i=1}^{3} \sum_{s=1}^{3} p_{s}\left(u_{i s}+e_{i s}\right) \\
& \text { s.a. } \\
& 3 x_{1}+x_{3}+\left(u_{11}-e_{11}\right)=30 \\
& 2 x_{2}+\left(u_{21}-e_{21}\right)=45 \\
& x_{3}+\left(u_{31}-e_{31}\right)=12 \\
& 3 x_{1}+x_{3}+\left(u_{11}-e_{11}\right)=41 \\
& 2 x_{2}+\left(u_{21}-e_{21}\right)=30 \\
& x_{3}+\left(u_{31}-e_{31}\right)=18 \\
& 3 x_{1}+x_{3}+\left(u_{11}-e_{11}\right)=60 \\
& 2 x_{2}+\left(u_{21}-e_{21}\right)=22 \\
& x_{3}+\left(u_{31}-e_{31}\right)=35 \\
& x_{i}, e_{i s}, u_{i s} \in \Re^{+}, i, s=1,2,3 \text {. }
\end{aligned}
$$

A solução do problema recurso anterior é $x_{1}=6, x_{2}=11, x_{3}=12, u_{12}=11, u_{21}=23$, $u_{32}=6, u_{13}=30, u_{22}=8, u_{33}=27$, com $P R=63,65$. O total de itens cortados nesse problema foi 18 itens do tipo 1, 22 itens do tipo 2 e 18 itens do tipo 3. Observe que tais quantidades não satisfazem com igualdade nenhum cenário específico, mas representam um compromisso entre produzir em excesso e pagar para estocar, e produzir em escassez e ser penalizado pela demanda não atendida. Supondo que, na prática, tenha ocorrido a demanda relativa ao cenário 1, a solução $P R$ obtida não é ótima para esse cenário. Porém, ela é uma boa solução dado 
que é impossível obter uma solução ideal sob todos os aspectos. De maneira geral, a solução em modelos estocásticos é balanceada ou protegida de determinados acontecimentos, isto é, tenta-se minimizar os riscos advindos das incertezas dos parâmetros.

Uma pergunta importante a ser respondida é se vale a pena resolver o modelo estocástico ou se uma estratégia mais simples de solução pode ser empregada. A estratégia mais simples de solução a ser testada é a $H D E$. Então, tendo em mãos o valor esperado da demanda para cada item, é possível escrever o $P V E$ :

$$
\begin{array}{rc}
P V E=\min & \bar{x}_{1}+\bar{x}_{2}+\bar{x}_{3} \\
\text { s.a. } & 3 \bar{x}_{1}+\bar{x}_{3}=43 \\
& \bar{x}_{2}=32 \\
\bar{x}_{3}=23 \\
\bar{x}_{i} \in \Re^{+}, i=1,2,3 .
\end{array}
$$

A solução do $P V E$ anterior é $\bar{x}_{1}=6,67, \bar{x}_{2}=16$ e $\bar{x}_{3}=23$, com $P V E=45,67$. O próximo passo é determinar o $E P V E$, isto é, $E P V E=p_{1} \times S 1+p_{2} \times S 2+S 3 \times p_{3}$, em que:

$$
\begin{gathered}
S 1=\min \quad x_{1}+x_{2}+x_{3}+u_{11}+\sum_{i=1}^{3}\left(u_{i 1}+e_{i 1}\right) \\
\text { s.a. } \quad x_{1}=6,67 ; x_{2}=16 ; x_{3}=23 \\
3 x_{1}+x_{3}+\left(u_{11}-e_{11}\right)=\mathbf{3 0} \\
2 x_{2}+\left(u_{21}-e_{21}\right)=\mathbf{4 5} \\
x_{3}+\left(u_{31}-e_{31}\right)=\mathbf{1 2} \\
x_{i}, e_{i s}, u_{i s} \in \Re^{+} ; i=1,2,3 ; s=1 . \\
\text { S2 min } \quad x_{1}+x_{2}+x_{3}+\sum_{i=1}^{3}\left(u_{i 2}+e_{i 2}\right) \\
x_{1}=6,67 ; x_{2}=16 ; x_{3}=23 \\
3 x_{1}+x_{3}+\left(u_{12}-e_{12}\right)=\mathbf{4 1} \\
2 x_{2}+\left(u_{22}-e_{22}\right)=\mathbf{3 0} \\
x_{3}+\left(u_{32}-e_{32}\right)=\mathbf{1 8} \\
x_{i}, e_{i s}, u_{i s} \in \Re^{+} ; i=1,2,3 ; s=2 .
\end{gathered}
$$




$$
\begin{gathered}
S 3=\min \quad x_{1}+x_{2}+x_{3}+u_{13}+\sum_{i=1}^{3}\left(u_{i 3}+e_{i 3}\right) \\
\text { s.a. } \quad x_{1}=6,67 ; x_{2}=16 ; x_{3}=23 \\
3 x_{1}+x_{3}+\left(u_{13}-e_{13}\right)=\mathbf{6 0} \\
2 x_{2}+\left(u_{23}-e_{23}\right)=\mathbf{2 2} \\
x_{3}+\left(u_{33}-e_{33}\right)=\mathbf{3 9} \\
x_{i}, e_{i s}, u_{i s} \in \Re^{+} ; i=1,2,3 ; s=3 .
\end{gathered}
$$

Observe que as variáveis de primeiro estágio foram fixadas nos valores encontrados pelo $P V E$. Portanto, os problemas $S 1, S 2$ e $S 3$ visam determinar apenas as variáveis de segundo estágio $e_{i s}$ e $u_{i s}$ para cada possível cenário $s$. Resolvendo-se os três programas, obtêm-se $S 1=$ 82, 68, $S 2=54,68$ e $S 3=88,66$, e $E P V E=\frac{1}{3} \times 82,68+\frac{1}{3} \times 54,68+\frac{1}{3} \times 88,66=75,34$.

Os resultados podem ser assim sumarizados: $P R=63,65$ e $E P V E=75,34$. Conseqüentemente, $\operatorname{VSE}=75,34-63,65=11,69$. Esse valor pode ser interpretado como o custo de ignorar a incerteza na escolha de uma decisão. Em outras palavras, ao optar pelo $P V E$ em detrimento ao $P R$, o decisor vai incorrer numa perda de 11,69. Então, o que é mais interessante para o decisor? Resolver o $P R$ ou o $P V E$ ? Isso vai depender de quanto o decisor está disposto a perder (ou deixar de lucrar). Nesse caso, o VSE corresponde a um pouco mais de $18 \%$ do valor do custo total de produção, que em muitos casos pode representar uma quantia bastante significativa para uma empresa. Ao mesmo tempo, não se pode ignorar o fato do $P R$ ser mais complexo e, portanto, o esforço computacional para resolvê-lo é bem maior. Na seção relativa aos experimentos numéricos, é possível perceber a diferença dos esforços computacionais para resolver o $P R$ e o $P V E$.

\subsection{Exemplo 2}

Considere um exemplo do programa PCERR com os seguintes dados:

- $S=4$ cenários;

- $p_{s}=1 / 4$, para $s=1, \ldots, 4$;

- $m=5$ tipos de itens demandados;

- $L=95$ (unidades de comprimento) é o tamanho do objeto disponível para cortar; 
- $c_{j}=1$ é o custo de cortar o objeto, para $j=1,2,3,4$;

- $c_{i}^{e}=1$ é a penalidade por exceder uma unidade da demanda do item do tipo $i$, para $i=1, \ldots, 5$;

- $c_{i}^{u}=1$ é a penalidade por escassez de uma unidade da demanda do item $i$, para $i=1, \ldots, 5$;

Os outros dados são fornecidos pela Tabela 6.2 dada a seguir.

\begin{tabular}{ccccccc}
\hline \hline \multirow{2}{*}{ Item } & Comprimento & \multicolumn{6}{c}{ Demanda por Cenário } & Demanda \\
& & 1 & 2 & 3 & 4 & Esperada \\
\hline \hline 1 & $l_{1}=12$ & 100 & 24 & 113 & 163 & 100 \\
2 & $l_{2}=17$ & 129 & 107 & 73 & 16 & 81 \\
3 & $l_{3}=29$ & 120 & 160 & 20 & 100 & 100 \\
4 & $l_{4}=37$ & 91 & 112 & 90 & 67 & 90 \\
5 & $l_{5}=76$ & 100 & 50 & 129 & 170 & 112 \\
\hline \hline
\end{tabular}

Tabela 6.2: Dados do exemplo 2.

As Tabelas 6.3 e 6.4 mostram os padrões de corte gerados em cada estratégia e a freqüência com que foram usados.

\begin{tabular}{c|ccccc}
$\mathbf{x}$ & \multicolumn{5}{|c}{ Padrão } \\
\hline \hline 13,124 & 7 & 0 & 0 & 0 & 0 \\
50 & 0 & 1 & 0 & 0 & 1 \\
1,5 & 5 & 2 & 0 & 0 & 0 \\
20 & 0 & 1 & 0 & 2 & 0 \\
50 & 0 & 0 & 2 & 1 & 0 \\
\hline \hline
\end{tabular}

\begin{tabular}{c|ccccc}
$\mathbf{x}$ & \multicolumn{5}{|c}{ Padrão } \\
\hline \hline 7 & 7 & 0 & 0 & 0 & 0 \\
81 & 0 & 1 & 0 & 0 & 1 \\
31 & 1 & 0 & 0 & 0 & 1 \\
20 & 1 & 0 & 0 & 2 & 0 \\
50 & 0 & 0 & 2 & 1 & 0 \\
\hline \hline
\end{tabular}

Tabela 6.3: Padrões de corte: $G C E$

Tabela 6.4: Padrões de corte: $H D E$

Observe que existe diferença tanto nos padrões de corte gerados quanto na freqüência com que eles são usados. Foram produzidos 100, 73, 100, 90 e 50, itens 1, 2, 3, 4 e 5, respectivamente, pela estratégia $G C E$. A estratégia $H D E$ produziu a própria demanda esperada. Nesse exemplo pequeno, apenas os itens 2 e 5 foram produzidos em quantidades diferentes do valor esperado. As funções objetivos valem $P R=323,214$ e $E P V E=352,500$. Só com essas considerações é possível responder o que é mais interessante e lucrativo para o decisor? Ainda não, pois é preciso que se verifique o $V S E$, isto é, $E P V E-P R=29,286$, com ganho $=9,1 \%$. Se o decisor não 
ignorar as incertezas do problema, poderá ter um lucro de $9,1 \%$ a mais do que se ele as ignorar. Ele pode decidir, com base nisso, seu interesse em considerar ou não as incertezas do problema. 


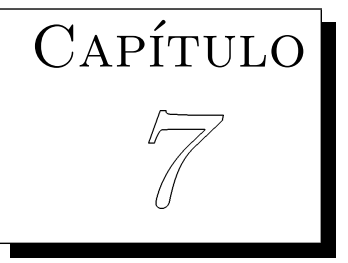

\section{Experimentos Computacionais}

Esse capítulo refere-se aos experimentos computacionais realizados com a finalidade de analisar o desempenho da estratégia $G C E$ em relação a algumas características de interesse do problema e compará-la, quando for adequado, com a estratégia HDE. Para esse estudo em particular, as características de interesse do problema são o valor ótimo da função objetivo, as porcentagens de itens em excesso e em escassez (em relação à quantidade total demandada) e o esforço computacional. Como se propôs analisar uma medida de desempenho (VSE) e uma extensão (ganho), eles também são considerados aqui como características de interesse. As duas estratégias foram implementados utilizando-se a linguagem PASCAL e o compilador DELPHI 6.0. Foram utilizadas duas máquinas para a realização dos testes, sendo que uma delas é um Pentium IV $(2,66 \mathrm{GHz})$ com $1 \mathrm{~GB}$ de memória RAM e a outra é um Pentium D $(2,66 \mathrm{GHz})$ com $512 \mathrm{MB}$ de memória RAM.

Os experimentos foram realizados em duas partes: testes A e B, cada um com objetivos diferentes. As próximas seções detalham cada um dos testes realizados e, ao final dos testes, faz-se uma consideração final acerca das estratégias. Os geradores dos problemas-teste foram baseados em Gau e Wäscher (1995). 


\subsection{Testes $A$}

Esses testes têm o objetivo de proporcionar uma visão geral acerca das estratégias $G C E$ e $H D E$, observando alguns parâmetros, tais como: valores ótimos das funções objetivos, porcentagens de itens em excesso e em escassez, número de iterações, tempo computacional, VSE e ganho. Os testes foram subdivididos em dois conjuntos: o primeiro, que adota todos os custos unitários e itens de tamanhos pequeno e médio, e o segundo conjunto de testes, que considera os custos variados e itens de tamanhos pequeno, médio e grande.

\subsubsection{Primeiro Conjunto de Testes}

Para fazer a análise do primeiro conjunto de testes, foram geradas classes de problemas-teste, variando-se alguns dados de entrada do problema PCERR e mantendo-se fixos outros, a saber:

1. Número de tipos de itens $(m)$ : foram utilizados os valores 10, 20 e 40;

2. comprimento dos itens $\left(l_{i}\right)$ : o limite inferior e superior do comprimento dos itens $\left(v_{1}\right.$ e $v_{2}$ do CUTGEN1) foram fixados em 0,01 e 0,2, respectivamente, para os itens de tamanho pequeno, e 0,2 e 0,5 considerando itens de tamanho médio;

3. número de cenários $(S)$ : foram adotados os valores 5,10 e 20 .

4. comprimento da barra em estoque $(L)$ : tamanho fixado em $L=1000$ (unidades de comprimento);

5. demanda $\left(d_{i s}\right)$ : para gerar a demanda do item $i$ no cenário $s$, procedeu-se em duas etapas. Na primeira etapa, gerou-se a "semente" da demanda de cada item $i\left(d_{i}\right)$ aleatoriamente no intervalo $\left[5 L / l_{i}, 10 L / l_{i}\right]$ para os itens pequenos e $\left[10 L / l_{i}, 20 L / l_{i}\right]$ para os itens grandes. Na segunda etapa, gerou-se $d_{i s}$ a partir dos valores absolutos de uma distribuição normal truncada com média $d_{i}$ e desvio-padrão $0,3 \times d_{i}$, isto é, $d_{i s} \sim N\left(d_{i}, 0,3 \times d_{i}\right)$. A idéia de gerar realizações para a demanda dessa forma foi baseada em Kall e Mayer ${ }^{1}(2006)$.

6. custos: o custo $\left(c_{j}\right)$ foi considerado constante igual a 1 para todo $j$ e representa o custo da barra disponível para o corte ou, simplesmente, o custo de cortar a barra. As penalidades

\footnotetext{
${ }^{1}$ Esse trabalho foi publicado em 2006 numa edição especial da revista Annals of Operations Research sobre programação estocástica.
} 
por escassez e excesso de produção foram consideradas independentes do tipo de item e constantes iguais a 1 , isto é, $c_{i}^{e}=c_{i}^{u}=1$, para todo $i$.

Dessa forma, foram geradas 18 classes de problemas, 9 classes com itens de tamanho pequeno e 9 classes com itens de tamanho médio, conforme ilustra a Tabela 7.1. As colunas da tabela indicam, respectivamente, a identificação da classe, o número de problemas-teste gerados em cada classe, o número de de tipos de itens e o seu tamanho ( $\mathrm{Pq}$ - pequeno, ou Md - médio), e o número de cenários na classe.

\begin{tabular}{ccccc}
\hline \hline Classe & \# Exemplos & \# Itens & Tamanho & \# Cenários \\
\hline \hline A1 & 50 & 10 & $\mathrm{Pq}$ & 5 \\
$\mathrm{~A} 2$ & 50 & 20 & $\mathrm{Pq}$ & 5 \\
$\mathrm{~A} 3$ & 50 & 40 & $\mathrm{Pq}$ & 5 \\
$\mathrm{~A} 4$ & 50 & 10 & $\mathrm{Pq}$ & 10 \\
$\mathrm{~A} 5$ & 50 & 20 & $\mathrm{Pq}$ & 10 \\
$\mathrm{~A} 6$ & 50 & 40 & $\mathrm{Pq}$ & 10 \\
$\mathrm{~A} 7$ & 50 & 10 & $\mathrm{Pq}$ & 20 \\
$\mathrm{~A} 8$ & 50 & 20 & $\mathrm{Pq}$ & 20 \\
$\mathrm{~A} 9$ & 50 & 40 & $\mathrm{Pq}$ & 20 \\
$\mathrm{~A} 10$ & 50 & 10 & $\mathrm{Md}$ & 5 \\
$\mathrm{~A} 11$ & 50 & 20 & $\mathrm{Md}$ & 5 \\
$\mathrm{~A} 12$ & 50 & 40 & $\mathrm{Md}$ & 5 \\
$\mathrm{~A} 13$ & 50 & 10 & $\mathrm{Md}$ & 10 \\
$\mathrm{~A} 14$ & 50 & 20 & $\mathrm{Md}$ & 10 \\
$\mathrm{~A} 15$ & 50 & 40 & $\mathrm{Md}$ & 10 \\
A16 & 50 & 10 & $\mathrm{Md}$ & 20 \\
A17 & 50 & 20 & $\mathrm{Md}$ & 20 \\
A18 & 25 & 40 & $\mathrm{Md}$ & 20 \\
\hline \hline
\end{tabular}

Tabela 7.1: Classes do Primeiro Conjunto de Testes

Os 875 problemas-teste foram resolvidos pelas estratégias $G C E$ e $H D E$. A Tabela 7.2 apresenta o valor médio da função objetivo de cada classe, o desvio-padrão médio (DP) correspondente, o VSE e o ganho médio obtido. Para simplificar o texto, daqui em diante está implícito que os valores tabelados indicam os resultados médios dos problemas-teste em cada classe, a não ser que se enfatize o contrário. Além disso, os melhores e piores resultados obtidos em cada análise estão em negrito e em itálico, respectivamente. 


\begin{tabular}{ccccccc}
\hline \hline Classe & $P R$ & DP & EPVE & DP & VSE & Ganho(\%) \\
\hline \hline A1 & 298,3 & 43,87 & 310,8 & 44,66 & 12,53 & 4,2 \\
A2 & 636,7 & 90,97 & 666,6 & 96,50 & 29,90 & 4,7 \\
A3 & 1288 & 126,1 & 1347 & 131,9 & 61,50 & 4,8 \\
A4 & 339,1 & 71,51 & 346,7 & 72,81 & 10,51 & 3,1 \\
A5 & 675,8 & 86,44 & 691,7 & 89,73 & 15,88 & 2,3 \\
A6 & 1333 & 106,7 & 1364 & 110,3 & 30,69 & 2,3 \\
A7 & 314,1 & 44,29 & 317,8 & 44,56 & 3,760 & 1,2 \\
A8 & 699,2 & 86,38 & 707,5 & 87,25 & 8,330 & 1,2 \\
A9 & 1409 & 125,3 & 1426 & 126,9 & 16,32 & 1,2 \\
A10 & 422,1 & 42,80 & 452,7 & 44,09 & 30,57 & 7,2 \\
A11 & 808,4 & 56,99 & 867,1 & 59,95 & 58,68 & 7,3 \\
A12 & 1653 & 82,35 & 1760 & 83,52 & $\mathbf{1 0 7 , 3}$ & 6,5 \\
A13 & 433,0 & 40,59 & 458,7 & 42,23 & 25,70 & 5,9 \\
A14 & 832,8 & 45,56 & 881,3 & 47,79 & 48,44 & 5,8 \\
A15 & 1652 & 59,66 & 1744 & 65,42 & 92,02 & 5,6 \\
A16 & 414,3 & 30,79 & 441,3 & 32,65 & 27,00 & 6,5 \\
A17 & 844,2 & 45,70 & 887,4 & 47,18 & 43,24 & 5,1 \\
A18 & 1680 & 51,99 & 1761 & 53,77 & 81,19 & 4,8 \\
\hline \hline Média & 874,1 & 68,78 & 912,9 & 71,17 & 39,08 & 4,5 \\
\hline \hline & & & & & & \\
\hline
\end{tabular}

Tabela 7.2: Valores médios das soluções $P R$ e EPVE, VSE e ganho. 
Como já era de se esperar, as funções objetivos ótimas $P R$ são inferiores às $E P V E$ em todas as classes, assim como os desvios-padrão correspondentes (HDE é uma estratégia heurística e, portanto, EPVE $\geq P R)$. O VSE é 39,08, o que representa um ganho de 4,5\%. Esse ganho pode ser interpretado como a quantia que o decisor lucra por adotar a estratégia $G C E$ em vez da $H D E$ e o $V S E$ indica o custo de desconsiderar as incertezas do problema. A Figura 7.1 compara os valores das funções objetivos nas duas estratégias e os seus desvios-padrão correspondentes (linhas verticais no meio de cada barra) em cada uma das 18 classes.

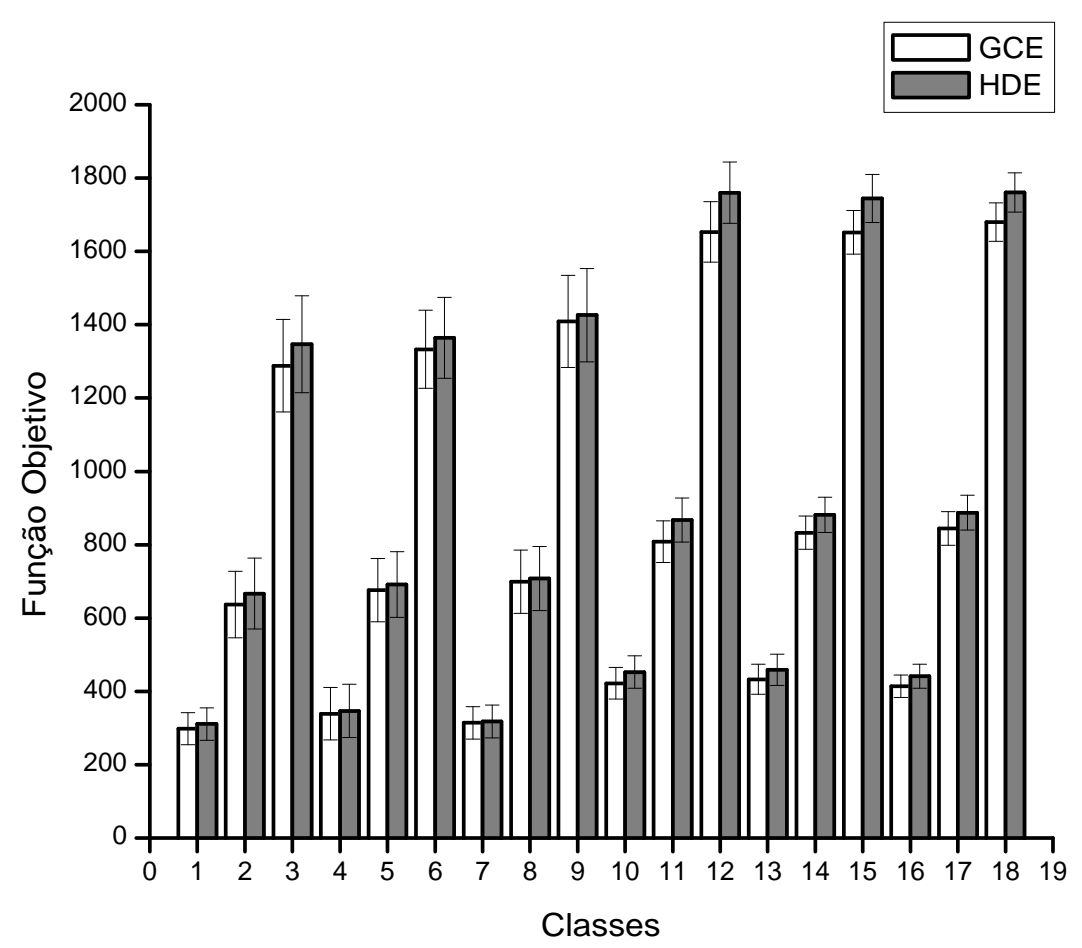

Figura 7.1: Comparação entre as funções objetivos.

Em relação à estratégia $G C E$, note que as soluções $P R$ de certas classes possuem alguns valores bem semelhantes. Assim, pode-se agrupá-las de acordo com a faixa de valores das suas funções objetivos. As classes 1, 4, 7, 10, 13 e 16 possuem a função objetivo na faixa [298, 434], as funções objetivos das classes 2, 5, 8, 11, 14 e 17 pertencem ao intervalo [637, 845], e as classes $3,6,9,12,15$ e 18, estão no intervalo [1288, 1680]. Cada um desses três agrupamentos possui o mesmo número de tipos de itens, mas o número de cenários é diferente. Por exemplo, no primeiro agrupamento, todas as classes possuem 10 tipos de itens, mas as classes 1 e 10 possuem 5 cenários, as classes 4 e 13 têm 10 cenários, e as classes 7 e 16, 20 cenários. Embora seja natural que as classes possuam tal comportamento em relação ao número de tipos de itens, é interessante notar 
que o número de cenários parece não influenciar em demasia a função objetivo. Vale ressaltar que, nesses experimentos, as classes de itens médios (10-18) apresentam uma função objetivo maior, comparada à função objetivo das correlatas classes de itens pequenos.

A Figura 7.2 mostra como varia o VSE e o ganho nas 18 classes de problemas-teste. Claramente, o VSE é superior nas classes de itens médios, o que torna o ganho maior nessas mesmas classes. Os menores ganhos são obtidos pelas classes 7, 8 e 9, enquanto os maiores, pelas classes 10 e 11 .
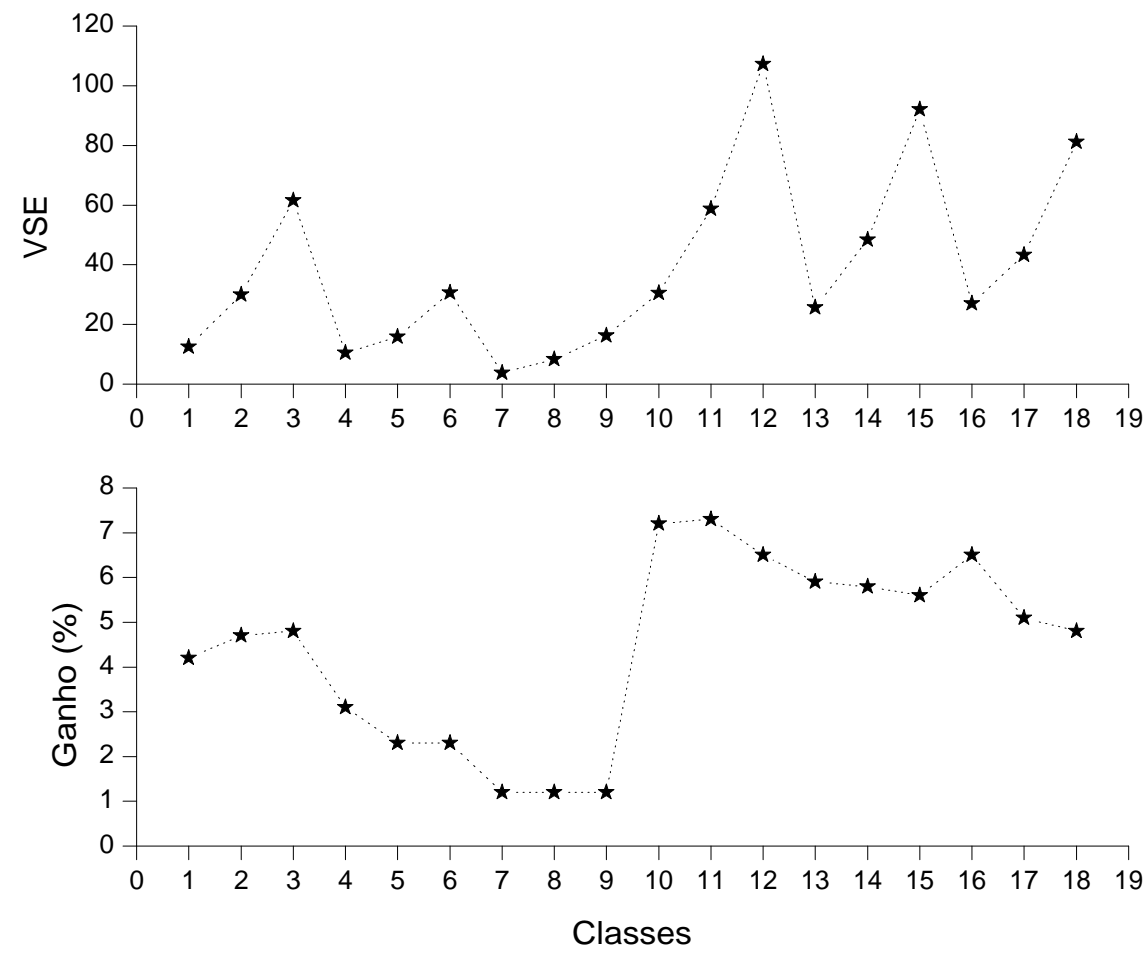

Figura 7.2: VSE e Ganho.

A Tabela 7.3 ilustra as porcentagens de itens em excesso e em escassez em relação à média de itens demandados por cenário. Pode-se observar que a estratégia $G C E$ obtém bem mais itens em escassez do que em excesso, diferentemente da estratégia $H D E$, que os mantém quase nos mesmos níveis. Considerando que esse conjunto de testes adotou todos custos (custo de cortar as barras, e as penalidades por itens produzidos em excesso e em escassez) unitários, talvez seja uma tendência da estratégia $G C E$ deixar de atender a demanda, considerando que o método possa escolher entre duas opções: cortar itens em excesso, pagar pelo corte e pelo excesso, ou apenas cortar itens a menos e só pagar pela escassez. Parece razoável que a estratégia $G C E$ opte pela segunda opção. Quanto à estratégia $H D E$, não é surpreendente que ela mantenha 
níveis muito semelhantes de itens em excesso e em escassez, uma vez que ela produz sempre a demanda média dos cenários. A situação ideal seria possuir números muito baixos para os itens em escassez e em excesso, pois a penalização na função objetivo seria mínima. Por isso, foram definidos como os piores resultados os máximos valores de itens em excesso e em escassez e eles estão em itálico. Analogamente, os melhores resultados representam o mínimo de excesso e escassez, e estão em negrito.

\begin{tabular}{cccccc}
\hline \hline & \multicolumn{3}{c}{$G C E$} & \multicolumn{2}{c}{$H D E$} \\
Classe & \# Itens & Escassez(\%) & Excesso(\%) & Escassez(\%) & Excesso(\%) \\
\hline \hline A1 & 1065 & 10,54 & 10,73 & $\mathbf{1 1 , 4 5}$ & $\mathbf{1 1 , 0 7}$ \\
A2 & 2175 & 11,28 & 11,49 & 12,29 & 11,92 \\
A3 & 4574 & $\mathbf{1 0 , 1 8}$ & 11,11 & 11,78 & 11,45 \\
A4 & 1146 & 13,66 & 10,03 & 12,27 & 11,87 \\
A5 & 2288 & 14,28 & 9,350 & 12,24 & 11,84 \\
A6 & 4468 & 13,95 & 9,790 & 12,31 & 11,91 \\
A7 & 989,7 & 14,10 & 10,75 & 12,72 & 12,23 \\
A8 & 2280 & 13,80 & 10,90 & 12,63 & 12,21 \\
A9 & 4652 & 13,70 & 10,72 & 12,47 & 12,07 \\
A10 & 767,6 & 21,32 & 4,570 & 12,32 & 11,77 \\
A11 & 1469 & 21,07 & 4,720 & 12,20 & 11,68 \\
A12 & 3104 & 21,33 & 4,460 & 12,22 & 11,69 \\
A13 & 777,2 & 21,48 & 5,460 & 12,51 & 11,92 \\
A14 & 1501 & 21,08 & 5,500 & 12,42 & 11,79 \\
A15 & 3019 & 20,84 & 5,570 & 12,37 & 11,77 \\
A16 & 651,2 & 23,61 & 5,347 & 12,98 & 12,23 \\
A17 & 1483 & 21,33 & 6,322 & 12,84 & 12,19 \\
A18 & 3005 & 21,20 & 6,273 & 12,81 & 12,18 \\
\hline \hline Média & 2627 & 17,19 & 7,950 & 12,38 & 11,88 \\
\hline \hline
\end{tabular}

Tabela 7.3: Escassez e Excesso de Produção.

A Figura 7.7 representa as informações sobre o excesso e a escassez da produção de itens para cada classe. Fica evidente o comportamento mais constante da estratégia $H D E$ frente à 
maior variação da estratégia $G C E$. Os números de itens em excesso e em ecassez são os valores das variáveis de segundo estágio. Então, a informação mais importante que se pode inferir dessa discussão é que as soluções obtidas pela $G C E$ parecem ser muito sensíveis às variações das características do problema. Em muitas aplicações práticas, não é desejado que isso ocorra, pois é importante que se alcance condições operacionais estáveis, isto é, soluções mais robustas.
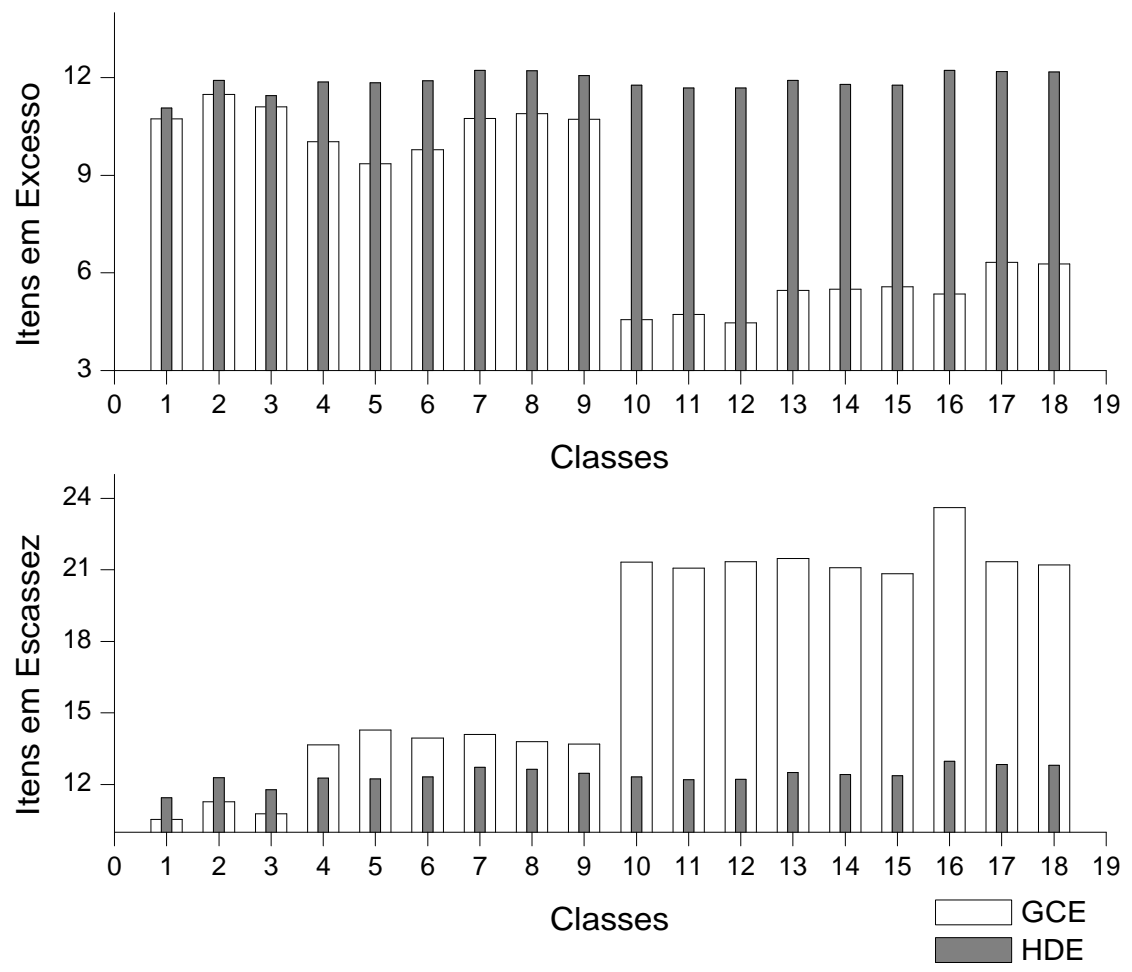

Figura 7.3: Número de Itens em Excesso e em Escassez.

Para finalizar os resultados desse conjunto de testes, é apresentada a Tabela 7.4 com o número de iterações que cada classe precisou para atingir a solução ótima e o referente tempo computacional em segundos. Além disso, são mostradas os tamanhos dos problemas-teste para cada estratégia. Os resultados indicam que é necessário um grande esforço computacional para se determinar as soluções $P R$, enquanto que as soluções $E P V E$ são rapidamente obtidas. Os casos mais complicados referem-se às classes 9 e 18, cujos problemas-teste demoram, em média, 30 e 87 minutos, respectivamente. Essas classes são as maiores em termos de dimensão dos problemas, o que sugere uma dependência entre esse parâmetro e o esforço computacional (iterações e tempo). Nesse contexto, é muito provável que o número de cenários influencie fortemente a estratégia $G C E$, contrariamente ao número de tipos de itens, que tem uma influência mais fraca. 


\begin{tabular}{|c|c|c|c|c|c|c|}
\hline \multirow[b]{2}{*}{ Classe } & \multicolumn{3}{|c|}{ Solução GC } & \multicolumn{3}{|c|}{ Solução HDE } \\
\hline & Dimensão & \# Iterações & Tempo(s) & Dimensão & \# Iterações & Tempo(s) \\
\hline $\mathrm{A} 1$ & $50 \times 50$ & 26,8 & 1,873 & $10 \times 10$ & 14,9 & 0,528 \\
\hline $\mathrm{A} 2$ & $100 \times 100$ & 49,6 & 4,177 & $20 \times 20$ & 26,3 & 0,65 \\
\hline A3 & $200 \times 200$ & 91,9 & 189,4 & $40 \times 40$ & 45,7 & 1,1 \\
\hline A4 & $100 \times 100$ & 40,0 & 3,245 & $10 \times 10$ & 14,6 & 0,43 \\
\hline A5 & $200 \times 200$ & 77,5 & 16,09 & $20 \times 20$ & 25,4 & 0,64 \\
\hline A6 & $400 \times 400$ & 146 & 177,0 & $40 \times 40$ & 46,1 & 1,1 \\
\hline $\mathrm{A} 7$ & $200 \times 200$ & 65,1 & 12,32 & $10 \times 10$ & 15,5 & 0,51 \\
\hline A8 & $400 \times 400$ & 130 & 150,5 & $20 \times 20$ & 24,9 & 0,66 \\
\hline A9 & $800 \times 800$ & 255 & 1915 & $40 \times 40$ & 45,5 & 2,8 \\
\hline A10 & $50 \times 50$ & 22,5 & 1,354 & $10 \times 10$ & 10,5 & 0,74 \\
\hline A11 & $100 \times 100$ & 70,3 & 5,307 & $20 \times 20$ & 37,4 & 2,3 \\
\hline $\mathrm{A} 12$ & $200 \times 200$ & 251 & 47,51 & $40 \times 40$ & 157 & 3,5 \\
\hline A 13 & $100 \times 100$ & 45,3 & 3,300 & $10 \times 10$ & 10,8 & 0,33 \\
\hline A14 & $200 \times 200$ & 132 & 25,79 & $20 \times 20$ & 38,7 & 0,84 \\
\hline A 15 & $400 \times 400$ & 444 & 415,5 & $40 \times 40$ & 152 & 9,6 \\
\hline A16 & $200 \times 200$ & 66,9 & 13,43 & $10 \times 10$ & 4,96 & 0,22 \\
\hline A17 & $400 \times 400$ & 220 & 248,4 & $20 \times 20$ & 39,6 & 2,8 \\
\hline A18 & $800 \times 800$ & 733 & 5277 & $40 \times 40$ & 156 & 2,0 \\
\hline Média & - & 159,2 & 472,6 & - & 48,1 & 1,9 \\
\hline
\end{tabular}

Tabela 7.4: Tempo Computacional e Número de Iterações. 
A Figura 7.4 ilustra o número de elementos da matriz de restrições (matriz $\mathbf{B}$ ) de cada estratégia para todas as classes. Observe que a grandeza desses números é bastante significativa entre as duas estratégias, especialmente quando as classes 9 e 18 são analisadas. A Figura 7.5 ao lado exibe o número médio de iterações que foram necessárias para atingir a solução ótima nos problemas-teste, e a Figura 7.6 mostra o respectivo tempo computacional médio.

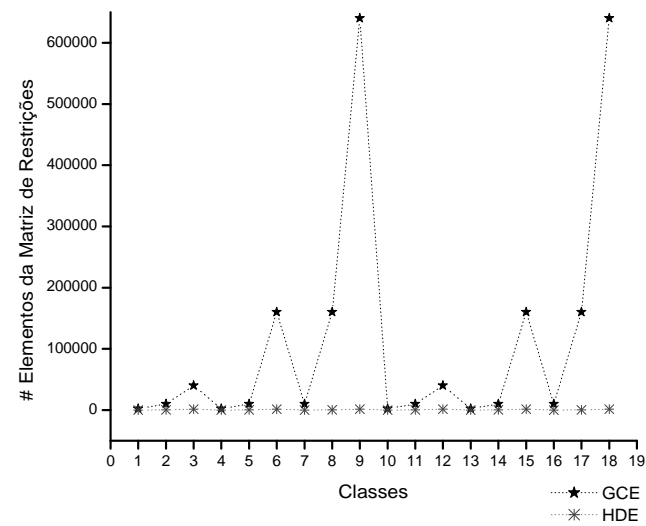

Figura 7.4: \# de Elementos da Matriz.

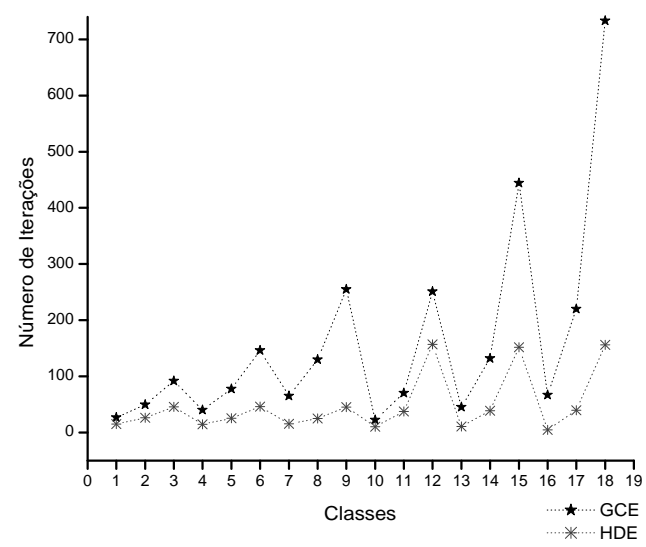

Figura 7.5: Número de Iterações.

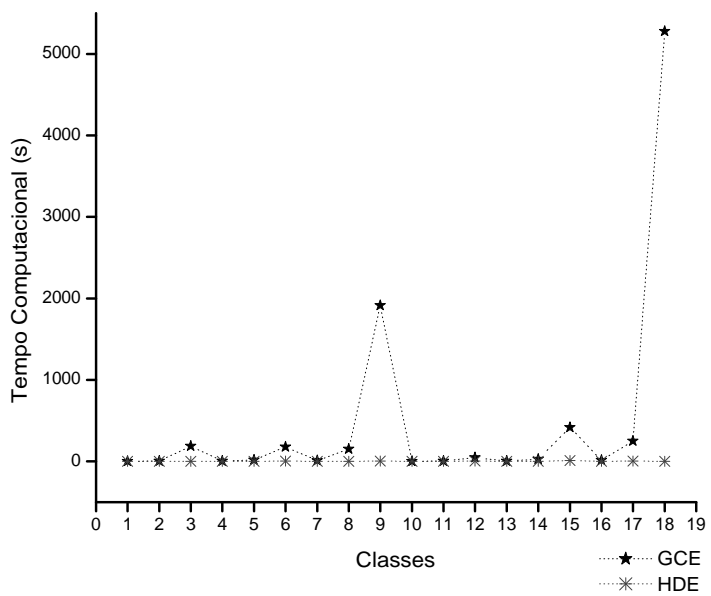

Figura 7.6: Tempo Computacional.

Vale ressaltar que a média do número de iterações e do tempo computacional é superior nas classes dos itens de tamanho médio. Esse resultado é bem conhecido na literatura a respeito dos problemas de corte de estoque. Em Gau e Wäscher (1995), são apresentados casos de problemas grandes $(m=50,75)$ em que o fator $v_{2}$ tem uma forte infulência nos tempos computacionais, principalmente para $v_{2}=0,5$. Embora o $m$ máximo considerado nesse trabalho valha 40, é possível perceber que os maiores tempos computacionais referem-se, justamente, às classes 
com $v_{2}=0,5$ e $m=40$, tanto na estratégia $G C E$ quanto na estratégia $H D E$ (com exceção é a classe 17, que apresenta um tempo computacional um pouco superior à classe 18).

\subsubsection{Segundo Conjunto de Testes}

O segundo conjunto de testes diferencia-se do primeiro em relação ao tamanho dos itens e aos custos. Foram adotados os mesmos fatores para gerar itens pequenos e $v_{1}=0,01$ e $v_{2}=1$, para gerar itens de tamanho pequeno, médio e grande. Os custos foram gerados da seguinte forma:

1. O custo de cortar a barra foi gerado, aleatoriamente, segundo uma distribuição normal com média 1,5 e desvio-padrão 0,5 , isto é $c_{j} \sim N(1,5 ; 0,5)$, independente de $j$, como no primeiro conjunto de testes;

2. o custo (penalidade) por excesso de produção de uma unidade do item do tipo $i$ foi considerado o mesmo (para $i=1, \ldots, m$ ) e gerado a partir da expressão: $c_{s t}=\bar{l} / L$, em que $\bar{l}$ representa a média do tamanho dos itens, isto é, $\bar{l}=\frac{\sum_{i=1}^{m} l_{i}}{m}$;

3. o custo (penalidade) unitária por escassez de produção de uma unidade do item do tipo $i$ foi considerado, arbitrariamente, o quádruplo de $c_{i}^{e}$, para $i=1, \ldots, m$.

A Tabela 7.5 indica o nome de cada classe, o número de problemas-teste gerados em cada classe, o número de itens e o seu tamanho ( $\mathrm{Pq}$ - pequeno, ou $\mathrm{Vr}$ - variado), e o número de cenários na classe. Note que se tem 17 classes, totalizando 850 problemas-teste.

Com essas novas classes, pretendia-se analisar dois tópicos principais:

I. A variação do número de itens em excesso e em escassez com relação aos custos;

II. a relação do $\operatorname{VSE}$ (e, conseqüentemente, do ganho) com o tamanho dos itens e com os custos.

Os tempos computacionais não foram reportados porque não era um objetivo desses testes a análise do esforço computacional. 


\begin{tabular}{lcccc}
\hline \hline Classe & \# Exemplos & \# Itens & Tamanho & \# Cenários \\
\hline \hline A19 & 50 & 10 & $\mathrm{Pq}$ & 5 \\
A20 & 50 & 20 & $\mathrm{Pq}$ & 5 \\
A21 & 50 & 40 & $\mathrm{Pq}$ & 5 \\
A22 & 50 & 10 & $\mathrm{Pq}$ & 10 \\
A23 & 50 & 20 & $\mathrm{Pq}$ & 10 \\
A24 & 50 & 40 & $\mathrm{Pq}$ & 10 \\
A25 & 50 & 10 & $\mathrm{Pq}$ & 20 \\
A26 & 50 & 20 & $\mathrm{Pq}$ & 20 \\
A27 & 50 & 40 & $\mathrm{Pq}$ & 20 \\
A28 & 50 & 10 & $\mathrm{Vr}$ & 5 \\
A29 & 50 & 20 & $\mathrm{Vr}$ & 5 \\
A30 & 50 & 40 & $\mathrm{Vr}$ & 5 \\
A31 & 50 & 10 & $\mathrm{Vr}$ & 10 \\
A32 & 50 & 20 & $\mathrm{Vr}$ & 10 \\
A33 & 50 & 40 & $\mathrm{Vr}$ & 10 \\
A34 & 50 & 10 & $\mathrm{Vr}$ & 20 \\
A35 & 50 & 20 & $\mathrm{Vr}$ & 20 \\
\hline \hline
\end{tabular}

Tabela 7.5: Classes do segundo conjunto de testes 
Análise I

Para analisar o primeiro tópico, veja a Tabela 7.6 com as porcentagens de itens em escassez e em excesso nas duas estratégias, e a Figura 7.7 que ilustra as informações.

\begin{tabular}{cccccc}
\hline \hline & \multicolumn{2}{c}{ Estratégia $G C E$} & \multicolumn{2}{c}{ Estratégia $H D E$} \\
Classe & \# Itens & Escassez(\%) & Excesso(\%) & Escassez(\%) & Excesso(\%) \\
\hline \hline A19 & 1090 & 5,86 & 19,2 & 12,2 & 11,8 \\
A20 & 2208 & 5,48 & 18,5 & 11,7 & 11,3 \\
A21 & 4529 & 5,60 & 19,2 & 11,9 & 11,6 \\
A22 & 1183 & 5,94 & 20,7 & 12,2 & 11,8 \\
A23 & 2256 & 6,01 & 20,3 & 12,1 & 11,6 \\
A24 & 4463 & 5,88 & 20,6 & 12,1 & 11,7 \\
A25 & 984,3 & 6,90 & 20,5 & 12,6 & 12,1 \\
A26 & 2312 & 6,28 & 21,2 & 12,3 & 11,9 \\
A27 & 4527 & 6,29 & 21,8 & 12,5 & 12,1 \\
A28 & 460,5 & $\mathbf{3 , 6 5}$ & 44,2 & 23,5 & 22,6 \\
A29 & 804,1 & 4,55 & 44,5 & 24,3 & 23,3 \\
A30 & 3214 & 5,44 & 19,4 & 11,9 & 11,4 \\
A31 & 867,1 & 5,61 & 23,1 & 12,8 & 12,3 \\
A32 & 1695 & 5,64 & 23,4 & 12,7 & 12,2 \\
A33 & 3297 & 5,77 & 22,5 & 12,6 & 12,1 \\
A34 & 1099 & 4,48 & $\mathbf{7 , 6 7}$ & $\mathbf{5 , 9 3}$ & $\mathbf{5 , 5 2}$ \\
A35 & 2158 & 4,05 & 8,20 & 6,05 & 5,60 \\
\hline \hline Média & 2185 & 5,50 & 22,0 & 12,9 & 12,4 \\
\hline \hline & & & & & \\
\hline
\end{tabular}

Tabela 7.6: Escassez e excesso de produção.

A estratégia $G C E$ deixou de atender apenas $5,5 \%$ da demanda, o que ocasionou um excesso de produção de $22 \%$, enquanto a estratégia $H D E$ manteve, praticamente, os mesmos níveis de escassez e de excesso de produção (veja a Figura 7.7). Por esses resultados, pode-se inferir que, devido aos altos custos por escassez de produção, a estrégia optou por cortar mais itens e obter um excesso de produção. Claramente, os valores dos custos influenciam apenas as soluções relativas à estratégia $G C E$. 

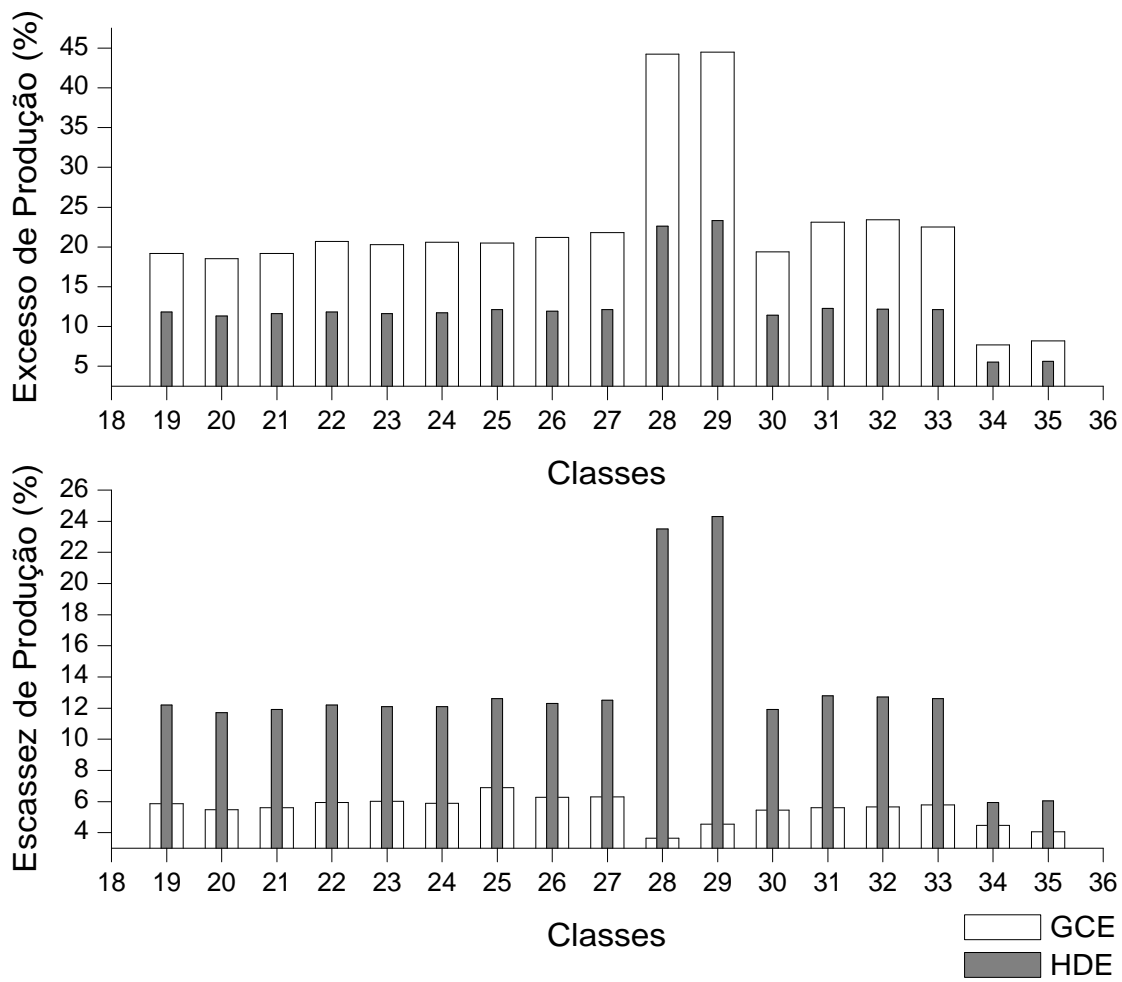

Figura 7.7: Número de itens em excesso e em escassez.

Para ter uma idéia do que a variação dos custos ocasiona, suponha que se tenha $c_{i}^{e}=$ $4 \times c_{i}^{u}$, para $i=1, \ldots, m$. É uma situação contrária àquela adotada nesse conjunto de testes. Então, tomando a classe 28 como referênci: 2 , obtém-se $74,64 \%$ de escassez de produção e zero de excesso. A partir do momento em que o custo por escassez é menor do que o custo por excesso, a estratégia $G C E$ passa a diminuir o número de itens cortados, chegando ao ponto de produzir o mínimo possível e não ter nenhum excesso de produção. Assim, em vez de "pagar" para cortar as barras e penalizar a função objetivo com possíveis excessos de produção, a estratégia apenas penaliza a função objetivo por escassez, o que faz diminuí-la. A Tabela 7.7 mostra o número de vezes que o custo por excesso é maior do que o custo por escassez e a rapidez com que diminui o excesso e aumenta a escassez, culminando com uma cota nula de excesso. Contrariamente, a Tabela 7.8 mostra o número de vezes que o custo por escassez é maior do que o custo por excesso. Perceba que zero de escassez só ocorre quando esse custo é 17 vezes maior do que o custo por excesso, em contrapartida ao zero de excesso que ocorre quando esse custo é 4 vezes menor.

\footnotetext{
${ }^{2}$ Pois é essa classe que apresenta o menor número de itens em escassez.
} 


\begin{tabular}{ccc}
\hline \hline Custos & Escassez & Excesso \\
\hline \hline$c_{i}^{e}=c_{i}^{u}$ & 43,16 & 8,15 \\
$c_{i}^{e}=2 \times c_{i}^{u}$ & 62,02 & 0,67 \\
$c_{i}^{e}=3 \times c_{i}^{u}$ & 70,34 & 0,15 \\
$c_{i}^{e}=4 \times c_{i}^{u}$ & $\mathbf{7 4 , 6 4}$ & $\mathbf{0 , 0 0}$ \\
$c_{i}^{e}=5 \times c_{i}^{u}$ & 76,00 & 0,00 \\
$c_{i}^{e}=6 \times c_{i}^{u}$ & 79,40 & 0,00 \\
$c_{i}^{e}=7 \times c_{i}^{u}$ & 79,67 & 0,00 \\
$c_{i}^{e}=8 \times c_{i}^{u}$ & 79,97 & 0,00 \\
$c_{i}^{e}=9 \times c_{i}^{u}$ & 81,88 & 0,00 \\
\hline \hline
\end{tabular}

Tabela 7.7: Variação da Escassez e Excesso de Produção na Classe 28.

\begin{tabular}{ccc}
\hline \hline Custos & Escassez & Excesso \\
\hline \hline$c_{i}^{u}=4 \times c_{i}^{e}$ & 3,65 & 44,2 \\
$c_{i}^{u}=5 \times c_{i}^{e}$ & 3,02 & 46,0 \\
$c_{i}^{u}=6 \times c_{i}^{e}$ & 1,09 & 49,4 \\
$c_{i}^{u}=7 \times c_{i}^{e}$ & 0,61 & 50,5 \\
$c_{i}^{u}=8 \times c_{i}^{e}$ & 0,41 & 51,3 \\
$c_{i}^{u}=9 \times c_{i}^{e}$ & 0,39 & 51,4 \\
$c_{i}^{u}=10 \times c_{i}^{e}$ & 0,39 & 51,4 \\
$c_{i}^{u}=11 \times c_{i}^{e}$ & 0,36 & 51,5 \\
$c_{i}^{u}=12 \times c_{i}^{e}$ & 0,22 & 52,1 \\
$c_{i}^{u}=13 \times c_{i}^{e}$ & 0,08 & 52,6 \\
$c_{i}^{u}=14 \times c_{i}^{e}$ & 0,02 & 52,9 \\
$c_{i}^{u}=15 \times c_{i}^{e}$ & 0,02 & 52,9 \\
$c_{i}^{u}=16 \times c_{i}^{e}$ & 0,01 & 52,9 \\
$c_{i}^{u}=17 \times c_{i}^{e}$ & $\mathbf{0 , 0 0}$ & $\mathbf{5 2 , 9}$ \\
\hline \hline
\end{tabular}

Tabela 7.8: Variação da Escassez e Excesso de Produção na Classe 28. 
Mesmo sem excesso de produção, se o custo de escassez continuar a diminuir, a função objetivo da estratégia $G C E$ também diminui, pois cada vez mais se torna interessante não produzir e ser penalizado por isso. Em situações extremas de custo por escassez nulo, a função objetivo vale zero, pois não há produção. As três seguintes situações são análogas e produzem soluções em que não há produção em escassez:

1. Custo de cortar a barra é nulo;

2. custo por escassez é muito alto;

3. custo por excesso é nulo.

\section{Análise II}

Para facilitar a análise, as classes A19-A35 foram resolvidas 2 vezes: na primeira rodada, considerou-se os próprios custos variados gerados, e na segunda, adotou-se os custos unitários. Dessa forma, a notação desses testes ganhou o símbolo $V$ (de custos Variados) e o $U$ (de custos unitários), para indicar que se trata da primeira e segunda rodadas, respectivamente. A Tabela 7.9 fornece os valores das funções objetivos das classes 19-35, assim como os desvios-padrão correspondentes, o VSE e o ganho.

Em relação à segunda rodada, pode-se afirmar que o $V S E$ e o ganho são maiores nas classes 28-35 do que nas classes 19-27. O ganho médio vale $12,1 \%$ e 2,77\%, uma diferença bastante considerável. Como essa rodada não está sob influência dos custos variados, o único fator que pode ter ocasionado tal diferença é o tamanho dos itens. No primeiro conjunto de testes, também se verificou que a média do ganho das classes referentes aos itens médios $(2,77 \%)$ era superior à média do ganho das classes de itens pequenos $(6,08 \%$ ) (reveja a Tabela 7.2).

Em relação à primeira rodada, uma análise análoga à anterior mostra que o ganho médio vale $9,87 \%$ e $16,9 \%$, respectivamente nas classes 19-27 e 28-35, o que confirma as considerações anteriores. Além disso, observe que o ganho médio de todas as classes da primeira rodada vale $13,1 \%$, enquanto da segunda rodada, $7,2 \%$. Uma diferença quase duas vezes maior. O custo por ignorar as incertezas é bem mais alto quando o problema possui itens de vários tamanhos e custos variados. 


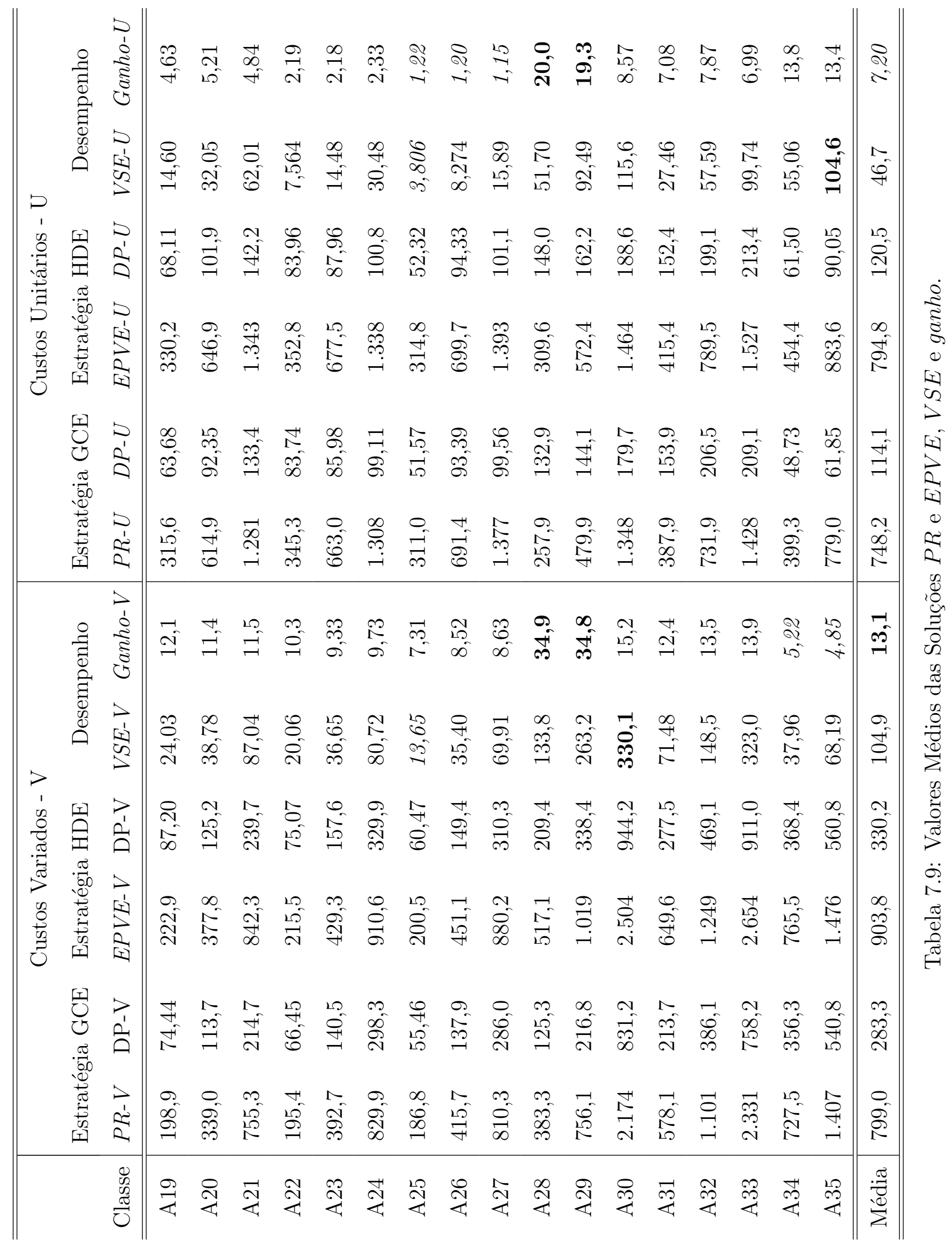


As Figuras 7.8 e 7.9 são bem ilustrativas das considerações anteriores. Observe que a superioridade do VSE e do ganho mantém-se em todas as classes, com exceção das duas últimas. O ganho máximo é alcançado nas classes 28 e 29 e o maior custo por ignorar as incertezas é obtido na classe 30 .

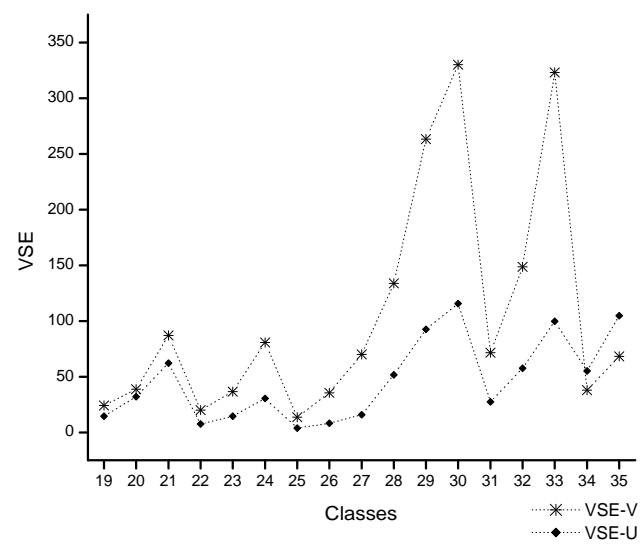

Figura 7.8: $V S E-V$ e $V S E-U$.

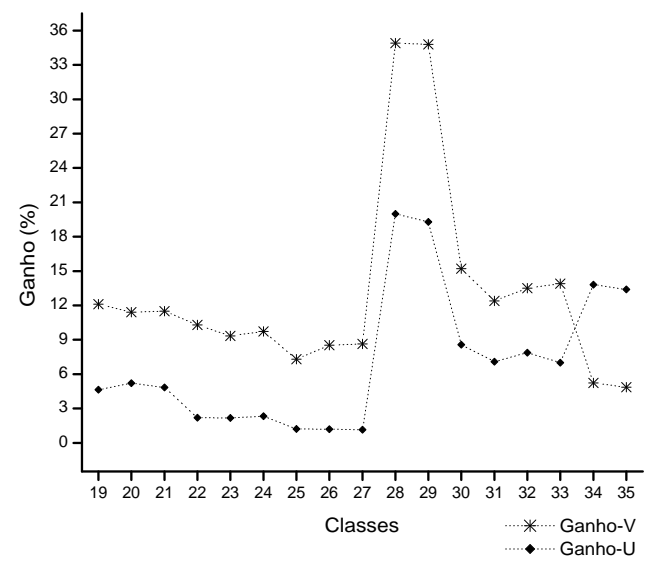

Figura 7.9: Ganho-V e Ganho-U.

\subsection{Testes $B$}

O objetivo dos testes B é avaliar o impacto que a variação da demanda entre os cenários ocasiona na função objetivo, no VSE e no ganho. Para isso, foram geradas, aleatoriamente, 36 classes com 20 problemas-teste cada e as mesmas características das classes A1-A9, isto é, $m=10,20$ e 30, apenas itens de tamanho pequeno, $S=5,10$ e 20 e custos unitários. A diferença entre cada grupo de 9 classes foi a maneira como a demanda foi gerada.

No primeiro grupo, a idéia era gerar classes com o menor desvio-padrão possível para a demanda entre os vários cenários, isto é, o menor desvio-padrão de um conjunto de 5, 10 e 20 elementos. Nos outros três grupos, gerou-se a demanda da mesma forma que nos testes A, porém, o desvio-padrão foi ligeiramente aumentado para cada grupo.

A Tabela 7.11 sumariza os resultados computacionais para as 36 classes. O primeiro grupo apresentou o VSE praticamente nulo. De fato, as 6 primeiras classes possuem o $V S E$ zero, enquanto as três últimas, têm um valor bem irrisório. O VSE médio é 0,213 e esse valor equivale a um ganho de $0,086 \%$. Note que a cada grupo, as funções objetivos $P R$ e EPVE aumentam consideravelmente, enquanto o VSE cresce, mas de maneira mais lenta. Essa observação não é surpreendente, uma vez que o aumento do desvio-padrão da demanda torna cada vez mais difícil evitar produzir a menos ou a mais da demanda quando se procura 
balancear a produção para satisfazer todos os cenários simultaneamente. A Tabela 7.10 mostra os aumentos das porcentagens de itens em escassez e em excesso quando há o aumento do desvio-padrão da demanda. O fato da porcentagem de itens em escassez aumentar mais do que a porcentagem de itens em excesso já foi discutido nos testes A.

Por esses resultados, tem-se a impressão de que o $V S E$ tem a tendência de ser pequeno quando não há muita aleatoriedade dos dados, isto é, quando o desvio-padrão (ou a variância, se preferir) é pequeno. Essa conjectura parece plausível com a definição do $V S E$ : se essa característica do problema mede o custo de ignorar a incerteza e ela é pequena no problema considerado, faz sentido que o $V S E$ seja um número bem pequeno. O resultado é interessante, pois mostra que em situações de mínima incerteza, talvez não valha a pena utilizar a estratégia $G C E$, pois a estratégia $H D E$ fornece resultados bem razoáveis e até mesmo idênticos, dependendo do problema. Mais ainda, o VSE nulo ainda indica que nem é necessário resolver o $P C E R R$, pois o simples $P V E$ fornece uma solução muito boa quando comparada à solução $P R$.

Ao mesmo tempo, quando o desvio-padrão da demanda aumenta, o VSE também aumenta, fazendo com que valha a pena investir na estratégia $G C E$ e ignorar a possibilidade de se obter uma boa solução com o $P V E$.

\begin{tabular}{cc|cc}
\hline \hline \multicolumn{2}{c|}{ Grupo 1 } & \multicolumn{2}{c}{ Grupo 2 } \\
\hline \hline Escassez(\%) & Excesso(\%) & Escassez(\%) & Excesso(\%) \\
1,43 & 1,00 & 12,7 & 10,1 \\
\hline \hline \multicolumn{2}{c|}{ Grupo 3 } & \multicolumn{2}{c}{ Grupo 4 } \\
\hline \hline Escassez(\%) & Excesso(\%) & Escassez(\%) & Excesso(\%) \\
21,0 & 18,6 & 30,2 & 19,0 \\
\hline \hline
\end{tabular}

Tabela 7.10: Valores médios (\%) de itens em escassez e em excesso nos grupos. 


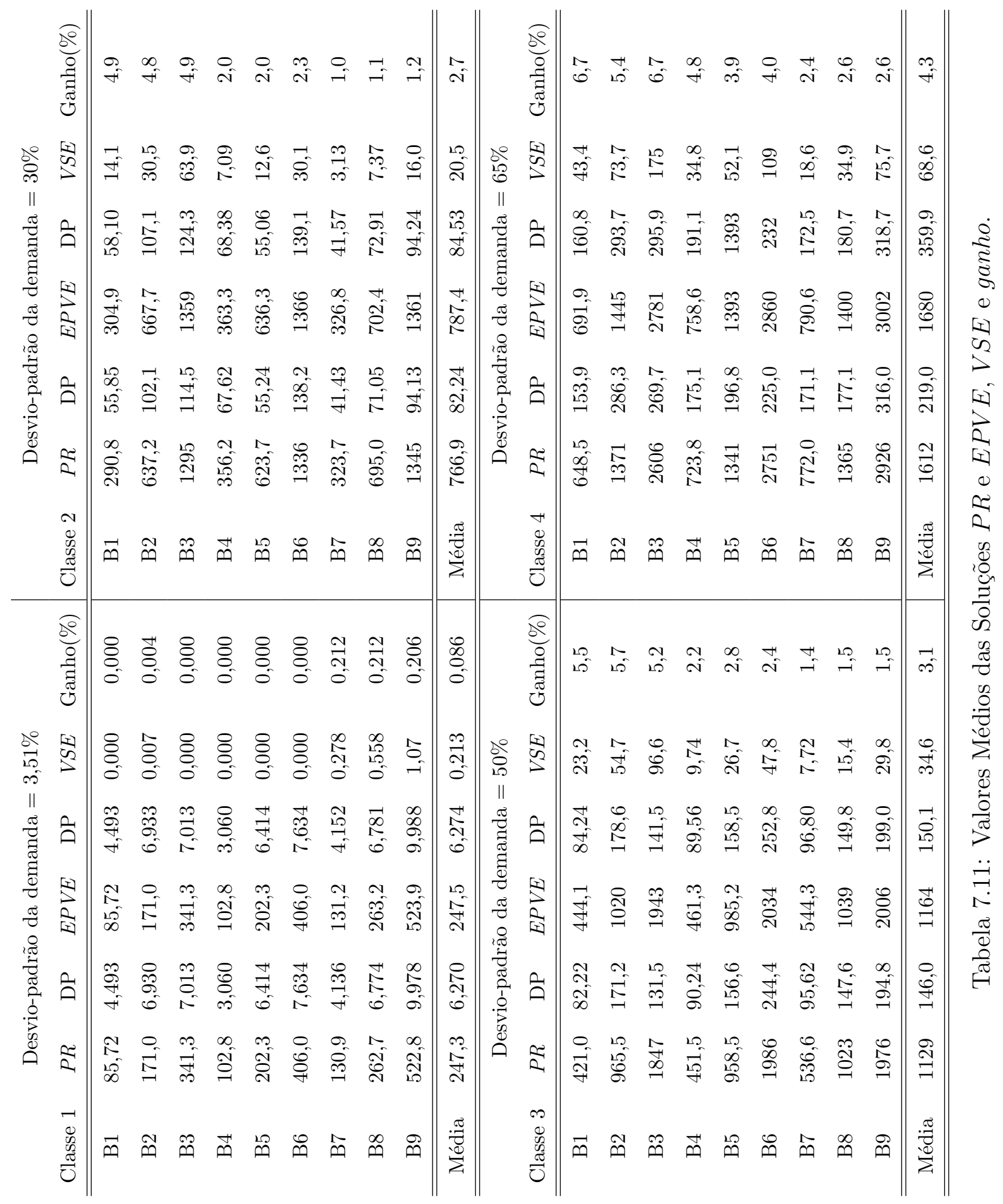




\subsection{Conclusões}

A partir dos experimentos computacionais (testes A e B), foi possível concluir sobre algumas características de interesse do problema e fazer algumas conjecturas finais, que são sumarizadas nessa seção.

1. As classes com itens médios possuem os maiores $V S E$ e ganho, enquanto as classes de itens pequenos, os menores;

2. existe uma tendência da estratégia $G C E$ em produzir mais itens em escassez do que em excesso quando todos os custos são unitários;

3. as soluções da estratégia $H D E$ são mais robustas quanto à quantidade de itens em escassez e em excesso. A GCE permite uma variabilidade muito maior;

4. o esforço computacional da $G C E$ é bem maior, mas a comparação não é muito adequado, uma vez as estratégias resolvem problemas de tamanhos bem distintos;

5. é mais razoável supor que o número de cenários é o maior responsável pelo grande esforço computacional da $G C E$, pois o $m$ não altera, significativamente, o esforço computacional da $H D E$;

6. as classes da $G C E$ com itens da tamanho médio apresentam um esforço computacional maior do que as classes com itens de tamanho pequeno. O trabalho de Gau e Wäscher (1995) já explicou esse fato, que pode ter origem em dificuldades computacionais para resolver, a cada iteração, um problema da mochila;

7. claramente, os custos têm uma forte influencia na determinação das variáveis de segundo estágio, isto é, nas quantidades de itens produzidos a mais e a menos da demanda;

8. em situações-limite: se o custo por escassez for zero (ou se o custo de cortar a barra/custo por excesso de itens for elevado), não há produção (corte de barras), e a função-objetivo é nula. Se o custo por excesso for nulo, não há escassez e é uma situação análoga a ter custo zero de cortar as barras e à situação em que o custo por escassez é muito alto;

9. quando os custos são variados, obtém-se um VSE maior;

10. o tamanho dos itens também influencia no $V S E$; as classes de itens cujos tamanhos são variados possuem um $V S E$ maior do que as classes com apenas itens pequenos; 
11. a variância ou desvio-padrão da demanda influencia diretamente no VSE;

12. com o desvio-padrão mínimo da demanda, obtém-se os casos de VSE e ganho mínimos;

13. situações-limite com a demanda: $E E V=P R$, o que implica que o $V S E=0$. Não há custo por ignorar as incertezas e nem lucro por resolver o estocástico; nesse caso, resolver o $P V E$ é equivalente a resolver o modelo recurso;

14. quanto maior for a aleatoriedade dos dados, mais interessante torna-se resolver o modelo recurso e adotar a estratégia $G C E$ em vez da $H D E$.

No total, foram resolvidos 2445 problemas-teste. Não se fez nenhuma estatística a respeito, mas é fácil observar que a maior parte deles apresentou um $V S E$ e ganho razoáveis, sendo que os máximos $V S E=330$ e ganho $=35 \%$ (reveja a Tabela 7.9 ) ocorrem em problemas que apresentam 30\% de variação de demanda entre os cenários, itens de tamanho variado (pequeno, médio e grande) e custos variados. Em contrapartida, os valores mínimos para o VSE e ganho ocorrem na situação em que o desvio-padrão (pode-se pensar na variância também) da demanda é a menor possível, mas não se pode afirmar nada se os outros parâmetros ajudaram a rebaixar o valor para zero. Porém, faz-se uma conjectura a respeito dessa situação:

Conjectura 7.1 Quando a demanda possui desvio-padrão mínimo, os outros parâmetros do problema não são relevantes na determinação do VSE. Além disso, pode-se esperarar um VSE bem baixo, o que indica ser suficiente resolver o PVE e não o modelo PCERR.

Observe que na situação mencionada, pode-se resolver o $P C E R R$ pela estratégia $H D E$ ou, simplesmente, tomar a solução $P V E$, pois, nesse caso, são bem próximas.

A literatura de programação estocástica diz que não há regra geral que conclua em que situações o $V S E$ é baixo ou alto. Porém, alguns autores propuseram condições gerais para problemas particulares (veja Birge e Louveaux (1997)).

Para o problema de corte com demanda estocástica, representado pelo modelo 3.1, porém, faz-se a seguinte conjectura:

Conjectura 7.2 Para o problema PCERR, o seu VSE sempre aumenta quando o desviopadrão da demanda aumenta e diminui quando o desvio diminui também. Os desvios-padrão minimos da demanda ocasionam valores mínimos para o VSE.

Porém, não se pode afirmar nada sobre os possíveis valores máximos de $V S E$, isto é, em que situações tem-se valores para o $V S E$, a partir dos quais um aumento da aleatoriedade não faz mais efeito. 
Conjectura 7.3 De maneira mais geral, quanto maior for a aleatoriedade dos dados do PCERR, mais elevados são os valores do VSE.

Esse resultado não garante, de fato, quão elevado é o $V S E$ em termos dos dados de entrada do PCERR. Todavia, ele indica uma direção a ser seguida. Se o decisor concluir que há pouca aleatoriedade nos dados, há grandes chances dele obter uma solução muito boa se resolver o $P V E$. Por outro lado, se existe uma grande aleatoriedade, vale a pena resolver o modelo recurso, pois tem boas chances de se obter um ganho razoável. 



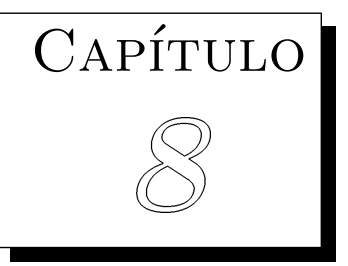

\section{Considerações Finais}

Nesse trabalho, foi formulado um modelo de programação estocástica de dois estágios com recurso para o problema de corte de estoque. O modelo proposto incorpora a incerteza associada à demanda dos clientes e fornece uma decisão ótima sob um conjunto de cenários.

Assim, a utilização da programação estocástica nesse trabalho constitui uma valiosa ferramenta de suporte ao decisor, que pode usar o modelo de dois estágios tanto para fins de planejamento tático (para analisar as perdas e os ganhos que pode obter quando um conjunto de situações são prováveis de ocorrer), quanto nas decisões do dia-a-dia (planejamento operacional).

A solução ótima do modelo de dois estágios descreve dois conjuntos de solução: as soluções de primeiro estágio e as de segundo estágio. As decisões de primeiro estágio são as mesmas para quaisquer cenários, e as de segunso estágio, variam de acordo com o cenário considerado. Esse fato torna o modelo recurso mais atraente do que um modelo puramente determinístico, pois ele fornece pelo menos um conjunto de decisões que é invariante com o cenário que se concretiza na prática. Isso implica que algumas decisões não precisam ser implementadas novamente a cada nova situação, pois elas são robustas em relação à demanda aleatória. Porém, observou-se que as ações corretivas possuem uma grande variabilidade; o modelo ?? não é capaz de controlar esse problema, pois não há nenhuma restrição sobre o recurso do modelo.

Em relação às estratégias propostas para resolver o modelo de dois estágios relaxado, pode-se concluir que a $G C E$ fornece a solução ótima de ??, dispensando um esforço computaci- 
onal considerável, se comparada à estratégia heurística. Além disso, a $G C E$ é a mais indicada para resolver o modelo recurso na maioria dos casos analisados, que sofrem uma influência razoável da aleatoriedade dos dados. Em poucas classes de problemas, entretanto, verificou-se que o $V S E$ foi muito baixo (e até mesmo zero). Nesses casos, não há justificativa para resolver o modelo recurso, uma vez que o $P V E$ fornece uma solução muito próxima da solução $P R$.

O VSE foi uma medida exaustivamente usada ao longo das discussões e considerações computacioanais, assim como a sua variação, o ganho. Ele é uma das poucas medidas que ajudam o decisor a optar por modelos estocásticos ou determinísticos, pois representa o custo de ignorar as incertezas num modelo e considerar o valor esperado das variáveis aleatórias como única possibiliadade de ocorrência.

Entretanto, um valor alto para o VSE não indica, necessariamente, que um modelo determinístico não possa funcionar bem na prática. Mas ele mostra, convictamente, quão influente é a aleatoriedade em determinado problema. Em última análise, a abordagem adotada vai depender da atitude do decisor em relação ao risco e quanto ele está disposto a pagar por ignorar a influência das incertezas nas suas decisões. 


\section{CAPÍTUlo}

\section{Pesquisas Futuras}

\subsection{O Problema de Corte de Estoque com Restrições de Chance}

A presente seção descreve uma outra abordagem para o problema de corte de estoque com demanda estocástica, que pode vir a ser estudado com mais detalhes em estudos futuros. Infelizmente, não foram efetuados testes computacionais para que ela pudesse, de alguma maneira, ser comparada ao modelo de dois estágios com recurso. Os resultados foram apresentados de forma informal, sem considerar alguns detalhes. A seção foi baseada nos trabalhos de Kataoka (1963) e Arenales et al. (2007).

Suponha um problema de corte de estoque unidimensional e sem restrições do número de barras em estoque, em que a demanda seja uma variável aleatória. Já foi visto como lidar com essa situação a partir da discretização de um número finito de cenários, que são incorporados ao modelo resultam em um aumento considerável da dimensão do problema.

Se não for desejado aumentar a dimensão do problema, se o número de cenários for muito grande, ou se for muito difícil determinar as penalidades incorridas na violação das restrições, é bem provável que o modelo recurso não seja muito compensador para o tomador de decisões.

Nesse caso, pode-se abordar o problema de corte com demanda estocástica como um problema de restrições de chance (chance constraints). Para isso, é preciso definir um nível de significância ou satisfação $\alpha$, de maneira que: 


$$
\operatorname{Prob}\left(\sum_{j} a_{i j} x_{j} \leq d_{i}\right) \leq \alpha_{i}, \forall i,
$$

isto é, a probabilidade de escassez de produção do item $i$ deve ser menor do que um $\alpha_{i}$.

Observe que $\sum_{j} a_{i j} x_{i j}$ fornece o número de itens do tipo $i$ produzidos; se ele for menor do que a demanda pelo item, então, $d_{i}-\sum_{j} a_{i j} x_{i j}$ é a escassez de produção do item.

Tipicamente, o nível de significância é $10 \%$ ou $5 \%$. Sendo assim, esse tipo de restrição garante que todos os itens do tipo $i$ serão produzidos em $90 \%$ dos casos $(\alpha=0,10)$, ou que a probabilidade de subprodução seja apenas $5 \%$.

Assim, pode-se formular o poroblema de corte de estoque com restrições probabilísticas da seguinte maneira:

$$
\begin{array}{ll}
\min & E\left(\sum_{j} c_{j} x_{j}\right) \\
\text { s.a: } & \operatorname{Prob}\left(\sum_{j} a_{i j} x_{j} \leq d_{i}\right) \leq \alpha_{i}, \forall i, j \\
& x_{j} \in Z^{+}, \forall j .
\end{array}
$$

Note que há $m$ restrições probabilísticas, uma para cada item, supondo que a demanda por eles seja uma variável aleatória independente. Se não for, a restrição pode ser substituída por uma restrição conjunta, isto é:

$$
\operatorname{Prob}\left(\sum_{j} a_{i j} x_{j} \leq d_{i}, \forall i, j,\right) \leq \alpha,
$$

de maneira que a restrição seja assegurada conjuntamente.

Para usar as ferramentas da programação linear na resolução do modelo 9.2 , é preciso transformar a restrição probabilística numa inequação equivalente determinística. Para isso, é necessário que a distribuição de probabilidade da variável aleatória $d_{i}$ seja conhecida.

Caso 1: $d_{i} \sim N\left(\bar{d}_{i}, \sigma_{b_{i}}\right)$

Se a variável aleatória $d_{i}$ possuir uma distribuição normal com valor médio $\bar{d}_{i}$ e variância $\sigma_{b_{i}}^{2}$ (ou desvio-padrão $\sigma_{b_{i}}$ ), a probabilidade em (9.3) pode ser transformada por simples subtração e divisão como se segue:

$$
\operatorname{Prob}\left(\sum_{j} a_{i j} x_{j} \leq d_{i}\right)=\operatorname{Prob}\left(\frac{d_{i}-\bar{d}_{i}}{\sigma_{d_{i}}} \geq \frac{\sum_{j} a_{i j} x_{j}-\bar{d}_{i}}{\sigma_{d_{i}}}\right) .
$$

Seja $z_{i}$ o valor que satisfaz a seguinte igualdade: 


$$
\operatorname{Prob}\left(\frac{d_{i}-\bar{d}_{i}}{\sigma_{d_{i}}} \leq z_{i}\right)=\alpha_{i}
$$

isto é, a função distribuição normal acumulada no ponto $z_{i}$ é igual a $\alpha_{i}$. Então, dado o nível de significância $\alpha_{i}$, o valor de $z_{i}$ pode ser obtido em tabelas de distribuição normal acumulada, e é negativo para $\alpha \leq 0,5$. Considerando que a função distribuição normal acumulada é uma função crescente, segue que:

$$
\frac{\sum_{j} a_{i j} x_{j}-\bar{d}_{i}}{\sigma_{d_{i}}} \geq z_{i} \Rightarrow \sum_{j} a_{i j} x_{j} \geq \bar{d}_{i}+z_{i} \sigma_{d_{i}},
$$

que é uma restrição linear para substituir a restrição probabilística inicial.

Como se trata de um problema de minimização, o sinal $\geq$ pode ser substituído pela igualdade. Finalmente, a formulação equivalente para o modelo 9.2 é:

$$
\begin{array}{ll}
\min & c^{T} x \\
\text { s.a: } & \sum_{j} a_{i j} x_{j}=\bar{d}_{i}+z_{i} \sigma_{d_{i}}, \forall i, j \\
& x_{j} \in Z^{+}, \forall j .
\end{array}
$$

Caso 2: $\left.d_{i} \sim U\left(l_{i}, u_{i}\right)\right)$

Se a variável aleatória $d_{i}$ possuir uma distribuição uniforme no intervalo $\left[l_{i}, u_{i}\right]$, a restrição probabilística pode ser transformada na seguinte restrição linear:

$$
\sum_{j} a_{i j} x_{j} \geq \alpha_{i} u_{i}+\beta_{i} l_{i}
$$

em que $\beta_{i}=1-\alpha_{i}$.

Na prática, podem haver outras distribuições para a variável aleatória $d_{i}$, mas nem sempre é possível transformar a restrição probabilística numa equivalente determinística e linear. Em muitos casos, a restrição torna-se não-linear, o que pode dificultar em demasia a solução do modelo.

Além do PCE com restrições probabilísticas, há outras sugestões de trabalhos futuros:

- comparar os dois modelos de corte com demanda estocástica: o modelo de dois estágios e o modelo com restrições probabilísticas. 
- Estender o PCE unidimensional com vários tipos de barras em estoque e em quantidades limitadas (extensão trivial, mas trabalhosa), e o PCE multiperíodo para o caso em que a demanda é estocástica. É bem razoável supor que a demanda de períodos futuros seja mais afetada pela aleatoriedade do que a demanda do período atual. Nesse sentido, o problema multiperíodo e estocástico pode ser mais realista do ponto de vista prático. Porém, considerando que o multiperíodo tem, em geral, grande porte, e os programas estocásticos também, talvez não valha a pena investir na abordagem por cenários, o que faria aumentar ainda mais o modelo.

- tratar a esparsidade do problema proposto, e tentar obter ganhos (em tempo computacional) para resolver os sistemas lineares da $G C E$. Observe que a $G C E$ não utiliza as conveniências do Simplex revisado, e, por isso, todos os sistemas lineares são resolvidos a cada nova iteração;

- incluir no modelo PCER restrições de recurso. Vladimirou e Zenios (1997) propõem programas estocásticos com a incorporação de condições de robustez para controlar a variabilidade das variáveis recurso. No caso aqui tratado, essas restrições podem ser referentes às variáveis de excesso e escassez de produção. Esse tipo de restrição aumentaria o valor da função objetivo, cuja otimalidade seria sacrificada para alcançar condições operacionais mais estáveis sob vários cenários. 


\section{Bibliografia}

[1] AlbornozA, V. M., BEnARIOB, P. and ROJAS, M. E., A two-stage stochastic integer programming model for a thermal power system expansion. International Transactions in Operational Research. 11: 243257 (2004).

[2] Alonso-Ayuso, A., ESCudero, L. F., GArÍn, A., OrTuÑo, M. T., PÉREZ, G., An approach for strattegic supply chain planning under uncertainty based on stochastic 0-1 programming, Journal of Global Optimization, 26: 97-124 (2003).

[3] AREnales, M. N.; ARmentano, V. A.; MORABito, R., YAnASSE, H. H., Pesquisa Operacional. Livro em edição.

[4] AREnales, M. N., MORABito, R., HORÁCiO, H. Y., (editores), "O Problema de Corte e Empacotamento ", Livro-texto de Mini curso, XXXVI CNMAC - Simpósio Brasileiro de Pesquisa Operacional, São João del Rei - MG, (2004).

[5] BENICH, M., Optimization under uncertainty in online trading agentes. 2004. Disponível em: <www.cs.brown.edu/publications/theses/ugrad/2004/mbenisch.pdf > . Acesso em 10 de janeiro de 2006.

[6] BIENSTOCK, D.; SHAPIRO, J. F., Stochastic programming models for strategic planning: an application to electric utilities. OR Center, MIT. Junho, 1979.

[7] BIRGE, J. R., Introduction to stochastic programming. Springer Series in Operations Research. 1999. 
[8] CHERRI, A. C., ARENALES, M. N., O problema de corte de estoque com reaproveitamento das sobras de material-Heurística FFD Modificada. In: Simpósio Brasileiro de Pesquisa Operacional, 38, 2005 Gramado - RS (2005).

[9] DANTZIG, G. B., Linear programming under uncertainty. Management Science. 50(12): 1764-1769. 2004.

[10] DANTZIG, G. B., Linear programming and extensions. Princeton, N. J. Princeton University Press. 1963.

[11] DOWSLAND, K., DOWSLAND, W., Packing problems. European Journal of Operational Research, 56: 2-14 (1992).

[12] DYCKHOFF, H., A typology of cutting and packing problems. European Journal Operational Research, 44: 145-159, (1990).

[13] GAU, T., WÄSCHER, G., CUTGEN: A problem generator for the standard onedimensional cutting stock problem. European Journal of Operational Research, 84: 572-579, (1995).

[14] GEMMILL, D. D., SANDERS, J. L., Approximate solutions for the cutting stock 'portfolio' problem. European Journal of Operational Research, 44(2): 167-174 (1990).

[15] GILMORE, P. C., GOMORY, R. E., "A linear programming approach to the cutting stock problem". Operations Research, 9: 848-859 (1961).

[16] GILMORY, P. C., GOMORY, R. E., "A linear programming approach to the cutting stock problem - Part II'. Operations Research, 11: 863-888 (1963).

[17] GILMORY, P. C., GOMORY, R. E., "Multi-stage cutting stock problems of two and more dimensions". Operations Research, 13: 94-120 (1965).

[18] JAMES, B. R., Probabilidade: Um Curso em Nível Intermediário. Projeto Euclides. (1981).

[19] KALL, P., WALACE, S. W., "Stochastic Programming", John Wiley \& Sons, New York (1994).

[20] KALL, P., MAYER, J., "Some insights into solution algorithms for SLP problems". Annals of Operations Research, 142: 147-164 (2006).

[21] KANTOROVICH, L. V., ZALGALlER, V. A., "Calculation of Rational Cutting of Stock" [in Russian], Lenizdat, Leningrad (1951). 
[22] KATAOKA, S., “A stochastic programming model”, Econometrica, 31(1-2): 181-196 (1963).

[23] KOUWENBERG, R., "Scenario generation and stochastic programming models for asset liability management". European Journal of Operational Research, 134: 279-292 (2001).

[24] KRICHAGINA, E. V., RUBIO, R., TAKSAR, M. I., WEIN, L. M., A dynamic stochastic stock cutting problem. Operations Research. 46(5): 690-701 (1998).

[25] LASDON, L. S., Optimization Theory for Large Systems. MacMillan, 1970.

[26] MORABITO, R., "Uma abordagem em grafo-e-ou para o problema de empacotamento: Aplicação ao carregamento de paletes e contêineres". Tese de Doutorado, EESC - USP, (1992).

[27] MORABITO, R., "Problemas de corte e empacotamento". Livro-texto de Mini-curso, Elavio, Montevidéu - Uruguai, (2004).

[28] PAULL, A. E., "The trim problem: an application of linear programming to the manufacture of newsprint paper". Report of the Montreal Meeting. September 10-13 (1954).

[29] POLDI, K. C., "Algumas extensões do problema de corte de estoque". Dissertação de Mestrado, ICMC - USP, 2003.

[30] POLDI, K. C., ARENALES, M. N., "O problema de corte de estoque multiperíodo". Anais do XXXVIII Simpósio Brasileiro de Pesquisa Operacional - SBPO. Gramado, RS. 2005.

[31] ROCKAFELLAR, R. T., WETS, R., "Scenarios analysis and policy aggregations in optimization under uncertainty". Mathematics of Operations Research, 16: 119-147 (1991).

[32] VOLPI, N. M. P., CARNIERI, C., SANQUETTA, C. R., "Uma análise da estocasticidade das informações sobre um modelo de programação linear". Pesquisa Operacional, 20(1): 101-115 (2000).

[33] WAGNER, H. "Pesquisa Operacional'. 2. ed., Ed. Prentice Hall do Brasil. (1986).

[34] WÄSCHER, G., HAU $\beta$ NER, H., SCHUMANN, H., An improved typology cutting and paccking problems". European Journal of Operational Research (Edição especial em problemas de corte e empacotamento, a aparecer). 



\section{Apêndice A. Prova da Afirmação 4.2}

Prova da afirmação: Embora as equações (4.2) admitam soluções com $e_{i k}$ e $u_{i k}$ ambas não-nulas, elas não são ótimas.

Suponha uma solução do programa $P C E R$ com $u_{\bar{i} \bar{k}}>0$ e $e_{\bar{i} \bar{k}}>0$, sendo a função objetivo associada $f=c^{o b j} \sum_{j} x_{j}+p_{1}\left(c_{1}^{e} e_{11}+\ldots+c_{m}^{e} e_{m 1}\right)+\ldots+p_{q}\left(c_{1}^{e} e_{1 q}+\ldots+c_{m}^{e} e_{m q}\right)+p_{1}\left(c_{1}^{u} u_{11}+\right.$ $\left.\ldots+c_{m}^{u} u_{m 1}\right)+\ldots+p_{q}\left(c_{1}^{u} u_{1 q}+\ldots+c_{m}^{u} u_{m q}\right)$.

Então, existe $\epsilon>0$, tal que $\hat{u}_{\bar{i} \bar{k}}=\left(u_{\bar{i} \bar{k}}-\epsilon\right)$ e $\hat{e}_{\bar{i} \bar{k}}=\left(e_{\bar{i} \bar{k}}-\epsilon\right)$ satisfazem o conjunto de restrições (4.2):

$$
\sum_{j} a_{i j} x_{j}+\left(\hat{u}_{\bar{i} \bar{k}}-\hat{e}_{\bar{i} \bar{k}}\right)=\sum_{j} a_{i j} x_{j}+\left(u_{\bar{i} \bar{k}}-\epsilon\right)-\left(e_{\bar{i} \bar{k}}-\epsilon\right)=\sum_{j} a_{i j} x_{j}+\left(u_{\bar{i} \bar{k}}-e_{\bar{i} \bar{k}}\right)=d_{i k} .
$$

Substituindo-se a solução $\hat{u}_{\bar{i} \bar{k}}$ e $\hat{e}_{\bar{i} \bar{k}}$ na função objetivo, com $\bar{i}=1$ e $\bar{k}=1$ sem perda de generalidade, tem-se

$$
\begin{aligned}
& \hat{f}=c^{o b j} \sum_{j} x_{j}+p_{1}\left(c_{1}^{e} \hat{e}_{11}+\ldots+c_{m}^{e} e_{m 1}\right)+\ldots+p_{q}\left(c_{1}^{e} e_{1 q}+\ldots+c_{m}^{e} e_{m q}\right)+p_{1}\left(c_{1}^{u} \hat{u}_{11}+\ldots+\right. \\
& \left.c_{m}^{u} u_{m 1}\right)+\ldots+p_{q}\left(c_{1}^{u} u_{1 q}+\ldots+c_{m}^{u} u_{m q}\right) .
\end{aligned}
$$

Substituindo-se $\hat{u}_{11}=\left(u_{11}-\epsilon\right)$ e $\hat{e}_{11}=\left(e_{11}-\epsilon\right)$ na função objetivo $\hat{f}$ acima, tem-se: 
$\hat{f}=c^{o b j} \sum_{j} x_{j}+p_{1}\left(c_{1}^{e}\left(e_{11}-\epsilon\right)+\ldots+c_{m}^{e} e_{m 1}\right)+\ldots+p_{q}\left(c_{1}^{e} e_{1 q}+\ldots+c_{m}^{e} e_{m q}\right)+p_{1}\left(c_{1}^{u}\left(u_{11}-\right.\right.$ $\left.\epsilon)+\ldots+c_{m}^{u} u_{m 1}\right)+\ldots+p_{q}\left(c_{1}^{u} u_{1 q}+\ldots+c_{m}^{u} u_{m q}\right)$,

que pode ser reescrita da seguinte maneira

$\hat{f}=c^{o b j} \sum_{j} x_{j}+p_{1}\left(c_{1}^{e} e_{11}+\ldots+c_{m}^{e} e_{m 1}\right)+\ldots+p_{q}\left(c_{1}^{e} e_{1 q}+\ldots+c_{m}^{e} e_{m q}\right)+p_{1}\left(c_{1}^{u} u_{11}+\ldots+\right.$

$\left.c_{m}^{u} u_{m 1}\right)+\ldots+p_{q}\left(c_{1}^{u} u_{1 q}+\ldots+c_{m}^{u} u_{m q}\right)-p_{1} c_{1}^{e} \epsilon-p_{1} c_{1}^{u} \epsilon=f-p_{1} c_{1}^{e} \epsilon-p_{1} c_{1}^{u} \epsilon=f-\epsilon p_{1}\left(c_{1}^{u}+c_{1}^{e}\right)$.

Como $p_{1}, c_{1}^{u}$ e $c_{1}^{e}$ são positivos, então $\hat{f}<f$. De forma genérica, tem-se

$$
\hat{f}=f-\epsilon p_{\bar{k}}\left(c_{\bar{i}}^{u}+c_{\bar{i}}^{e}\right),
$$

quaisquer que sejam $\bar{i}$ e $\bar{k}$ e sabendo-se que $p_{k}, c_{i}^{u}, c_{i}^{e}>0$ para todo $i, k$. 